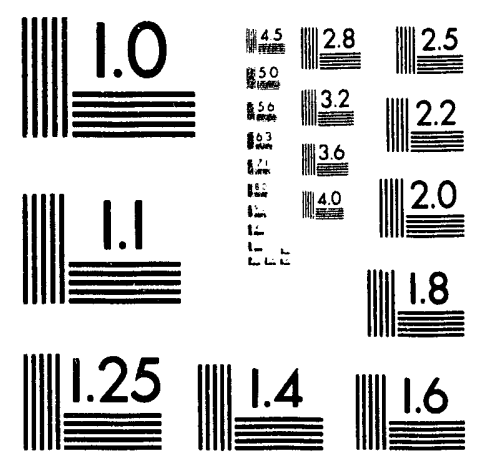



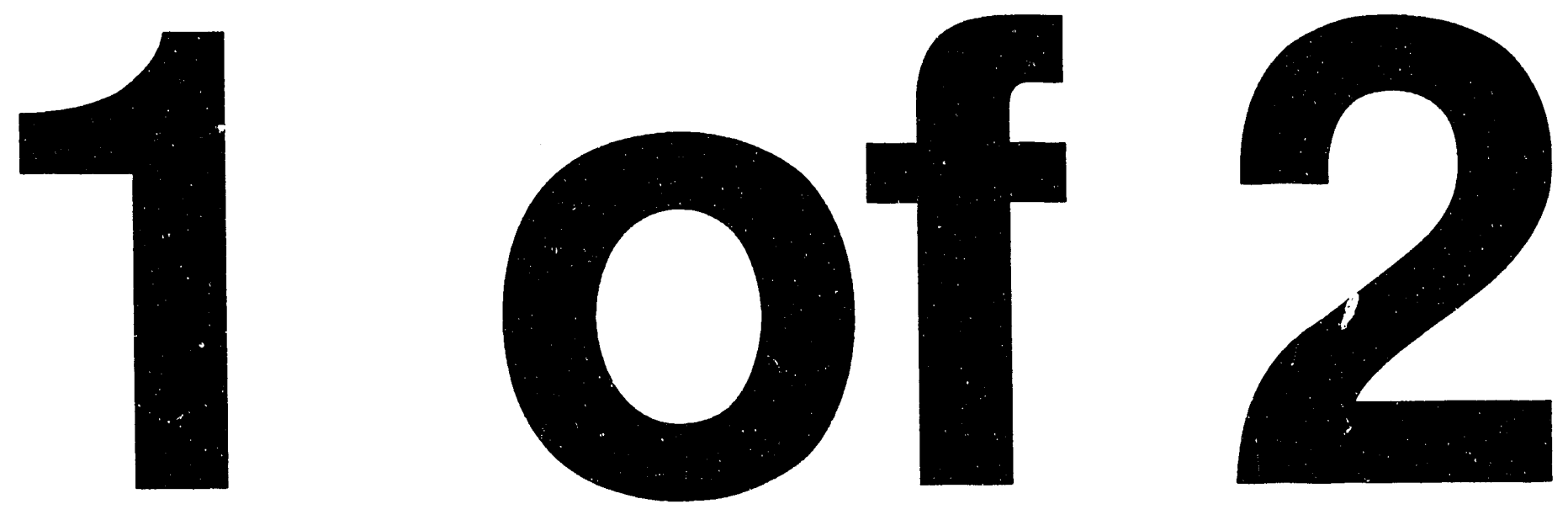


\title{
A SYSTEM ANALYSIS COMPUTER MODEL FOR THE HIGH FLUX ISOTOPE REACTOR (HFIRSYS Version 1)
}

Michael C. Sozer

Engineering Technology Division

April 1992

\author{
Prepared for the \\ Research Reactors Division
}

Prepared by the

OAK RIDGE NATIONAL LABORATORY

Oak Ridge, Tennessee 37831-8045 managed by

MARTIN MARIETTA ENERGY SYSTEMS, INC. for the

U.S. DEPARTMENT OF ENERGY under contract DOE-AC05-84OR21400

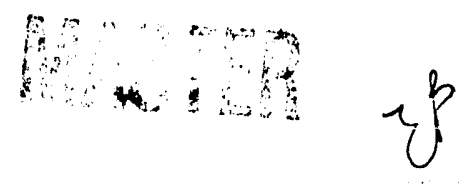




\section{CONTENTS}

Page

ABSTRACT

1. INTRODUCTION ……................................................................................

2. DESCRIPTION OF THE HIGH FLUX ISOTOPE REACTOR SYSTEM $\ldots . . .4$

2.1 HIGH PRESSURE SYSTEM ……...................................................... 4

2.2 REACTOR VESSEL AND CORE _........................................................ 6

2.3 LOW PRESSURE SYSTEM ….................................................... 7

2.4 SECONDARY COOLANT SYSTEM ………..................................... 7

2.5 PRESSURIZER PUMP SUBSYSTEM …............................................. 8

2.6 EMERGENCY DEPRESSURIZATION SYSTEM …………................... 9

2.7 PRESSURE CONTROL ................................................................. 10

2.8 NEW OPERATING CONDITIONS AND SET POINTS …................... 11

3. DESCRIPTION OF THE HFIRSYS COMPUTER MODEL …....................... 13

3.1 DESCRIPTION OF MODULAR MODELING SYSTEM …….............. 14

3.1.1 MMS-EASE+ User Interface and Model Definition File ............ 15

3.1.2 Summary of MMS Validation Tests ............................................. 15

3.1.3 Advanced Continuous Simulation Language (ACSL) ................... 16

3.1.4 Basic MMS Modeling Approach/Equations …………………........ 20

3.1.5 Thermodynamic Property Routines .............................................. 26

3.1.6 Standard MMS Modules Used in HFIRSYS …............................. 26

3.2 IN-HOUSE ADDITIONS TO MMS FOR MODELING HFIR .............. 27

3.2.1 Structural Expansion/Contraction in Pressure and Enthalpy

3.2.2 Reactor Vessel and Core Module ...................................................... 28

3.2.2.1 The Vessel Inlet Plenum Model ...................................... 29

3.2.2.2 The Core Inlet Region Model ……………….................. 32

3.2.2.3 The Core Model ………………............................................ 33

3.2.2.4 The Core Exit Region Model ........................................... 45

3.2.2.5 The Vessel Outlet Plenum Model …………………......... 46

3.2.3 Heat Exchangers (Coolers) …........................................................ 47

3.2.4 Circular Horizontal Tank ....................................................... 51

3.2.5 Combined Pony Motor and AC Motor Model ………................... 53

3.2.6 Pressurizer Pumps Model …………………................................. 54

3.2.7 Flow Model for Pipe Breaks ……………….................................. 57

3.2.8 Relief Valves ........................................................................... 58

3.3 CONTROL SYSTEM MODEL ..................................................... 59

3.3.1 Letdown Valve Controller ….................................................... 59

3.3.2 Secondary Flow Control ………...................................................... 61

3.3.3 Primary Head Tank Level Control ................................................ 62

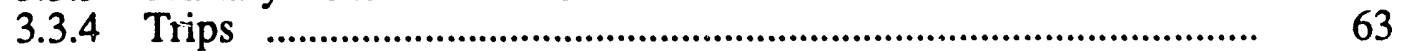




\section{CONTENTS (continued)}

Page

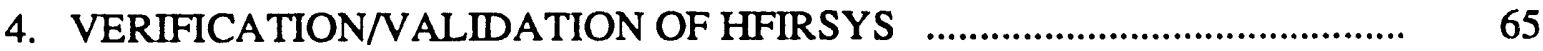

4.1 COMPARISON TO HFIR DEPRESSURIZATION EXPERIMENTS ... 65

4.1.1 Dixon's Depressurization Experiments at HFIR ........................ 67

4.1.2 Change in Water Temperature During Depressurization ............. $\quad 69$

4.1.3 System Elasticity Constant Based on Fluid Compressibility ...... $\quad 73$

4.1.4 System Elasticity Constant Based on Structural Elasticity .......... $\quad 74$

4.1.5 System Elasticity Constant Based on Fluid Compressibility and Structural Elasticity

4.1.6 Comparison of HFIRSYS Depressurization Predictions to Test Data 75

76

4.2 COMPARISON TO MEASURED PUMP COASTDOWN DATA ....... 77

4.3 COMPARISON TO MEASURED FLOW RATES THROUGH DEPRESSURIZATION VALVES 79

REFERENCES 80

APPENDIX A. PUMP PERFOR'MANCE CURVES $\quad$.................................... 84

APPENDIX B. RUNNING THE HFIRSYS MODEL ................................... 85

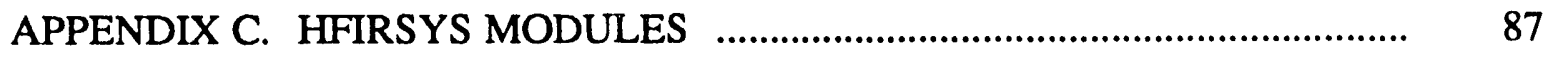

APPENDIX D. SUPPLEMENTARY PROGRAMS USED IN VALIDATION .. 90 


\section{LIST OF FIGURES}

Figure $\quad \underline{\text { Page }}$

1 HFIR primary coolant system ................................................................ 92

2 Top view of the HFIR primary coolant piping ….................................... 93

3 Main circulation pumps with main ac and de pony motors ........................ 94

4 Cross sectional view of the vessel and core ................................................. 95

$5 \quad$ Reactor vessel and core dimensions ...................................................... 96

6 The reactor pool and the vessel …............................................................ 97

7. Dimensions of the core and fuel elements ................................................. 98

8 A functional diagram of the magnetic drive of the main pressurizer

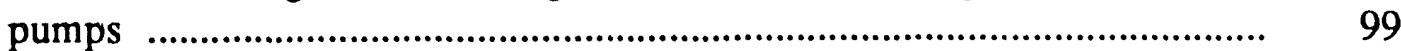

$9 \quad$ Pressurizer pump subsystem …………………........................................ 100

10 A block diagram of the HFIRSYS model ................................................. 101

11 A schematic drawing of the HFIRSYS model ............................................ 102

12 A flow chart of compiling and executing an MMS program ..................... 103

13 Input and output variables for standard MMS Modules …........................ 104

14 A schematic drawing of the fuel and bypass channel models ................... 105

15 A schematic drawing of the heat exchanger model .................................... 106

16 A schematic drawing of the primary head tank model ............................... 107

17 Comparison of HFIRSYS reactor inlet pressure (no structural elasticity) to system pressure calculated using $\mathrm{K}_{\mathrm{fs}}=18.3 \mathrm{psi} / \mathrm{gal}$ and $\mathrm{K}_{\mathrm{fs}}=24.23 \mathrm{psi} / \mathrm{gal}$ for $1844 \mathrm{ft}^{3}$ of primary coolant system volume $\ldots . . . . . \quad 108$

18 Comparison of HFIRSYS reactor inlet pressure (structural elasticity included, $\mathrm{k}_{\mathrm{pv}}=9.7210^{-7} \mathrm{psi}^{-1}$ ) to system pressures calculated using $\mathrm{K}_{\mathrm{fs}}=24.23 \mathrm{psi} / \mathrm{gal}$ for $1844 \mathrm{ft}^{3}$ of primary coolant system volume

19 Comparison of time dependent behavior of HFIRSY'S reactor inlet pressure (no structural elasticity) to system pressure calculated using $\mathrm{K}_{\mathrm{fs}}=24.23 \mathrm{psi} / \mathrm{gal}$ for $1844 \mathrm{ft}^{3}$ of primary coolant system volume

20 Comparison of time dependent behavior of HFIRSYS reactor inlet pressure (structural elasticity included) to system pressure calculated using $\mathrm{K}_{\mathrm{fs}}=18.3 \mathrm{psi} / \mathrm{gal}$ for $1844 \mathrm{ft}^{3}$ of primary coolant system volume

21 Comparison of HFIRSYS reactor inlet pressure (no structural elasticity) to system pressure calculated using $\mathrm{K}_{\mathrm{fs}}=20.74 \mathrm{psi} / \mathrm{gal}$ and $\mathrm{K}_{\mathrm{fs}}=27.47 \mathrm{psi} / \mathrm{gal}$ for $1626 \mathrm{ft}^{3}$ of primary coolant system volume

22 Comparison of HFIRSYS reactor inlet pressure (structural elasticity included) to system pressures calculated using $\mathrm{K}_{\mathrm{fs}}=20.74 \mathrm{psi} / \mathrm{gal}$ and $\mathrm{K}_{\mathrm{fs}}=27.47 \mathrm{psi} / \mathrm{gal}$ for $1626 \mathrm{ft}^{3}$ of primary coolant system volume 


\section{LIST OF FIGURES (continued)}

Figure

23 Comparison of HFIRSYS flow coastdown profile (dotted line) to the experimentally measured profile (solid line)

114

24 Comparison of HFIRSYS secondary flow coastdown profile (dottedline) to the experimentally measured profile (solid line)

25 Comparison of HFIRSYS speed coastdown profile for the main prespressurizer pumps to the experimentally measured data

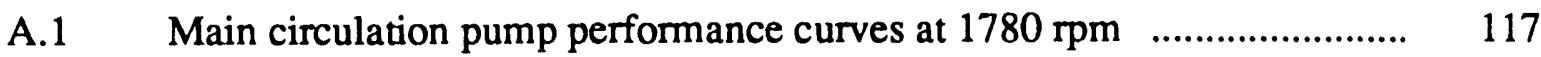

A.2 Pump head as a function of flow rate for ac and dc pony motor operation of the main circulation pumps

A.3 Flow coastdown profile for the main circulation pumps

A.4 Main pressurizer pump performance curves at $2616 \mathrm{rpm}$

120

A.5 Main pressurizer pump performance curves at $3485 \mathrm{rpm}$

121

A.6 Pump head as a function of flow rate for the main pressurizer pumps .... 122

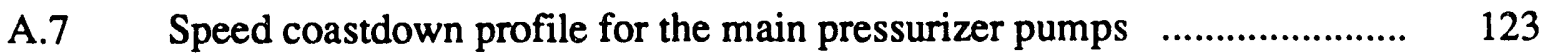

A.8 Auxiliary pressurizer pump performance curves at $3541 \mathrm{rpm} \quad \ldots \ldots \ldots \ldots . . . . . . . \quad 124$

A.9 Pump head as a function of flow rate for the secondary coolant pumps . 125

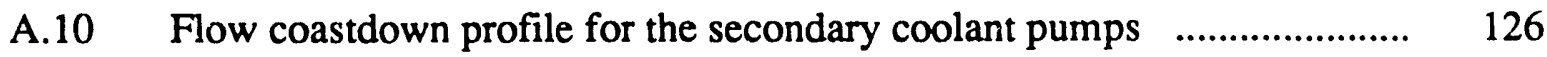

A.11 A general percent torque vs percent speed curve applicable to any centrifugal, axial or mixed flow pump 


\section{LIST OF TABLES}

Table

Page

1 Measured primary coolant flow rates during the operation of the dc pony motors

2 Approximate flow fractions based on the vessel inlet flow

$3 \quad$ Measured flow rates through the depressurization valves at different reactor pressures

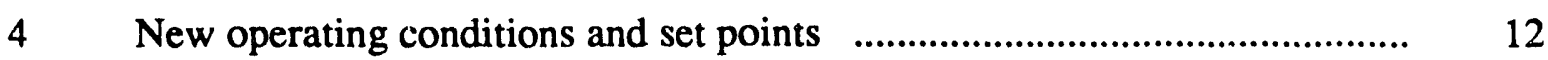

$5 \quad$ Stiffness ratio and relative stiffness ........................................................... 18

$6 \quad$ The MMS modules used in HFIRSYS ....................................................... 27

7 Flow characteristics of a two-inch swing check valve as a function of pressure drop

8 Fraction of reactor power based on $85 \mathrm{MW}$ within $0.9 \mathrm{~s}$ after scram

9 Fraction of reactor power based on $85 \mathrm{MW}$ from $1 \mathrm{~s}$ to $36000 \mathrm{~s}$ after scram

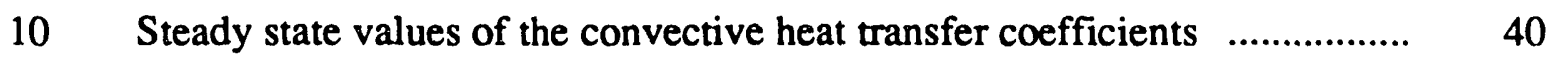

11 Hot channel and hot spot multiplication factors ......................................... 40

12 Values of the flow conductance terms of hot, bypass and average channels

13 Steady state values of $\mathrm{k}_{\mathrm{dt}}, \mathrm{k}_{\mathrm{df}}$, and $\mathrm{k}_{\mathrm{ds}}$ for single (CL1) and double (CL2) heat exchanger model

14 The dc pony motor torque as a function of speed ........................................ 54

15 Moment of inertia of the main circulation pump and its motors ................. 54

16 Parameters related to scram in HFIRSYS ................................................... 63

17 Parameters related to main circulation pump trip in HFIRSYS ................... 63

18 Parameters related to pressurizer pump trip in HFIRSYS ........................... 64

19 Dixon's data and calculated system elasticity constants ............................... 68

20 Adiabatic depressurization tests and the calculated reductions in the liquid water temperature

21 HFIR system elasticity constants based on water compressibility $\left(\mathrm{K}_{\mathrm{f}}\right)$, structural elasticity $\left(\mathrm{K}_{\mathrm{s}}\right)$; structural elasticity and water compressibility $\left(\mathrm{K}_{\mathrm{fs}}\right)$; and the structural elasticity coefficient $\left(\mathrm{k}_{\mathrm{pv}}\right)$ 


\title{
A SYSTEM ANALYSIS COMPUTER MODEL FOR THE HIGH FLUX ISOTOPE REACTOR
} (HFIRSYS Version 1)

\author{
Ahmet Sozer
}

\begin{abstract}
A system transient analysis computer model (HFIRSYS) has been developed for analysis of small break loss of coolant accidents (LOCA) and operational transients. The computer model is based on the Advanced Continuous Simulation Language (ACSL) that produces the FORTRAN code automatically and that provides integration routines such as the Gear's stiff algorithm as well as enabling users with numerous practical tools for generating Eigen values, and providing debug outputs and graphics capabilities, etc. The HFIRSYS computer code is structured in the form of the Modular Modeling System (MMS) code. Component modules from MMS and in-house developed modules were both used to configure HFIRSYS. A description of the High Flux Isotope Reactor, theoretical bases for the modeled components of the system, and the verification and validation efforts are reported. The computer model performs satisfactorily including cases in which effects of structural elasticity on the system pressure is significant; however, its capabilities are limited to single phase flow. Because of the modular structure, the new compon'nt mudels from the Modular Modeling System can easily be added to HFIRSYS for analyzing their effects on system's behavior. The computer model is a versatile tool for studying various system transients. The intent of this report is not to be a users manual, but to provide theoretical bases and basic information about the computer model and the reactor.
\end{abstract}




\section{INTRODUCTION}

A computer model has been developed to perform system transient analyses for the High Flux Isotope Reactor (HFIR). A brief description of the reactor system is provided so that readers may develop an understanding of the level of detail included in the computer model as it is compared to the real system. A short description of the history of the reactor is expected to clarify the reasons behind the work.

The HFIR is a research reactor designed to generate high thermal neutron fluxes $\left(4 \times 1015\right.$ nuetrons $\mathrm{cm}^{-2} \mathrm{~s}^{-1}$ ) originally at $100 \mathrm{MW}$ and the reactor currently operates at $85 \mathrm{MW}$. The reactor is a pressurized light water moderated and cooled reactor and does not generate electricity. 1 The reactor vessel is under water and pressurized by pressurizer pumps, unlike commercial PWRs that have pressurizers. The reactor core is composed of 540 fuel plates distributed among two concentric annular regions. It has a height of 24 in. and a diameter of $17.1 \mathrm{in.}$ The primary purpose of HFIR is to produce trans-plutonium isotopes for use in the heavy element research programs and also to provide experimental facilities on site.

The construction of HFIR was completed in 1965. It had been operated until it was shut down in November 1986 due to concerns mainly over increased pressure vessel embrittlement. Restart activities concerning various aspects of HFIR were undertaken in November 1986. The operational conditions had been redefined ( $85 \mathrm{MW}$ and $482.7 \mathrm{psia}$ ) and HFIR started operating at low power in April 1989.

As part of the restart activities, the HFIRSYS computer model has been developed to analyze various system transients (both operational transients and small break loss of coolant accidents). An extensive analysis capability using RELAP5 has also been built in order to perform necessary calculations for Chap. 15 of the safety analysis report (SAR). Prior to HFIRSYS, analog computer models of HFIR that do not have the flexibility of the digital computer models and the HFIR fuel element steady state heat transfer analysis code have existed.2,3 The HFIRSYS model is based on Modular Modeling System (MMS) computer code (version 2, 1986) whose development has been sponsored by EPRI and Babcock and Wilcox Corporation.4,9 The MMS code is based on the Advanced Continuous Simulation Language (ACSL), a FORTRAN-based flexible simulation environment for dynamic systems analysis, heat transfer, fluid flow and control system studies. The reactor, heat exchanger (coolers), and horizontal and circular water tank, and pressurizer pump models have been developed in-house. The heat generation in the core is represented using steady state and decay heat power profiles. 
Structural expansion and contraction due to pressurization and depressurization, respectively, are included in the primary coolant system modules. This required modification of the original MMS pipe modules.

The primary coolant system and the pressurizer pump with its primary head tank and piping are included. The primary system pressure control is accomplished through the control of the letdown valves. Automatic control actions such as reactor trip, main circulation pump trip at low reactor pressure, secondary coolant pump trip, and pressurizer pump trip at high discharge and low suction pressure are also incorporated.

Verification and validation of HFIRSYS (version 1) have been performed. The in-house developed coding has been reviewed to verify that the coding portray the intended mathematical equations (model). Validation efforts have been limited to areas where experimental data were available. Comparisons between HFIRSYS predictions and data from depressurization experiments, pump coastdown tests, and flow measurements were made. The code provided satisfactory results in these tests. 


\section{DESCRIPTION OF THE HIGH FLUX ISOTOPE REACTOR SYSTEM}

The HFIR composed of high and low pressure systems is a pressurized light water moderated and cooled research reactor. A brief description of the important portions of the system is provided in this section; however, more information with numerous illustrations can be found in Ref. 1. Because the current version of the computer model is configured to run transients including scram, the report does not include information on neutronics. (Only steady state and decay heat power profiles have been incorporated into the code to represent heat generation.)

\subsection{HIGH-PRESSURE SYSTEM}

A schematic of the high-pressure system (primary coolant system) is provided in Fig. 1 which has been taken from Ref. 1 . The high pressure system has the reactor vessel, four heat exchanger loops with coolers and main circulation pumps and two primary connections to the low pressure system. The connections are the letdown lines and pressurizer pump discharge line into the primary coolant system. There are check valves at the discharge lines of the main circulation pumps. High pressure stainless steel piping connects the reactor vessel with the pumps and heat exchangers. Water from the heat exchangers travels in a 20-in. line and passes through a strainer before it enters the top of the reactor vessel through two diametrically opposed 16 -in. lines. The hot leg is a single 18-in. line. The primary heat exchangers are parallel-counter-flow (shell and U-tube type) and mounted vertically. Only three heat exchangers are required for fullpower operation.

The pipe dimensions and elevations of the primary coolant system are shown in plan drawing No. 1546-01-M-5506. The top view of the primary coolant pipes, reactor vessel, heat exchangers, and main circulation pumps are presented in Fig. 2. In the figure, the arrows indicate flow direction.

The four main circulation pumps are vertical shaft centrifugal pumps; each pump takes its suction from an individual heat exchanger. The discharge pipe is a 10-in. line and connected to 20 -in. cold leg. Each pump delivers about 5,360 gpm during normal operation. They are driven by $600 \mathrm{hp} \mathrm{ac}$ motors and 3-hp dc pony motors under normal operational conditions. Primary coolant system flow rates with no power in the core were measured during HFIR hydraulic tests in 1964.5 The measurements indicated that each 
dc pony motor is capable of providing flow in the range of 1,305 to $1,380 \mathrm{gpm}$. The average flows measured during those tests are listed in Table 1.

Table 1. Measured primary coolant flow rates during the operation of the different number of dc pon' motors

\begin{tabular}{cc}
\hline $\begin{array}{c}\text { Number of dc pony } \\
\text { motors }\end{array}$ & $\begin{array}{c}\text { Primary coolant flow rate } \\
(\mathrm{gpm})\end{array}$ \\
\hline 1 & $1,305-1,380$ \\
2 & 2,130 \\
3 & 2,525 \\
4 & 2,760 \\
\hline
\end{tabular}

The dc pony motors are capable of removing decay heat. If the reactor vessel pressure is below 249.7 psia, the main circulation motors are tripped; however, the dc pony motors continue to operate. The pumps coast down to three dc pony motor flow from the full flow in about $8.95 \mathrm{~s}$ measured during hydraulic tests performed at HFIR with no heat generation in the core. 5 A slightly different calculated value for the coast down time was also reported in an earlier memo: the pump speed decreases to the $\mathrm{dc}$ pony motor speed (about 258-275 rpm) in about $9.8 \mathrm{~s}$ after an ac motor is tripped.6 A schematic drawing shows orientation of ac and dc motors, and a main circulation pump in Fig. 3.

The manufacturers pump curves and measured flow coast down curve are provided in Appendix A. The other significant set of pumps are the pressurizer pumps. Information on the pressurizer pumps is provided in Sects. 2.5 and 2.7.

The HFIR pressure relief system protects the high pressure primary coolant system against overpressure. The system includes two parallel paths. Each path has a relief valve and a rupture disk located upstream of the relief valve. The rupture disks prevent leakage through the relief valves. The relief valves reseat after overpressure relief. The pressure relief system is connected to the cold leg through a 4-in. line and discharges into the underground primary coolant storage tank also through a 4-in. line.

The burst pressure for the rupture disks is $650 \mathrm{psig}$. The set point for the relief valves is $625 \mathrm{psig}$. The vent lines connected to the region between the relief valves and rupture disks allow venting leakage from the rupture disks. 
The information on the pressure relief system was taken from: "HFIR FSAR Chap. 6-Interfaces With Other FSAR Chapters," by H. G. O'Brien, April 8, 1991.

\subsection{REACTOR VESSEL AND CORE}

Figure 4 provides a detailed view of the vertical cross sections of the reactor vessel and the core. Only one of the two core inlets are shown. There is only one core outlet. The flow paths are not shown in the figure. The coolant enters the core from above and flows downward into the outlet. The flow is split into mainly target, control plate, beryllium reflector and core regions. The approximate flow fractions based on the vessel inlet flow for these regions are calculated from the drawing (A-SK-PCH880122-1) and are shown in Table 2. The normal operational vessel inlet flow is about $16,700 \mathrm{gpm}$.

Table 2. Approximate flow fractions based on the vessel inlet flow

\begin{tabular}{lc}
\hline \multicolumn{1}{c}{ Region } & Flow fraction \\
\hline Core & 0.81 \\
Target & 0.05 \\
Control plate & 0.11 \\
Reflector & 0.02 \\
$\begin{array}{l}\text { Beam tubes and experimental } \\
\text { facilities }\end{array}$ & 0.01 \\
\hline
\end{tabular}

The reactor vessel is submerged in the reactor pool $18 \mathrm{ft}$ in diameter and $36 \mathrm{ft}$ deep. The reactor pool normal water level has an elevation of $848 \mathrm{ft}$. The vessel dimensions are shown in Fig. 5. It has an internal diameter of $94 \mathrm{in}$. and a height of $19 \mathrm{ft}$ including narrow outlet portion of the vessel. There is a two-inch check valve between the vessel and the pool and the valve is connected to the vessel through a two-inch line. The depressurization valves are connected to the vessel through a common three-inch line that is also used to sense inlet plenum pressure and connected to the vessel at an elevation of $824 \mathrm{ft}$. The check valve elevation is $831 \mathrm{ft}$ and the elevation of the junction of its pipe to the vessel is $824 \mathrm{ft}$, about $2 \mathrm{ft}$ below the center line of the reactor inlet. (These two connections occupy two out of eight three-inch rabbit holes located at an elevation of $824 \mathrm{ft}$ on the reactor vessel.) These valves, normally closed, become activated in some of the HFIR system transients. The check valve opens allowing water from the pool into the 
inlet plenum if the reactor pressure is below about 24 psia. The depressurization valves are used to depressurize the system if the automatic depressurization system is activated. The elevations and dimensions of the pool and the reactor vessel are shown in Fig. 6.

The fuel region of the core is presented in Fig. 7, a reproduction of Fig. 5.2.4 of Ref. 1. The target array, fuel elements, control plates, and beryllium reflector are the reactor core components. There is a total of 540 fuel elements distributed between inner and outer annulus. The active fuel length is $20 \mathrm{in}$. The channel width between two fuel plates and the fuel plate thickness is 0.050 in.

\subsection{LOW PRESSURE SYSTEM}

The low pressure system is separated from the primary coolant system by the letdown valves and the pressurizer pumps. This system contains dearator, pumps, prefilters, demineralizers, after filters, primary coolant head tank and interconnecting piping. The letdown flow through the letdown valves goes into the letdown header, also referred to as 90-s holdup line, and through the cleanup system and returns to the primary head tank. The pressurizer pump forces the coolant from the primary head tank back into the primary cor lant system at about $120 \mathrm{gpm}$.

There is a 20,000 gal primary coolant storage tank which provides makeup for replacement of coolant lost through leaks in the system. This tank is large enough to hold the entire water of the primary coolant system.

\subsection{SECONDARY COOLANT SYSTEM}

HFIR does not generate electricity; heat generated by the core is removed by secondary water and dissipated to the atmosphere by an induced-draft cooling tower. During normal operation, about $11,500 \mathrm{gpm}$ passes through the prim ary rolant heat exchangers and remaining secondary coolant goes through this bypass line. The secondary flow is controlled to keep the reactor inlet temperature at $120^{\circ} \mathrm{F}$. There are three main secondary coolant pumps (PU6A, PU6B, and PU6C). Two of these pumps

operate during the normal operation and have a combined capacity of $\sim 26,000 \mathrm{gpm}$. The fourth pump for auxiliary cooling ( U14) has a $r$ apacity of $6,000 \mathrm{gpm}$ and provides shutdown and emergency coolant. This small pump has two speed settings, high and low. The high speed setting $(\sim 6,000 \mathrm{gpm})$ is required for shutdown cooling and the low speed setting $(-3,000 \mathrm{gpm})$ is for $10 \mathrm{MW}$ operation. 
When the reactor is tripped, the main secondary coolant pumps are tripped, the auxiliary secondary coolant pump starts at the high speed setting, and the bypass valve opens allowing the coolant to bypass the tower. There is cooling of the secondary water but only through mixing with the coolant in the basin. There is about 400,000 gal water in the basin at about $85^{\circ} \mathrm{F}$. The coolant temperature is about $85^{\circ} \mathrm{F}$ at the inlet of the heat exchangers during the normal operation. The secondary coolant pump head and coastdown curves are provided in Appendix A.

\subsection{PRESSURIZER PUMP SUBSYSTEM}

There are three pressurizer pumps, to 0 of which are similar in size and capacity and called the main and the standby pressurizer pumps. The third pump, emergency pressurizer pump, is smaller in size and capacity. The main and standby pressurizer pumps, nine-stage horizontal shaft centrifugal pumps, take water from the primary head tank and discharge into the primary coolant system. They are driven by a $300 \mathrm{HP}$ and $3560 \mathrm{rpm}$ motor. The magnetic drive (clutch) between the motor and the pump allows pressurizer pumps to operate at different speeds. Only one of these pumps runining at a constant speed is needed during the normal operation. A functional block diagram of the magnetic clutch is presented in Fig. 8. These pumps have a rating of $300 \mathrm{gpm}, 3485 \mathrm{rpm}$, and $300 \mathrm{HP}$. Inertia of the components and torque vs speed characteristics were requested from Allis-Chalmers Pump Incorporated. Allis-Chalmers provided a general percent torque vs percent speed curve applicable to any centrifugal, axial, or mixed flow pump and it is included in Appendix A. Inertia of pump rotor assembly including pump coupling is $\left(15.87 \mathrm{lb}_{\mathrm{m}} \mathrm{ft}^{2}\right)$, and inertia of coupling of electric motor to magnetic drive is $\left(2.28 \mathrm{lb}_{\mathrm{m}} \mathrm{ft}^{2}\right) .7$ The combined inertia of the pump impeller, shaft, couplings, clutch and water is estimated to be $120 \mathrm{lb}_{\mathrm{m}} \mathrm{ft}^{2}$ from the measured pressurizer pump speed coastdown data. 8 This value does not include motor inertia since the motor is decoupled from the clutch during pump trip. The manufacturers pump curves and speed coastdown data are shown in Appendix A. ${ }^{10}$ These curves have been redrawn using the originals supplied by the manufacturer at ORNL.

The emergency pump starts running if the pressurizer pump discharge flow drops below $75 \mathrm{gpm}$ and is able to provide flow to the main circulation pump seals if reactor pressure is below 213 psia.

The main and the standby pumps are located at $819.5 \mathrm{ft}$ and the primary head tank at $834.5 \mathrm{ft}$. The discharge point to the cold leg is in between the main circulation pumps 
and the reactor inlet and at an elevation of $831.1 \mathrm{ft}$. The operating pressurizer pump and emergency pressurizer pump provides coolant for the main circulation pump seals. The emergency pressurizer pump discharge line is separate from that of the main and standby pressurizer pumps; its discharge line is connected to the main circulation pump seals. A simple schematic drawing of the pressurizer pumps with elevations and pipe dimensions are shown in Fig. 7.

The primary head tank receives letdown return flow, make-up flow, small flows from pump seals, reactor top vent flow, and pressure relief flow. The length and the diameter of the tank are $11.667 \mathrm{ft}$ and $6.5 \mathrm{ft}$, respectively. The tank water level is controlled to keep about $90 \%$ of the tank capacity. After going through the primary coolant cleanup system, the letdown flow returns to the primary head tank. The make-up flow from the plant demineralizer or the demineralized water storage tank $(20,000 \mathrm{gal}$ capacity) is controlled to keep the tank level constant. Two make-up flow pumps drive water from the demineralizer system and the demineralized water storage tank into the primary head tank. The maximum flow from the demineralizer system is about $90 \mathrm{gpm} .11$ Any additional water is taken from the demineralized water storage tank.

\subsection{EMERGENCY DEPRESSURIZATION SYSTEM}

The emergency depressurization system is designed to protect the system against a combination of a temperature below $90^{\circ} \mathrm{F}$ and high pressure. If the depressurization system is activated it will open the depressurization valves and trip the pressurizer pump depressurizing the primary coolant system in a few seconds. Flow rates through the depressurization valves were measured during system pressure checks/depressurization system by the HFIR maintenance personnel on Jan. 15, 1988.12 The tests were conducted to measure flow through each valve and flow through both valves. The depressurization valves are connected to the letdown header where the pressure is -12 psia. The test results, listed in Table 3, are for primary system pressure equal to 214.7 psia and 484.7 psia: (Because the valves are connected to the same line, keeping both of them open does not cause an appreciable increase in the flow rates.) 
Table 3. Measured flow rates through the depressurization valves at different reactor pressures

\begin{tabular}{lcc}
\hline \multicolumn{1}{c}{ Valves } & $\begin{array}{c}\text { Reactor pressure } \\
\text { (psia) }\end{array}$ & $\begin{array}{c}\text { Flow } \\
\text { rate } \\
\text { (gpm) }\end{array}$ \\
\hline V-337A & 214.7 & 94 \\
V-337A & 484.7 & 140 \\
V-337B & 214.7 & 94 \\
V-337B & 484.7 & 138 \\
V-337A \& V-337B & 214.7 & 96 \\
V-337A \& V-337B & 484.7 & 143 \\
\hline
\end{tabular}

\subsection{PRESSURE CONTROL}

The control of primary coolant system pressure is very important since boiling conditions can form rapidly at the core and consequently result in damage to the fuel. Additionally, the normal system pressure is considered too high if the reactor inlet temperature is below $90^{\circ} \mathrm{F}$; the automatic depressurization system is activated in order to protect the vessel against a combination of low temperature and high pressure. Furthermore, several components are tripped depending on the magnitude of reactor pressure as indicated in Sect. 2.3.

The system is pressurized by the pressurizer pumps. Only one pressurizer pump is needed under the normal operational conditions and it runs at a constant speed. The running pressurizer pump is commonly referred to as the main pressurizer pump. (The pump speed is easily adjustable with a knob in the control room; the speed is adjusted manually during startups of the plant.) At the normal operational speed, the main pressurizer pump provides $\sim 120 \mathrm{gpm}$ to the primary coolant system. The $120 \mathrm{gpm}$ makes up for the flow through 3 letdown lines. Each letdown line contains a control valve and two block valves. The control valves are controlled to keep the reactor pressure (inlet plenum pressure) at $482.7 \mathrm{psia}$ ( $468 \mathrm{psig}$ ). If the reactor pressure falls below $407.7 \mathrm{psia}$ (393 psig), the block valves are closed preventing any further flow through the letdown lines. The letdown control valves have equal percentage characteristics, which provides large pressure drop at low flow conditions. The third pressurizer pump, called the emergency pressurizer pump, is small and has low head and low flow capability. This 
pump is energized if the pressurizer pump flow is below $75 \mathrm{gpm}$ and is able to provide flow if primary coolant system pressure is below 213 psia.

The running pressurizer pump is tripped if any of the following conditions prevail:

1. pressurizer pump discharge pressure is equal or above $532.7 \mathrm{psia}$;

2. pressurizer pump suction line pressure is $\leq 15.2 \mathrm{psia}$ ( $\leq 0.5 \mathrm{psig}$ ) (the trip is delayed $5 \mathrm{~s}$ and at the end of $5 \mathrm{~s}$, if the pressure is still below 15.2 psia, the trip takes place);

3. primary head tank capacity is below $25 \%$; and

4. high discharge temperature $\left(150^{\circ} \mathrm{F}\right)$.

If the pressurizer pumps are tripped on high discharge pressure or low suction pressure, they can only be restarted manually.

The primary coolant system has relief valves, opening at $625 \mathrm{psig}(639.7 \mathrm{psia})$, and rupture disks, rupturing at $650 \mathrm{psig}$ (664.7 psia), to protect the system against high pressure.

\subsection{NEW OPERATING CONDITIONS AND SET POINTS}

The new operating conditions and some of the pressure and temperature set points are listed in Table 4. 
Table 4. New operating conditions and set points

New operating conditions

Power, MW thermal

Reactor coolant inlet temperature, ${ }^{\circ} \mathrm{F}$

Primary system pressure, psia

Letdown flow rate, gpm

Primary flow rate, gpm

Pool temperature, ${ }^{\circ} \mathrm{F}$

Tower basin temperature, ${ }^{\circ} \mathrm{F}$

\section{Pressure Set Pointsa}

Normal operating pressure, psia (psig)

Low pressure alarm, psia (psig)

Block valve closure, psia (psig)

Low pressure scram, psia (psig)

High pressure alarm, psia (psig)

Pressurizer pump cut off

(discharge pressure), psia (psig)

Main circulation pump cut off, psia (psig)

Depressurization valve closure, psia (psig)
85

120

482.7

120

16,700

95

85

$482.7(468)$

$432.7(418)$

$407.7(393)$

$382.7(368)$

$507.7(493)$

$532.7(518)$

$249.7(235)$

$239.7(225)$

High Inlet temperature scram, ${ }^{\circ} \mathrm{F}$

Minimum pressurization temperature

85

(at internal vessel wall), ${ }^{\circ} \mathrm{F}$

Depressurization temperature set-

point (low inlet temperature), ${ }^{\circ} \mathrm{F}$

90

Secondary coolant pump cut off, ${ }^{\circ} \mathrm{F}$

Upon Scram

$a$ All of the set points except for pressurizer pump discharge pressure are reactor inlet plenum pressure. 


\section{DESCRIPTION OF THE HFIR COMPUTER MODEL}

The HFIRSYS computer code has been developed based on the Modular Modeling System (MMS) code (version 2, 1986). A short history, applications, and basic modeling approach of MMS have been summarized in Sect. 3.1.1 through 3.1.5. The in-house additions made in order to model HFIR are described in Sect. 3.2.

The HFIR system transient model does not include all of the details of the primary coolant and the low pressure systems. There are four heat exchanger (cooler) loops, three of which are necessary for normal operation. In HFIRSYS, two of the three heat exchanger loops are combined into a single loop and the other loop includes one cooler and a main circulation pump. This allows studying transients including trip of either one, two, or three main circulation pumps. A schematic drawing of the HFIRSYS model with component modules is shown in Fig. 10. The pipe sections between the main circulation pumps and the reactor inlet are combined into a single pipe. The check valves in the primary coolant system are not modelled mechanistically. A logical variable can be used to prevent reverse flow. The pipe section between the reactor outlet and the cooler inlets are combined into a single hot leg. Short pipes are included between the cooler outlets and the main circulation pump inlets. (Short pipe sections are especially necessary when pumps cavitate. The reason is explained in Sect. 3.1.4.) Original MMS pipe Modules were modified to include structural elasticity.

The in-house developed reactor vessel module includes inlet plenum, core inlet region, core, core outlet region, and vessel outlet plenum models. Heat generation in the core is represented by tabulated steady state and decay heat data. Two-phase flow phenomena are not included. Transients up to two-phase flow generation can be run by HFIRSYS. Incipient and critical heat fluxes are calculated for the hot spot.

The three pressurizer pumps are included and their suction and discharge lines are combined. The pipes between the pressurizer pump and the primary head tank is modelled by a single pipe and the ones between the discharge of the pressurizer pump and the cold leg is also modelled by a single pipe. The check valves in the discharge line of the pressurizer pumps are represented using logical variables which can prevent reverse flow in the model. Letdown lines have control valves and block valves; their back pressure is fixed (letdown header is not modelled). The block valves are closed in $4 \mathrm{~s}$ at their pressure set point. The in-house developed circular primary head tank model receives letdown and demineralizer flow. The demineralizer system is not modelled; however, flow from the demineralizer system is controlled. The letdown control valves are controlled to 
keep reactor pressure at $468 \mathrm{psig}$. Leakage from the primary coolant system is ignored because the make up flow compensates for it.

The trips associated with the main circulation pumps, secondary coolant pumps, pressurizer pumps, and reactor are included. The secondary flow is controlled by controlling flow conductance, a simple approach. The secondary system does not have reai pump curves and flow coastdown data. The main circulation pump motor model includes $\mathrm{dc}$ pony motor torque data; after a pump trip the total torque decays to the dc pony motor torque if the $\mathrm{dc}$ pony motor is available. The main circulation pumps use homologous pump curves unlike other pumps included in the model.

Among the nine available numerical schemes, the Gear's stiff algorithm is preferred for integration of state variables.

A block diagram of HFIRSYS which indicates the names of the modules and flow streams is shown in Fig. 10. This drawing is especially helpful for anyone who works closely with the HFIRSYS program, such as making changes, following flow paths and analyzing FORTRAN, etc. The HFIRSYS is written in ACSL and ACSL generates the FORTRAN code automatically.

\subsection{DESCRIPTION OF MODULAR MODELING SYSTEM}

The MMS development was started by EPRI in August 1978 and, marketing and further development of it has been carried out by Babcock \& Wilcox Company (B\&W) since August, 1984. The purpose was to provide an efficient and economical tool for analysis of power plant (fossil and nuclear) dynamics, operational strategy development, post-trip evaluations, plant availability improvement evaluations, efficiency upgrades and control analysis. 4,9 The user friendly MMS code is expected to supplement the existing transient analysis codes like RETRAN and RELAP by providing capabilities for scoping safety analyses of both fossil and nuclear power plants and for long term transient analyses. 15

Plant components are represented by component modules which are separate individual routines based on the Advanced Continuous Simulation Language (ACSL). The simulation language, ACSL, is FORTRAN-based and more information about ACSL are given in Sect. 3.1.3. Each module has its specific name and can be used as many times as necessary by providing a separate name in a model (i.e., there are so many pipes and pumps in a given plant). Modules interact through input and output variables. A general classification of the modules divides them into two groups, storage modules which compute pressure and resistive modules which compute flow rate. There are modules 
possessing both of these functions. Figure 13 shows input/output variables for different module types. Much more information is available in the literature.4,9 Volumes 1 and 3 of the Modular Modeling System manuals and the ACSL manual are three necessary documents for anybody who works with MMS and with any model based on MMS.4,16,20

\subsubsection{MMS-EASE + User Interface and Model Definition File}

The MMS code has a separate program for construction of plant models and insertion of plant specific data into components. This program is called the MMS-EASE+ pre- and post-processor for MMS and runs on IBM PCs; it is a user friendly graphics interface. 18 Plant models are constructed by selecting icons representing different components and by drawing lines between them on the screen to represent physical connections. Once a plant or subsystem model is drawn on the screen, plant specific data on individual components can be inserted into component-data sheets. MMS-EASE+ automatically converts input data into an acceptable format by the MMS code; this step is called autoparameterization. Once the autoparameterization is completed, a model definition file (model source code), including input commands, can be prepared by selecting the option from a menu. A command file can also be prepared by selecting proper options from menus. The input and command files can then be transferred to the main frame computer where the MMS modules and ACSL reside. A command file possessing run time commands allows users to specify variables of interest to be stored for plotting or output on the screen as a calculation continues to run. It can also have specific values for constants, start and stop commands, and procedures, etc.

Running a program in ACSL is the same as running an MMS program; therefore, one needs two files to run a program, command and model definition files. The user interface increases efficiency as well as making input preparation and plant model setup a more tolerable process for engineers.

\subsubsection{Summary of MMS Validation Tests}

MMS-applications to PWRs and BWRs in the areas of enhancements, development, validation against plant data, codes, and experimental data are reported in the open literature.13-15 Validation of MMS for those applications are valid for only those component modules included in the system models and specific data incorporated into those modules for the specific plant model; it does not necessarily validate any system model configured differently and/or including different modules. To the best knowledge of the 
author, there has not been a systematic approach to verify and validate individual component modules; there is not a list of component modules that are known to give valid results within specific range of pressure, temperature, flow rate, heat generation rate, etc. and that are known to give valid results with known varying rates at which variables of interest change. Early validation tests against nuclear plant data and codes include: dynamic performance of Unit 1 and overcooling event on Unit 2 of Three Mile Island (comparison to RETRAN results and plant data), and simulation of the Arkansas Nuclear One, Unit 2 (ANO-2) turbine trip transient (comparison to RETRAN results and plant data).13 The MMS code was primarily applied to balance of plant and results were compared to plant data and predictions of RETRAN extensively. 14 Simulation of the first $1000 \mathrm{~s}$ of the Three Mile Island Unit 2 (TMI-2) accident, the Prairie Island Unit-1 tube rupture transient, transition from forced convection to natural convection at low power in TMI-2, Crystal River loss of instrumentation power supply event, and a steamline break transient (comparison to RETRAN-01) have been performed by MMS users. 15 Two of the several validation tests against experimental data includes: comparison to LOFT L3-7 small break LOCA, steam generator tube rupture experiments (also comparisons to RELAP-5 predictions; break flow, pressure, temperature, and water level were predicted reasonably well by MMS).13 An overall review of MMS including validation studies are also provided. 17 The most recent collection of the work performed for nuclear plants using MMS are included in the proceedings of the conference on power plant training simulators and modeling. 19

\subsubsection{Advanced Continuous Simulation Language (ACSL)}

MMS has been developed based on Advanced Continuous Simulation La?guage (ACSL), which provides various integration routines such as the Gear's stiff variable step and variable order routine, an interactive run time executive, linear analysis routines, graphics, macro capability and many other tools. 20 The simulation language is based on FORTRAN. Once a program is developed such as an MMS model using ACSL, it is converted into a FORTRAN program automatically by the ACSL translator. The translator generates error messages; for example, if there are unspecified variables, they are listed. It puts equations into executable order as well as interconnects the preprogrammed modules. The combination of MMS and ACSL and the steps involved in generating an executable file are shown in Fig. 12, reproduced from Ref. 4.

The MMS code fully exploits MACRO capabilities of ACSL. Each component module is nothing more than a macro. Each time a macro is called, the same code with 
different variable names is generated. (If two calls are made to the same macro using two different names, there will be two codes generated with different names.) This may be best explained by an example. Following is a fictitious macro:

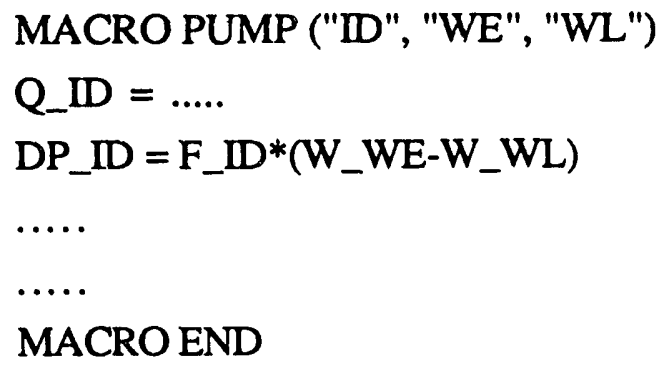

Whenever a call is made to this macro, one needs to specify a three-letter-identification (ID), entering flow stream name (WE), and leaving flow stream name (WL):

$$
\text { PUMP ("CP1", "IN1", "OUT1") }
$$

The three-letter-ID will be attached to SPD_ID and DP_ID to form the QCP1 and DPCP1 parameters (wherever_ID appears in the code). The argument IN1 will be attached to W_WE to form WIN1 and the argument OUT1 to W_WL to form WOUT1. Another call to the pump macro will generate a different set of parameters (the same code with different parameter names):

$$
\text { PUMP ("CP2", "IN2", "OUT2") }
$$

This generates QCP2, DPCP2, WIN2, and WOUT2. Note that the resulting parameter names cannot have more than 6 characters.

Some features of ACSL are worth repeating here. Linear analysis capabilities when using the Gear's stiff algorithm allows calculation of the Jacobian and Eigen values. (The Jacobian, a square matrix of dimension equal to the number of state variables, represents the partial derivative of the state derivatives with respect to the state variables.) Eigen values $\left(\lambda_{\mathrm{i}}\right)$ can be used to calculate a "stiffness ratio" for the problem in hand:

$$
\begin{aligned}
& \text { Stiffness ratio }=\frac{\max \left(\mid \text { real part of } \lambda_{i} \mid, \ldots .\right)}{\min \left(\mid \text { real part of } \lambda_{i} \mid, \ldots .\right)} \\
& \text { for } \mathrm{i}=1, \ldots, \mathrm{n} .
\end{aligned}
$$


The magnitude of the stiffness ratio indicates how stiff a problem is as indicated in Table 5.21

Table 5. Stiffness ratio and relative stiffness

\begin{aligned} & \hline Stiffness ratio Stiffness \\ & \hline 20 Not stiff \\ & 1000 Stiff \\ & 1000000 Very stiff \\ & \hline\end{aligned}

There are nine integration algorithms and the Gear's algorithm is the most sophisticated and Euler is the simplest of them. The input parameter IALG is set equal to a number between 0 and 9 to select an integration routine; IALG=2 calls the Gear's algorithm. Once initial conditions (for example, YIC) and an equation describing the derivative $(\mathrm{dY} / \mathrm{dt})$ is coded, then the integration can be done for the state variable $\mathrm{Y}$ by

$$
\begin{aligned}
& Y=\operatorname{INTEG}\left(\frac{d Y}{d t}, Y I C\right) \text { or } \\
& Y=\operatorname{INTVC}\left(\frac{d Y}{d t}, Y I C\right)
\end{aligned}
$$

In control system design and analysis, state-space matrices $\mathrm{A}, \mathrm{B}, \mathrm{C}$, and D are readily generated under the ANALYZ command. Error summary for each state is provided whenever a calculation is stopped when variable step algorithms are utilized. Number of times predictor/corrector fail (PC FAIL) to converge is reported. Error control determines the state with the largest relative error, difference in the magnitude of a state between two iterations divided by allowed error. Any existing FORTRAN subroutine or function can be accessed by using a CALL statement and attaching the subroutine or the function at the end of the program. The CALL statement is somewhat different from that of regular FORTRAN, one needs to check with the ACSL manual before making calls to subroutines or functions. A debug output can be obtained by simply setting:

$A C S L>N D B U G=1$ 
at the ACSL prompt (ACSL>). The debug output include all of the constants, variables, derivatives, and initial conditions in an organized way and in the alphabetical order. All of the state variables are listed in a column in alphabetical order. A second column represents their corresponding derivatives, while a third column represents their corresponding initial values. Debug outputs are invaluable. Restart files are generated by a single command during run time at the ACSL prompt:

\section{ACSL> SAVE 'filename' .}

Restoring restart files is equally easy:

\section{ACSL > RESTOR 'filename' .}

After restoring a restart file, calculation can be continued by typing continue:

\section{ACSL> CONTIN .}

Discrete events can be modelled using the DISCRETE and SCHEDULE commands. Actions can be scheduled to occur in time such as turning a pump on or off or opening a valve using the SCHEDULE command. ACSL generates a

\section{RRR.DAT}

file for each run in the local directory; this file stores the data points for those variables specified in the PREPAR command. It is used for plots. Regular plots as well as semilog and log-log plots can be made. Those variable names not included in the PREPAR command can not be plotted. Placing time as the first variable in PREPAR is advisable. The RANGE command is very convenient for determining the minimum and the maximum values of state variables such as maximum and minimum reactor core outlet pressure and temperature; this command also utilizes the RRR.DAT file. Function tables allow description of one dependent variable in terms of one, two, or three independent variables. The values inserted into tables can be replaced during run time using SET command. Appendix B includes sample command and model definition files and a sample debug output. 


\subsubsection{Basic MMS Modeling Approach/Equations}

The MMS code utilizes the lumped parameter approach. Solid structures and liquid volumes are represented by nodes. The number of nodes in a component module depends on the specific component model; however, nodes in various comfonents are large in general. The independent variables for fluid nodes are selected as pressure (p) and enthalpy ( $h$ ). The other properties are described as functions of pressure and enthalpy. Node ayerage values of the derivatives of pressure and enthalpy are calculated from pressure derivative:

$$
\frac{\mathrm{dP}}{\mathrm{dt}}=\frac{\rho\left(w_{\mathrm{e}}-\mathrm{w}_{1}-\rho \frac{\mathrm{dV}}{\mathrm{dt}}\right)-\left.\frac{\partial \rho}{\partial \mathrm{h}}\right|_{\mathrm{p}}\left(\mathrm{w}_{\mathrm{e}} \mathrm{h}_{\mathrm{e}}-\mathrm{w}_{1} \mathrm{~h}_{1}-\mathrm{w}_{\mathrm{e}} \mathrm{h}+\mathrm{w}_{1} \mathrm{~h}+\mathrm{Q}-\mathrm{W}_{\mathrm{s}}\right)}{3600 \mathrm{~V}\left(\left.\rho \frac{\partial \rho}{\partial \mathrm{P}}\right|_{\mathrm{h}}+\left.0.185 \frac{\partial \rho}{\partial \mathrm{h}}\right|_{\mathrm{p}}\right)}
$$

and, enthalpy derivative:

$$
\frac{a h}{a r}=\frac{\left.\frac{\partial \rho}{\partial \mathrm{P}}\right|_{h}\left(w_{\mathrm{e}} h_{\mathrm{e}}-w_{1} h_{1}-w_{\mathrm{e}} \mathrm{h}+w_{1} \mathrm{~h}+\mathrm{Q}-\mathrm{w}_{\mathrm{s}}\right)+0.185\left(w_{\mathrm{e}}-\mathrm{w}_{1}\right)-\rho \frac{\mathrm{dV}}{\mathrm{dt}}}{3600 \mathrm{~V}\left(\left.\rho \frac{\partial \rho}{\partial \mathrm{P}}\right|_{\mathrm{h}}+\left.0.185 \frac{\partial \rho}{\partial \mathrm{h}}\right|_{\mathrm{p}}\right)}
$$

where

$$
\begin{aligned}
& \left.h=\text { average node enthalpy (Btu, } \mathrm{b}_{\mathrm{m}}\right) \text {, } \\
& h_{e}=\text { entering flow enthalpy }\left(B t u / b_{m}\right) \text {, } \\
& \left.h_{\mathrm{I}}=\text { leaving flow enthalpy (Btu/lt } t_{m}\right) \text {, } \\
& \mathrm{Q}=\text { net heat transfer rate }(\mathrm{Btu} / \mathrm{h}) \text {, } \\
& \mathrm{P}=\text { pressure (psia), } \\
& \mathrm{V}=\text { node volume (f }{ }^{3} \text { ), } \\
& w_{c}=\text { entering flow }\left(\mathrm{lb}_{\mathrm{m}} / \mathrm{h}\right) \text {, } \\
& w_{1}=\text { leaving flow }\left(\mathrm{lb}_{\mathrm{m}} / \mathrm{h}\right) \text {, } \\
& \mathrm{W}_{\mathrm{s}}=\text { shaft work }(\mathrm{Btu} / \mathrm{h}) \text {, } \\
& \mathrm{t}=\text { time (s), and } \\
& \rho=\text { density }\left(\mathrm{lb}_{\mathrm{m}} / \mathrm{ft}^{3}\right) \text {. }
\end{aligned}
$$

These equations have been rederived at ORNL; the above forms of the equations are not presented in the MMS theory manual. The equations are coded into the modules in 
these forms. The control volume (node volume) is constant in general. An assumption made in application of these equations to modules; that is, assumption A-14 (page 3-15):4

"The rate of change of the property leaving the node is approximately equal to the rate of change of the average property."

Depending on the type of MMS modules (storage-resistive or resistive-storage), pressure, enthalpy and property derivatives are calculated at entering or leaving ports of a module. This assumption is a reasonable approach in single phase flow; however, it necessitates the use of very short pipes if two phase flow conditions exist at either end of a node. (For example, the pump suction of a pump inlet pipe can be in two phase during pump cavitation.)

The derivative of density as a function of pressure and enthalpy is calculated from:

$$
\frac{\mathrm{d} \rho}{\mathrm{dt}}=\left.\frac{\partial \rho}{\partial \mathrm{h}}\right|_{\mathrm{P}} \frac{\mathrm{dh}}{\mathrm{dt}}+\left.\frac{\partial \rho}{\partial \mathrm{P}}\right|_{\mathrm{h}} \frac{\mathrm{dP}}{\mathrm{dt}}
$$

The inlet and outlet flows are calculated either within a node or in the adjacent nodes depending on the type of the node. Modules are specified as being storage, resistive, and combination of both. A storage module calculates pressure and a resistive module calculates flow rate using the known entering and leaving pressures. A storage-resistive module calculates entering (inlet) pressure and leaving (outlet) flow rate. It uses the pressure calculated by the downstream module for calculation of the flow rate. Figure 13 demonstrates which parameters are input and which ones are output to different types of modules. 4 Arrows toward boxes mean that those parameters are input and arrows pointing away from boxes mean that those parameters are output. The MMS momentum equation used for calculating flow rate is:

$$
\frac{d w}{d t}=\frac{C_{1}}{L}\left[\frac{1}{C_{b}}\left(w_{c} V_{e}-w_{1} V_{1}-w \frac{d L}{d t}\right)+g_{c}\left(A_{e} P_{c}-A_{1} P_{1}-F_{w}\right)+\operatorname{Apg}\left(z_{c}-z_{1}\right)\right]
$$

where

$A=$ average flow cross sectional area $\left(\mathrm{ft}^{2}\right)$,

Ae = entering flow cross sectional area $\left(\mathrm{ft}^{2}\right)$, 
$A_{1}=$ leaving flow cross sectional area $\left(\mathrm{ft}^{2}\right)$,

$F_{W}=$ friction and form loss pressure drop ( $\left(b_{f}\right)$,

$\mathrm{g}$ = gravitational acceleration $\left(\mathrm{f} / \mathrm{s}^{2}\right)$,

$g_{c}=32.1739 \mathrm{lb} / \mathrm{ft} / \mathrm{lb}_{\mathrm{f}} \mathrm{s}^{2}$,

$\mathrm{L}=$ node length $(\mathrm{ft})$,

$P_{e}=$ pressure at the entrance (psia),

$P_{1}=$ pressure at the outlet (psia),

$w$ = average flow rate $\left(\mathrm{lb}_{\mathrm{m}} / \mathrm{h}\right)$,

$\mathrm{V}_{\mathrm{e}}=$ entering flow velocity $(\mathrm{ft} / \mathrm{s})$,

$\mathrm{V}_{\mathrm{l}}$ = leaving flow velocity $(\mathrm{ft} / \mathrm{s})$,

$z_{e}=$ elevation of the entrance ( $f t$ ),

$z_{1}=$ elevation of the outlet $(\mathrm{ft})$,

$\rho=$ average density $\left(\mathrm{lb}_{\mathrm{m}} / \mathrm{ft}^{\mathrm{t}} \mathrm{3}\right)$, and

$\mathrm{t}=$ time (s).

$$
\begin{aligned}
& \mathrm{C}_{\mathrm{t}}=\mathrm{g}_{\mathrm{c}} \frac{144 \mathrm{in}^{2}}{\mathrm{ft}^{2}} \frac{3600 \mathrm{~s}}{\mathrm{~h}}=1.669310^{7} \\
& \mathrm{C}_{\mathrm{b}}=\mathrm{g}_{\mathrm{c}} \frac{144 \mathrm{in}^{2}}{\mathrm{ft}^{2}} \frac{3600^{2} \mathrm{~s}^{2}}{\mathrm{~h}^{2}}=6.009310^{10}
\end{aligned}
$$

The friction and form loss term is

$$
F_{w}=\left(\frac{A w^{2}}{K_{c f}^{2} \rho}\right)\left(\frac{\Delta P^{2}}{\Delta P^{2}+K F M}\right)
$$

where

$$
\begin{aligned}
\mathrm{K}_{\mathrm{cf}} & =\text { MMS flow conductance term }\left(\mathrm{lb}_{\mathrm{m}} / \mathrm{h}\right)(\mathrm{psi})-0.5\left(\mathrm{lb}_{\mathrm{m}} / \mathrm{ft} 3\right)-0.5 \\
\mathrm{KFM} & =\text { low flow multiplication factor, and } \\
\Delta \mathrm{P} & =\text { pressure difference. }
\end{aligned}
$$

The parameter KFM and the term in the second paranthesis are superficial and introduced to improve integration efficiency. This artificial term reduces the magnitude of $\mathrm{dw} / \mathrm{dP}$ as the pressure difference approaches zero. The default value for KFM is $0.5 \mathrm{psi} 2$. 
An equation for the flow conductance term, $K_{\mathrm{cf}}$, can be derived through simple manipulation of the existing equations. The pressure drop $\left(\Delta \mathrm{P}_{\text {fric }}\right)$ due to friction and form loss is expressed as

$$
\Delta P_{\text {fric }}=f\left(\frac{L}{D}\right)_{p} \frac{\rho v^{2}}{2 g_{c}}+k \frac{\rho v^{2}}{2 g_{c}}
$$

where

$$
\begin{aligned}
\mathbf{f} & =\text { friction factor (Darcy's), } \\
\left(\frac{\mathrm{L}}{D}\right)_{\mathbf{p}} & =\text { length to diameter ratio for pipe sections, } \\
\mathbf{k} & =\text { form loss factor, and } \\
\mathbf{v} & =\text { fluid velocity. }
\end{aligned}
$$

The form loss factor is

$$
k=f \frac{L}{D}
$$

therefore, when $k$ and $f$ are known for a given volume, an $\frac{L}{D}$ ratio can be calculated. Then the $\frac{L}{D}$ ratio in the following equation represents the total value:

$$
\Delta P_{\text {fric }}=f\left(\frac{L}{D}\right) \frac{w^{2}}{2 g_{c} \rho \cdot A^{2}}
$$

The MMS flow conductance term is defined as

$$
K_{c f}=\frac{w}{\left(\rho \Delta P+\frac{\rho^{2} \Delta H}{144}\right)^{0.5}}=\frac{w}{\left(\rho \Delta P_{\text {fric }}\right)^{0.5}}
$$

where

$$
\begin{aligned}
& \Delta H=\text { elevation change, and } \\
& \Delta P=\text { pressure difference }\left(\Delta P=\Delta P_{\text {fric }}-\frac{\rho \Delta H}{144}\right)
\end{aligned}
$$


If the $\Delta \mathrm{P}_{\text {fric }}$ terms in both equations are set equal to each other, a new equation for $\mathrm{K}_{\mathrm{cf}}$ can be obtained. The friction factor $(f)$ is assumed to remain constant in MMS. The new $\mathrm{K}_{\mathrm{cf}}$ equation is

$$
K_{c f}=A\left[\frac{1}{f}\left(\frac{D}{L}\right) 2 g_{c}\right]^{0.5} .
$$

This allows calculation of the flow conductance without the knowledge of pressures.

The MMS assumption made in application of this equation to modules (A-16, page $3-15)^{4}$ is

"The rate of change of the entering flow is approximately equal to the rate of change of the average flow."

Actually it is either entering flow or leaving flow depending on the type of modules. In application of this equation to modules, the entering and leaving momentum fluxes are neglected with respect to the other terms.

The MMS equation for conduction and convection heat transfer rate is:

$$
\mathrm{Q}=\mathrm{U} A \Delta \mathrm{T}
$$

where
$A=$ heat transfer surface area $\left(\mathrm{ft}^{2}\right)$,
$\mathrm{Q}=$ heat transfer rate $(\mathrm{Btu} / \mathrm{h})$,
$\Delta \mathrm{T}=$ temperature difference $\left({ }^{\circ} \mathrm{F}\right)$, and
$\mathrm{U}=$ overall heat transfer coefficient $\left(\mathrm{Btu} / \mathrm{ft}^{2} \mathrm{~h}^{\circ} \mathrm{F}\right)$.

The overall heat transfer coefficient including conductive and convective resistances for a constant heat transfer area is described by

$$
U=\frac{1}{\frac{1}{h_{i}}+\frac{d_{1}}{k_{1}}+\frac{d_{2}}{k_{2}}+\frac{d_{3}}{k_{3}}+\frac{1}{h_{0}}}
$$


where

$$
\begin{aligned}
& d_{1}=\text { thickness of solid region one }(\mathrm{ft}), \\
& d_{2}=\text { thickness of solid region two }(\mathrm{ft}), \\
& d_{3}=\text { thickness of solid region three }(\mathrm{ft}), \\
& \mathrm{h}_{\mathrm{i}}=\text { inner surface convective heat transfer coefficient }\left(\mathrm{Btu} / \mathrm{ft}^{2} \mathrm{~h}^{\circ} \mathrm{F}\right), \\
& \mathrm{h}_{\mathrm{O}}=\text { outer surface convection heat transfer coefficient }\left(\mathrm{Btu} / \mathrm{ft}^{2} \mathrm{~h}^{\circ} \mathrm{F}\right), \\
& \mathrm{k}_{1}=\text { thermal conductivity of solid region one }\left(\mathrm{Btu} / \mathrm{ft} \mathrm{h}^{\circ} \mathrm{F}\right), \\
& \mathrm{k}_{2}=\text { thermal conductivity of solid region two }\left(\mathrm{Btu} / \mathrm{ft} \mathrm{h}^{\circ} \mathrm{F}\right), \text { and } \\
& \mathrm{k}_{3}=\text { thermal conductivity of solid region three }\left(\mathrm{Btu} / \mathrm{ft} \mathrm{h}^{\circ} \mathrm{F}\right) .
\end{aligned}
$$

The three solid regions can represent for example: fuel, clad and an oxide layer.

The convective heat transfer coefficient is calculated using only flow dependence of heat transfer coefficient:

$$
\mathrm{h}=\mathrm{h}_{\mathrm{ss}}\left(\frac{\mathrm{w}}{\mathrm{w}_{\mathrm{ss}}}\right)^{0.8}
$$

where

$$
\begin{aligned}
\mathrm{h} & =\text { heat transfer coefficient }\left(\mathrm{Btu} / \mathrm{f} \mathrm{t}^{2} \mathrm{~h}^{\circ} \mathrm{F}\right), \\
\mathrm{h}_{\mathrm{ss}} & =\text { steady state value of the heat transfer coefficient }\left(\mathrm{Btu} / \mathrm{ft} 2 \mathrm{~h}^{\circ} \mathrm{F}\right), \\
\mathrm{w} & =\text { flow rate }\left(\mathrm{lb}_{\mathrm{m}} / \mathrm{h}\right), \text { and } \\
\mathbf{w}_{\text {ss }} & =\text { steady state flow rate }\left(\mathrm{lb}_{\mathrm{m}} / \mathrm{h}\right) .
\end{aligned}
$$

The steady state heat transfer coefficients $\left(\mathrm{h}_{\mathrm{ss}}\right)$ are in general calculated from a convective heat transfer correlation. Derivatives of structure temperatures are calculated from the temperature derivative equation:

$$
\frac{\mathrm{dT}_{\mathrm{m}}}{\mathrm{dt}}=\frac{\mathrm{Q}_{\mathrm{g}}-\mathrm{Q}}{3600.0 \mathrm{MC_{ \textrm {p } }}}
$$

where

$$
\begin{aligned}
M & =\text { metal mass }\left(\mathrm{lb}_{\mathrm{m}}\right), \\
\mathrm{C}_{\mathrm{p}} & =\text { specific heat of metal }\left(\mathrm{Btu} / \mathrm{lb}_{\mathrm{m}}{ }^{\circ} \mathrm{F}\right), \\
\mathrm{Q}_{\mathrm{g}} & =\text { internal heat generation rate }(\mathrm{Btu} / \mathrm{h}),
\end{aligned}
$$


$T_{m}=$ metal temperature $\left({ }^{\circ} \mathrm{F}\right)$, supscript $\mathrm{m}$ can represent fuel, clad, pipe walls etc., and

$\mathrm{t}=$ time (s).

The MMS fluid flow equation used in some of the MMS modules is nothing more than the steady state momentum equation including pressure and elevation terms only:

$$
w_{e}=C\left[\rho_{c}\left(P_{c}-P_{1}\right)+\frac{g}{g_{c}} \rho_{e}^{2}\left(z_{e}-z_{1}\right)\right]^{0.5}
$$

where $\mathrm{C}$ is called "flow conductance," which is an equivalent of $\mathrm{K}_{\mathrm{cf}}$, and defined by

$$
\begin{aligned}
& C=A\left(2 g_{d} / k\right) 0.5, \text { and } \\
& k=\text { friction or form loss coefficient. }
\end{aligned}
$$

This equation is widely used in the standard MMS modules such as valves.

\subsubsection{Thermodynamic Property Routines}

The thermodynamic property routines are reported under two different categories by the MMS developers. 4 The two categories are the steam property routines and the RETRAN routines. In the section on steam property routines, there are 27 FORTRAN FUNCTIONS whose names are listed and units are provided. These routines are also referred to as the MMS team property library. The routines which have been used in the RETRAN computer code of EPRI are explained in the RETRAN routines section. The FUNCTION names and units are also provided. Because HFIR has a solid primary coolant system (no gas or vapor space), accurate calculation of water density is important. The system pressure is very responsive to changes in the water density. A comparison of water density of the ASME steam tables to those of MMS shows a maximum $0.21 \%$ difference for pressures $30,100,300$, and 500 psia at temperatures 90,100 , and $200^{\circ} \mathrm{F}$.

\subsubsection{Standard MMS Modules Used in HFIRSYS}

The MMS modules incorporated into HFIRSYS are listed in Table 6. 
The characteristics of these modules are described in detail in the MMS theory manual. 4 Use of connective modules (CONNI) are avoided in the primary coolant system model.

Table 6. The MMS modules used in HFIRSYS

\begin{tabular}{|c|c|c|}
\hline Name & MMS-module & HFIR-component \\
\hline Divider & DIV & $\begin{array}{l}\text { Cooler inlets and outlets, pressurizer pump } \\
\text { inlet }\end{array}$ \\
\hline Junction/divider & JNCDIV & $\begin{array}{l}\text { Discharge of main circ. pumps and } \\
\text { pressurizer pump discharge line, inlet to } \\
\text { cold leg, pressurizer pumps discharge }\end{array}$ \\
\hline Trip & TRIP & $\begin{array}{l}\text { Low pressure scram, main circ. pump } \\
\text { trip }\end{array}$ \\
\hline Motor & MOTOR & Main circ. pump motors (modified) \\
\hline Actuator & ACT & Letdown control valves \\
\hline PID controller & PIDCNT & $\begin{array}{l}\text { Letdown control valves controller, secon- } \\
\text { dary flow controller }\end{array}$ \\
\hline $\begin{array}{l}\text { Fump } \\
\text { (single phase) }\end{array}$ & PUMP & Main and standby pressurizer pump \\
\hline $\begin{array}{l}\text { Pump } \\
\text { (two phase) }\end{array}$ & PUMP4Q & Main circulation pumps \\
\hline $\begin{array}{l}\text { Pipe } \\
\text { (resistive-storage) }\end{array}$ & PIPERS & $\begin{array}{l}\text { Hot leg, main circ. pump inlet, cooler } \\
\text { outlet, pump suction line }\end{array}$ \\
\hline $\begin{array}{l}\text { Pipe } \\
\text { (storage-resistive) }\end{array}$ & PIPESR & Cold leg, pressurizer pump discharge line \\
\hline Valve & VALVEI & Letdown valves, pipe breaks \\
\hline
\end{tabular}

\subsection{IN-HOUSE ADDITIONS TO MMS FOR MODELING HFIR}

\subsubsection{Structural Expansion/Contraction in Pressure and Enthalpy Equations}

Modifications to the standard MMS pressure and enthalpy derivative equations have been made at ORNL in order to account for structural expansion or contraction during pressure-transients. The change in the volume of a conduit due to the radial expansion or contraction is given by 22 


$$
\frac{d V}{d t}=\frac{2 V r}{e E}\left(\frac{d P}{d t}\right)
$$

where

$$
\begin{aligned}
r & =\operatorname{radius}(\mathrm{ft}) \\
\mathrm{e} & =\text { thickness }(\mathrm{ft}) \\
\mathrm{E} & =\text { Young's modulus of elasticity (psi), } \\
V & =\text { fluid volume }(\mathrm{ft} 3), \text { and } \\
\mathrm{t} & =\text { time }(\mathrm{s})
\end{aligned}
$$

The term ( $2 \mathrm{r} / \mathrm{e} \mathrm{E})$ is defined as "the structural elasticity coefficient," $k_{\mathrm{pv}}$, then the rate of change of volume is:

$$
\frac{d V}{d t}=k_{p v} V \frac{d P}{d t}
$$

Then the value of $\mathrm{dV} / \mathrm{dt}$ can be inserted into Eqs. (1) and (2) and after reorganizing Eqs. (1) and (2), they take the following forms:

pressure derivative:

$$
\frac{d P}{d t}=\frac{\rho\left(w_{c}-w_{1}\right)-\left.\frac{\partial \rho}{\partial h}\right|_{p}\left(w_{e} h_{e}-w_{1} h_{1}-w_{e} h+w_{1} h+Q-w_{s}\right)}{3600 v\left(\rho^{2} k_{p v}+\left.\rho \frac{\partial \rho}{\partial P}\right|_{h}+\left.0.185 \frac{\partial \rho}{\partial h}\right|_{p}\right)}
$$

enthalpy derivative:

$$
\frac{d h}{d t}=\frac{\left(\rho k_{p v}+\left.\frac{\partial \rho}{\partial p}\right|_{h}\right)\left(w_{e} h_{c}-w_{1} h_{1}-w_{c} h+w_{1} h+Q-w_{s}\right)+0.185\left(w_{c}-w_{1}\right)}{3600 v\left(\rho^{2} k_{p v}+\left.\rho \frac{\partial \rho}{\partial P}\right|_{h}+\left.0.185 \frac{\partial \rho}{\partial h}\right|_{p}\right)}
$$

where all of the parameters are defined previously.

\subsubsection{Reactor Vessel and Core Module}

HFIR is a unique reactor design and the existing MMS modules can not be used to model the vessel and the core. The vessel model has been developed using the standard 
MMS equations, the lumped parameter approach with the standard MMS assumptions. ${ }^{4}$ It is divided into five regions: the vessel inlet plenum, core inlet, core, core outlet, and vessel outlet plenum. The inlet and outlet flows of the vessel are not calculated in the vessel model and provided by cold and hot leg pipe models. The enthalpy, pressure, and heat transfer across the vessel wall into the pool water are calculated for the inlet plenum. The vessel-pool check valve and depressurization valves are included. If the reactor inlet temperature falls as low as $90^{\circ} \mathrm{F}$, then the depressurization valves are opened and the pressurizer pump is tripped in order to avoid combination of low temperature and high pressure. The vessel outlet plenum is represented by two equations for calculation of enthalpy of the vessel exit flow and vessel outlet pressure and a flow equation from the lower plenum (core exit) to the vessel outlet plenum. No heat transfer across the solid outlet plenum boundaries are considered. There is a core inlet region between the vessel inlet plenum and the core. This region allows calculation of flow from the vessel inlet plenum to the core inlet region as well as calculation of core inlet pressure and enthalpy. The core region is represented by average, hot, and bypass channels. Calculations are done for only one average and one hot channel and multiplied by the total number of these channels to compute the total flow through, for example, average channels. There is not a separate region for control plates and target. They are lumped with the bypass region. There is no neutronics model included in the core. Steady state and decay heat power are tabulated functions of time in the ACSL function table format. The flow rates for each of these channels are calculated using the MMS standard momentum balance equation and heat transfer from the metal to the coolant includes conduction and convection. A hot spot at the exit of the hot channel is also modelled. The core exit region is the collection volume for flows from the average, hot and bypass channels. Pressure and enthalpy are calculated; pressure is used to calculate flow rate from the core exit region (lower plenum) to the vessel outlet plenum. The vessel exit pressure and enthalpy are calculated in the vessel outlet plenum region. The vessel exit flow is calculated in the adjacent hot leg pipe module.

\subsubsection{The Vessel Inlet Plenum Model}

The inlet plenum enthalpy and pressure are calculated from Eqs. (13) and (14). The coolant in this region is treated as well-mixed. The specific vessel inlet plenum pressure and enthalpy derivative equations are respectively 


$$
\frac{d P_{i}}{d t}=\frac{\rho_{i}\left(w_{c l}+w_{c v}-w_{b k}-w_{s}\right)-\left.\frac{\partial \rho}{\partial h}\right|_{p}\left(w_{c l} h_{c l}-w_{c l} h_{i}+w_{c v} h_{c v}-w_{c v} h_{i}+Q_{i}\right)}{3600 v_{i}\left(k_{p v} \rho_{i}^{2}+\left.\rho_{i} \frac{\partial \rho}{\partial P}\right|_{h}+\left.0.185 \frac{\partial \rho}{\partial h}\right|_{p}\right)}
$$

and,

$$
\frac{d h_{i}}{d t}=\frac{0.185\left(w_{c l}+w_{c v}-w_{b k}-w_{s}\right)+\left(\left.\frac{\partial \rho}{\partial P}\right|_{h}+k_{p v} \rho_{i}\right)\left(w_{c l} h_{c l}-w_{c l} h_{i}+w_{c v} h_{c v}-w_{c v} h_{i}+Q_{i}\right)}{3600 v_{i}\left(k_{p v} \rho_{i}^{2}+\left.\rho_{i} \frac{\partial \rho}{\partial P}\right|_{h}+\left.0.185 \frac{\partial \rho}{\partial h}\right|_{p}\right)}
$$

where

$$
\begin{aligned}
& \mathrm{h}=\text { enthalpy }(\mathrm{Btu} / \mathrm{hb}) \text {, } \\
& h_{\mathrm{cl}}=\text { cold leg enthalpy }\left(B t u / b_{m}\right) \text {, } \\
& h_{c v}=\text { enthalpy of vessel-pool check valve flow }\left(B t u / / b_{m}\right) \text {, } \\
& h_{i}=\text { vessel inlet plenum enthalpy }\left(B t u / b_{m}\right) \text {, } \\
& \mathrm{k}_{\mathrm{pv}}=\text { structural elasticity coefficient (psi-1), } \\
& \mathbf{P}_{\mathbf{i}}=\text { vessel inlet plenum pressure (psia), } \\
& \mathrm{Q}_{\mathrm{i}}=\text { heat transfer rate between the vessel-pool and inlet plenum }(\mathrm{Btu} / \mathrm{h}) \text {, } \\
& V_{i}=\text { vessel inlet plenum volume }\left(\mathrm{ft}^{3}\right) \text {, } \\
& w_{b k}=\text { break flow }\left(l_{\mathrm{m}} / \mathrm{h}\right) \text {, } \\
& w_{c l}=\text { reactor inlet flow }\left(\mathrm{lb}_{\mathrm{m}} / \mathrm{h}\right) \text { (subscript cl represents cold leg), } \\
& \mathrm{w}_{\mathrm{cv}}=\text { vessel-pool check valve flow }\left(\mathrm{lb}_{\mathrm{m}} / \mathrm{h}\right) \text {, } \\
& w_{S}=\text { flow from the vessel inlet plenum to core inlet }\left(\mathrm{lb}_{\mathrm{m}} / \mathrm{h}\right) \text {, } \\
& \rho=\text { water density }\left(\mathrm{lb}_{\mathrm{m}} / \mathrm{ft}^{3}\right) \text {, and } \\
& \rho_{\mathrm{i}}=\text { vessel inlet plenum density }\left(\mathrm{lb}_{\mathrm{m}} / \mathrm{ft}^{3}\right) \text {. }
\end{aligned}
$$

The vessel inlet plenum is a storage type node; that is, only pressure and enthalpy are calculated. No flow equation is needed for this node. The vessel wall temperature is calculated from Eq. (9). The metal mass represents the vessel wall mass and there is no heat generation in the vessel wall $\left(\mathrm{Q}_{\mathrm{g}}=0.0\right)$. The inlet plenum volume (KVIRX1) is represented by a single node. The net heat transfer rate includes two parts: heat transfer from the inlet plenum to the exterior surface of the vessel and from the exterior surface of 
the vessel to the pool water. A constant thermal conductivity is used for the vessel wall. The convective heat transfer coefficient at the interior wall of the vessel (KHIRX1) and at the exterior wall (KUWRX1) are assumed constant. Most of the small break transients are fast and short, and heat transfer to the pool during these transients is not important. For long term transients in which the heat transfer to the pool becomes significant, proper heat transfer correlations need to be incorporated into the model.

There is a check valve between the pool and the vessel (the vessel-pool check valve). This valve resides at an elevation of about $831 \mathrm{ft}$ and is connected to the vessel through a two-inch line. The line is connected to one of the eight rabbit holes, which are at an elevation of $824 \mathrm{ft}$, on the vessel. The valve will open if the inlet plenum pressure is below about 24 psia. The pressure drop across the valve is determined by the pool water level and the inlet plenum pressure. The swing check valve is a two-inch valve and its pressure vs. flow characteristics are represented by the flow characteristics of a two-inch class 200 brass swing check valve in Table 7.23

Table 7. Flow characteristics of a two-inch swing check valve as a function of pressure drop

\begin{tabular}{cccc}
\hline \multirow{2}{*}{$\begin{array}{c}\text { Pressure drop } \\
\text { (psi) }\end{array}$} & $\begin{array}{c}\text { Velocity } \\
(\mathrm{ft} / \mathrm{s})\end{array}$ & \multicolumn{2}{c}{ Flow rate } \\
\cline { 3 - 4 } & 15.0 & 156.9 & $(\mathrm{gpm})$ \\
\hline 2.20 & 15.0 & 104.6 & 78004.0 \\
1.00 & 8.0 & 92.1 & 45762.0 \\
0.80 & 7.5 & 78.5 & 39002.0 \\
0.60 & 6.8 & 71.1 & 35362.0 \\
0.50 & 6.0 & 62.8 & 31722.0 \\
0.40 & 5.2 & 54.4 & 27041.0 \\
0.30 & 4.2 & 44.0 & 21841.0 \\
0.20 & 4.0 & 41.8 & 20801.0 \\
0.18 & 2.6 & 27.2 & 13521.0 \\
0.10 & & & \\
\hline
\end{tabular}

In converting velocities to flow rates, the internal cross sectional area of a 2 -in. sch 40 pipe and water density equal to $62.2 \mathrm{lb} / / \mathrm{ft}^{3}$ are used. The flow rate vs pressure drop values are inserted into a function table (named KWWRX1). The pressure drop is calculated and corresponding flow rate from the table is input to the inlet plenum as the check valve flow. The pool side pressure of the check valve is a function of the pool water level; once the level drops below the valve, no coolant will be transferred to the vessel.

The automatic depressurization valves serve two functions in HFIRSYS: pipe break and valve. When they are used as a break, the coolant is discharged into the pool and the pool pressure is the back pressure. The flow through each and both of the two 
automatic depressurization valves were measured during system pressure checks/ depressurization system by the maintenance people. 12 The flow rate at two different primary system pressures are presented in Sect. 2.6. When they are used as the emergency depressurization valves, the coolant is discharged into the letdown header where pressure is about 11.7 psia. (The parameter KBK4 in the command file needs to be set equal to 1 for breaks and to 0 for valves.) The flow through automatic depressurization valves is calculated from Eq. (10). In the equation the inlet plenum pressure and the letdown header pressure describes the pressure drop through the valves.

\subsubsection{The Core Inlet Region Model}

Between the vessel inlet plenum and core, there is a core inlet region. This node is a resistive storage type; that is, inlet flow rate and exit pressure are calculated. No heat transfer takes place in this region and the pressure drop is low. The pressure and enthalpy derivative equations, simplified forms of Eq. (1) and Eq. (2), are

$$
\frac{d P_{s}}{d t}=\frac{\frac{\rho_{i}+\rho_{s}}{2}\left(w_{s}-w_{c}\right)-\left.\frac{\partial \rho}{\partial h}\right|_{p} w_{s}\left(h_{i}-h_{s}\right)}{3600 V_{s}\left(\left.\frac{\rho_{i}+\rho_{s}}{2} \frac{\partial \rho}{\partial P}\right|_{h}+\left.0.185 \frac{\partial \rho}{\partial h}\right|_{p}\right)}
$$

and,

$$
\frac{\mathrm{dh}_{\mathrm{s}}}{\mathrm{dt}}=\frac{0.185\left(\mathrm{w}_{\mathrm{s}}-\mathrm{w}_{\mathrm{c}}\right)+\left.\frac{\partial \rho}{\partial \mathrm{P}}\right|_{\mathrm{h}} \mathrm{w}_{\mathrm{s}}\left(\mathrm{h}_{\mathrm{i}}-\mathrm{h}_{\mathrm{s}}\right)}{3600 \mathrm{~V}_{\mathrm{s}}\left(\left.\frac{\rho_{\mathrm{i}}+\rho_{\mathrm{s}}}{2} \frac{\partial \rho}{\partial \mathrm{P}}\right|_{\mathrm{h}}+\left.0.185 \frac{\partial \rho}{\partial \mathrm{h}}\right|_{\mathrm{p}}\right)}
$$

where,

$$
\begin{aligned}
& h_{s}=\text { core inlet enthalpy }\left(B t u / l b_{m}\right), \\
& P_{s}=\text { core inlet pressure (psia), } \\
& w_{c}=\text { total core flow (bypass, target and fuel channels) }\left(1 b_{m} / h\right), \\
& w_{s}=\text { flow rate from the vessel inlet plenum to core inlet region }\left(\mathrm{lb}_{m} / \mathrm{h}\right), \text { and } \\
& \rho_{s}=\text { water density of core inlet region }\left(\mathrm{lb}_{\mathrm{m}} / \mathrm{ft} 3\right) .
\end{aligned}
$$


The flow from the vessel inlet plenum to core inlet region $\left(w_{s}\right)$ is calculated from

$$
\frac{d w_{s}}{d t}=1.66924810^{7} \frac{A_{s}}{L_{s}}\left[P_{i}-P_{s}+\frac{\rho_{i}+\rho_{s}}{2144} \Delta Z_{s}-\frac{w_{s}\left|w_{s}\right|}{K_{c s}^{2}} \frac{2}{\rho_{i}+\rho_{s}}\right]
$$

where,

$$
\begin{aligned}
A_{S} & =\text { flow cross sectional area }\left(\mathrm{ft}^{2}\right), \\
\mathrm{L}_{\mathrm{s}} & =\text { length of core inlet region }(\mathrm{ft}), \\
\mathrm{K}_{\mathrm{cs}} & =\text { flow conductance of core inlet region }\left(\mathrm{lb}_{\mathrm{m}} / \mathrm{h}\right) \mathrm{psi}-0.5\left(\mathrm{lb}_{\mathrm{m}} / \mathrm{ft}^{3}\right)-0.5, \text { and } \\
\Delta \mathrm{Z}_{\mathrm{s}} & =\text { elevation difference between core inlet and vessel inlet }(\mathrm{ft}) .
\end{aligned}
$$

\subsubsection{The Core Model}

The HFIR core has 540 fuel plates and so many corresponding fuel channels. The core dimensions are shown in Fig. 5. The core model is based on the average and hot fuel channels, and a bypass region. All of the fuel elements in the inner and the outer fuel annuli are treated by the same flow channel geometry. 24 Schematic drawings of a fuel channel and bypass channel are shown in Fig. 14. There is no inner and outer annuli fuel plates in the core model. A fuel channel is composed of halves of two fuel plates and the flow channel between them. They are assumed to be perfectly symmetrical; therefore, no heat transfer occurs at fuel plate center lines. As mentioned before, the lumped parameter approach is used. Each fuel channel has two nodes representing the coolant and the fuel. Fuel plates are treated as flat slabs. The heat transfer equation, Eq. (6), and the temperature equation, Eq. (9), are solved for only one average fuel channel and only one hot channel. There is actually no difference between the equations for two channel types except for the power and flow multiplication factors which cause more heat generation and less flow in the hot channel.

The overall heat transfer coefficient from the fuel plate centerline to bulk fluid is

$$
U=\frac{i}{\frac{d_{f}}{k_{f}}+\frac{d_{c}}{k_{c}}+\frac{d_{o}}{k_{o}}+\frac{1}{h_{o}}}
$$

where

$$
\begin{aligned}
& d_{c}=\text { clad thickness }(f t) \\
& d_{f}=\text { half thickness of fuel }(f t)
\end{aligned}
$$


$\dot{d}_{0}=$ oxide thickness ( $\mathrm{ft}$ )

$h_{0}=$ convective heat transfer coefficient $\left(\right.$ Btu $\left./ \mathrm{ht}^{2}{ }^{\circ} \mathrm{F}\right)$

$\mathrm{k}_{\mathrm{c}}=$ clad thermal conductivity $\left(\mathrm{Btu} / \mathrm{h} \mathrm{ft}{ }^{\circ} \mathrm{F}\right)$

$k_{f}=$ fuel thermal conductivity $\left(B t u / h f{ }^{\circ} F\right)$

$\mathrm{k}_{0}=$ oxide thermal conductivity $\left(\mathrm{Btw} / \mathrm{h} \mathrm{ft}^{\circ} \mathrm{F}\right)$

$\mathrm{U}=$ overall heat transfer coefficient $\left(\mathrm{Btu} / \mathrm{h} \mathrm{ft}{ }^{\circ} \mathrm{F}\right)$.

The numerical values used for tile average fuel plate ${ }^{28}$ are

$$
\begin{aligned}
& \mathrm{d}_{\mathrm{f}}=15 \mathrm{mils}=1.2510^{-3} \mathrm{ft}, \\
& \mathrm{d}_{\mathrm{c}}=9.4 .5 \mathrm{mils}=7.9210^{-4} \mathrm{ft}, \\
& \mathrm{d}_{0}=0.68^{\circ} \mathrm{mils}=5.8310^{-5} \mathrm{ft}, \\
& \mathrm{k}_{c}=87.4 \mathrm{Btu} / \mathrm{h} \mathrm{ft}{ }^{\circ} \mathrm{F}, \\
& \mathrm{k}_{\mathrm{f}}=67.62 \mathrm{Btu} / \mathrm{h} \mathrm{ft}{ }^{\circ} \mathrm{F}, \text { and } \\
& \mathrm{k}_{\mathrm{o}}=1.3 \mathrm{Btu} / \mathrm{h} / \mathrm{t}^{\circ} \mathrm{F} .
\end{aligned}
$$

The thermal conductivity of fuel plate is weighted based on the number of inner fuel plate: (171), number of outer fuel plates (369), the inner fuel thermal conductivity $\left(76.3 \mathrm{Btu} / \mathrm{h} \mathrm{f:}{ }^{\circ} \mathrm{F}\right)^{28}$ and outer fuel thermal conductivity $\left(63.6 \mathrm{Btu} / \mathrm{h} \mathrm{ft}{ }^{\circ} \mathrm{F}\right)^{28}$ as follows:

$$
k_{f}=\frac{76.3171+63.6369}{540}=07.62 \mathrm{Btu} / \mathrm{h} \mathrm{ft}^{\circ} \mathrm{F} .
$$

The clad thickness is adjusted based on oxide layer thickness. The oxide layer thickness is $25.4 \%$ thicker than the thickness of metal ( $\mathrm{Al}$ ) consumed; thus, the original clad thickness ( 10 mils) is reduced as follows:

$$
d_{c}=10-\frac{0.689}{1.254}=9.45 \mathrm{mils}
$$

For the hot channels, the oxide and clad thicknesses ${ }^{28}$ are

$$
\begin{aligned}
& \mathrm{d}_{\mathrm{o}}=1.21 \mathrm{mils}=1.2510^{-3} \mathrm{ft} \text {, and } \\
& \mathrm{d}_{\mathrm{c}}=10-1.21 / 1.254:=9.035 \mathrm{mils}=7.510^{-4} \mathrm{ft} .
\end{aligned}
$$

The remaining parameters are the same as those for the average fuel plates.

Two different approact::s are available for calculation of the overall heat transfer coefficient in HFIRSYS. In the first apr roach, the convective heat transfer coefficient between fuel plate surface and the fluid is calculated based on Eq. (8) which assumes that 
the flow rate is the only variable. This is a simplification used in MMS. The second approach accounts for each term in the overall heat transfer coefficient separately. The convective heat transfer coefficient is calculated based on the Hausen forced convection correlation Eq. (28) which accounts for viscosity variation from the wall temperature to the bulk fluid temperature. A logical parameter FHTRX1 allows selection of either the first, simple approach (FHTRX1=.FALSE.) or the second (FHTRX1=.TRUE.).

First, the simple approach is explained. The overall heat transfer coefficient was implemented in terms of an effective thickness (KDA) and effective thermal conductivity (KKA):

$$
\begin{aligned}
& K \mathcal{K})=d_{f}+d_{c}+d_{0} \\
& K K A=\frac{d_{f}+d_{c}+d_{o}}{\frac{d_{f}}{k_{f}}+\frac{d_{c}}{k_{c}}+\frac{d_{0}}{k_{o}}}
\end{aligned}
$$

The heat transfer rate is then

$$
\mathrm{Q}=\frac{\mathrm{A} \Delta \mathrm{T}}{\frac{\mathrm{KDA}}{\mathrm{KKA}}+\frac{1}{\mathrm{~h}}}
$$

where
A $=$ fuel plate heat transfer area $\left(\mathrm{ft}^{2}\right)$, and
$\mathrm{h}=$ convective heat transfer coefficient $\left(\mathrm{Bru} / \mathrm{h} \mathrm{ft}^{2} \mathrm{~F}\right)$

The temperature difference $\Delta \mathrm{T}$ is the difference between fuel plate center line temperature and bulk fluid temperature. For the hot channel, the same parameters are KDH and $\mathrm{KKH}$.

The numerical values are

$$
\begin{aligned}
\mathrm{KDA} & =2.1 \quad 10^{-3} \mathrm{ft}, \\
\mathrm{KKA} & =29.01 \mathrm{Btu} / \mathrm{h} \mathrm{ft}^{\circ} \mathrm{F}, \\
\mathrm{KDH} & =2.1 \quad 10^{-3} \mathrm{ft}, \text { and } \\
\mathrm{KKH} & =20.2 \mathrm{Btu} / \mathrm{h} \mathrm{ft}{ }^{\circ} \mathrm{F} .
\end{aligned}
$$

If the second approach is preferred, the convective heat transfer coefficient is calculated based on the previous time step values. This may result in appearance of the following comment: "Derivative function evaluation not repeatable." The terms in the overall heat transfer coefficient are not lumped into KDA and KKA type terms. This 
approach provides more realistic representation of heat transfer to the coolant than the first approach does.

The derivatives of the center line temperatures of the average plate, hot plate, and hot spot are

$$
\begin{aligned}
& \frac{d T_{f}}{d t}=\frac{Q_{f a}-Q_{a}}{3600\left(C_{p} M\right)_{a}} \\
& \frac{d T_{m}}{d t}=\frac{Q_{f p}-Q_{p}}{3600\left(C_{p} M\right)_{h} K_{h s}} \text {, and } \\
& \frac{d T_{x}}{d t}=\frac{Q_{f s}-Q s}{3600\left(C_{p} M\right)_{h}\left(1-K_{h s}\right)} .
\end{aligned}
$$

where

$$
\begin{aligned}
\left(C_{p} M\right)_{a}= & \text { thermal capacity of average plate }(B t u / P F), \\
\left(C_{p} M\right)_{h} K_{h s}= & \text { thermal capacity of hot plate }(B t u / F), \\
\left(C_{p} M\right)_{h}\left(1-K_{h s}\right)= & \text { thermal capacity of hot spot }(B t u / F), \\
K_{h s}= & \text { surface fraction of hot plate excluding hot spot, } \\
\left(1-K_{h s}\right)= & \text { surface fraction of hot spot, } \\
Q_{a}, Q_{p}, Q_{s}= & \text { net heat transfer rates for the average, and hot plates and hot spot } \\
& \text { respectively, } \\
Q_{f a}, Q_{f p}, Q_{f s}= & \text { net rates for the average, heat generation and hot plates, and hot spot } \\
& \text { respectively, and } \\
T_{f}, T_{m}, T_{x}= & \text { center line temperatures of the average and hot plate and hot spot } \\
& \text { respectively. }
\end{aligned}
$$

The same equations are also implemented for the bypass channel; however, the metal thickness parameter in the overall heat transfer coefficient equation represents cylindrical geometry. The bypass metal, beryllium, has numerous holes allowing the coolant to cool it. Beryllium is assumed to be composed of identical hollow cylindrical elements with the coolant in the hole. A temperature equation, Equation 5-62 on page 127 of M. M. ElWakil, is provided for heat generating hollow cylinders with clad. 25

The boundary conditions and the equation are 


$$
\begin{aligned}
\frac{d T}{d r} & =0 \text { at } r=r_{0} \text { and } \\
T & =T_{0} \text { at } \quad r=r_{0} \\
T_{0}-T_{b} & =\frac{q^{\prime \prime} r_{0}^{2}}{4 k_{f}}\left[\left(\frac{r_{i}}{r_{0}}\right)^{2}-2 \ln \left(\frac{r_{i}}{r_{0}}\right)-1\right]+\frac{q^{\prime \prime \prime} r_{0}^{2}}{2}\left\{\left[1-\left(\frac{r_{i}}{r_{0}}\right)^{2}\right]\left[\frac{1}{k_{c}} \ln \frac{r_{i}}{r_{i}-c_{i}}+\frac{1}{h\left(r_{i}-c_{i}\right)}\right]\right\}
\end{aligned}
$$

where

$r_{i}, r_{0}=$ inner and outer radii,

$c_{i}=$ clad thickness,

$k_{c}, k_{\mathbf{f}}=$ clad and solid cylinder thermal conductivities,

$\mathrm{h}=$ convective heat transfer coefficient,

$\mathrm{T}_{\mathrm{b}}=$ bulk fluid temperature,

$\mathrm{T}_{0}=$ temperature at $\mathrm{r}_{0}$, and

$\mathrm{q}^{\prime \prime \prime}=$ volumetric heat generation rate

This equation is put in the form of Eq. (6):

$$
Q=\frac{2 \pi r_{i} L\left(T_{0}-T_{b}\right)}{\frac{1}{k_{f}}\left(-\frac{r_{i}}{2}\right)\left[1+\frac{2}{1-\left(r_{i} / r_{o}\right)^{2}} \ln \left(\frac{r_{i}}{r_{o}}\right)\right]+\frac{1}{h}}
$$

where

$$
\begin{aligned}
& \mathrm{L}=\text { length of the hollow cylinder, and } \\
& \mathrm{Q}=\text { heat transfer rate. }
\end{aligned}
$$

It has been implemented into the code in the following form:

$$
Q=\frac{K A B\left(T_{0}-T_{b}\right)}{\frac{K D B}{K K B}+\frac{1}{h}}
$$

where

$$
\mathrm{KAB}=2 \pi \mathrm{r}_{\mathrm{i}} \mathrm{L},
$$


$\mathrm{KDB}=-\frac{\mathrm{r}_{\mathrm{i}}}{2}\left[1+\frac{2}{1-\left(\mathrm{r}_{\mathrm{i}} / \mathrm{r}_{\mathrm{o}}\right)^{2}} \ln \left(\frac{\mathrm{r}_{\mathrm{i}}}{\mathrm{r}_{\mathrm{o}}}\right)\right]$, and

$\mathrm{KKB}=$ thermal conductivity of reflector material.

The heat generation is distributed over fuel elements, coolant, and bypass metal. The bypass metal includes target, reflector, and control plates since control plates and the target region are not modelled separately. Currently, $94.2 \%$ of the heat is generated in the fuel elements and $5.8 \%$ in the bypass region. No heat generation occurs in the coolant. The input parameters describing these fractions are

KFFRX1 = fraction of heat generated in the fuel,

KFBRX1 = fraction of heat generated in the bypass metal, and

heat generation in the coolant is calculated based on the magnitude of these variables and hot plate and hot spot factors. There is no neutronics model in the core; the heat generation for steady state operation and after scram (decay heat) are represented in the form of tabulated data. The decay heat fraction based on $85 \mathrm{MW}$ as a function of time after shutdown for HFIR have been placed in table KDCRX1 and shown in Tables 8 and 9.26, 27 The first $0.9 \mathrm{~s}$ after scram includes decay heat and diminishing fission power.

Table 8. Fraction of reactor power based on 85 MW within $0.9 \mathrm{~s}$ after scram

\begin{tabular}{cc}
\hline Time after shutdown (s) & Fraction \\
\hline 0.01 & 0.9957 \\
0.05 & 0.7255 \\
0.1 & 0.2688 \\
0.15 & 0.1508 \\
0.20 & 0.1182 \\
0.25 & 0.1153 \\
0.30 & 0.1142 \\
0.35 & 0.1131 \\
0.40 & 0.1121 \\
0.45 & 0.1112 \\
0.50 & 0.1104 \\
0.55 & 0.1096 \\
0.60 & 0.1087 \\
0.65 & 0.1079 \\
0.70 & 0.1072 \\
0.75 & 0.1064 \\
0.80 & 0.105 \\
0.85 & 0.105 \\
0.90 & 0.1044 \\
\hline
\end{tabular}


Table 9. Fraction of reactor power based on $85 \mathrm{MW}$ from $1 \mathrm{~s}$ to $36000 \mathrm{~s}$ after scram

\begin{tabular}{cccc}
\hline $\begin{array}{c}\text { Time After } \\
\text { Shutdown }\end{array}$ & Fraction & $\begin{array}{c}\text { Time After } \\
\text { Shutdown }\end{array}$ & Fraction \\
\hline $1(\mathrm{~s})$ & 0.0949 & $1920(\mathrm{~s})$ & 0.0133 \\
3 & 0.0791 & 2040 & 0.0130 \\
5 & 0.0703 & 2160 & 0.0128 \\
9 & 0.0601 & 2400 & 0.0123 \\
20 & 0.0480 & 2640 & 0.0119 \\
40 & 0.0390 & 2880 & 0.0116 \\
60 & 0.0341 & 3120 & 0.0112 \\
80 & 0.0312 & 3600 & 0.0106 \\
100 & 0.0291 & 7200 & 0.0081 \\
120 & 0.0275 & 10800 & 0.0069 \\
140 & 0.0265 & 14400 & 0.0061 \\
160 & 0.0254 & 18000 & 0.0056 \\
180 & 0.0246 & 21600 & 0.0052 \\
200 & 0.0240 & 25200 & 0.0048 \\
220 & 0.0234 & 28800 & 0.0046 \\
240 & 0.0230 & 32400 & 0.0044 \\
360 & 0.0208 & 36000 & 0.0042 \\
480 & 0.0195 & & \\
600 & 0.0185 & & \\
720 & 0.0177 & & \\
840 & 0.0170 & & \\
960 & 0.0164 & & \\
1080 & 0.0159 & & \\
1200 & 0.0154 & & \\
1320 & 0.0150 & & \\
1440 & 0.0146 & & \\
1560 & 0.0142 & & \\
1680 & 0.0139 & & \\
\hline
\end{tabular}

The temperature of the average fuel, hot fuel, hot spot, and bypass metal is calculated from Eq. (9). The thermal conductivities (k) and material thicknesses (d) are assumed to be constant. The heat transfer coefficients are calculated from Eq. (8). The steady state flow rates for the average and hot channels ( $\left.w_{S s} s\right)$ are calculated by dividing the core-fuel region flow by 540; however, a flow reduction factor (KCHRX1) based on flow cross sectional areas of average and hot channels is applied to hot channel flow. The flow distribution fractions inside the vessel is presented in Sect. 2.2. The steady state conveclive heat transfer coefficients are shown in Table 10.28 
Table 10. Steady state values of the convective heat transfer coefficients

\begin{tabular}{lcc}
\hline $\begin{array}{c}\text { Convective heat transfer } \\
\text { coeffecient }\end{array}$ & Name & Value $\left(\mathrm{Btu} /{ }^{\circ} \mathrm{Fft}^{2} \mathrm{~h}\right)$ \\
\hline Average fuel channel & KHARX1 & 15,000 \\
Hot channel & KHHRX1 & 15,000 \\
Bypass channel & KHBRX1 & $9052^{a}$ \\
\hline
\end{tabular}

${ }^{a^{a}}$ This value is estimated by $\mathrm{T}$. L. Wilson, ORNL.

The minimum values of convective heat transfer coefficients of average and hot channels are limited by the value of the Nusselt number for fully developed laminar flow inside rectangular channels: 29

$$
\mathrm{Nu}=7.54
$$

where

$$
\begin{aligned}
\mathrm{Nu} & =\text { Nusselt number }=\frac{\mathrm{hD}_{\mathrm{h}}}{\mathrm{k}}, \\
\mathrm{h} & =\text { heat transfer coefficient }\left(\mathrm{Btu} / \mathrm{h} \mathrm{ft}^{\circ} \mathrm{F}\right), \\
\mathrm{D}_{\mathrm{h}} & =\text { hydraulic diameter }(\mathrm{ft}), \text { and } \\
\mathrm{k} & =\text { thermal conductivity of coolant }\left(\mathrm{Btu} / \mathrm{h} \mathrm{ft}{ }^{\circ} \mathrm{F}\right) .
\end{aligned}
$$

The same set of equations are used for the hot spot except for changing the heat transfer surface area and heat generation rate. The heat generation rate of the fuel in the hot channel and of the hot spot is higher than that of the fuel in an average channel. The average heat generation rate is multiplied by the factors in Table 11 to obtain the heat generation rate for the hot channel fuel and for the hot spot:

Table 11. Hot channel and hot spot multiplication factors

\begin{tabular}{ccc}
\hline $\begin{array}{c}\text { Multiplication } \\
\text { factor }\end{array}$ & Name & Value \\
\hline Hot fuel & KFPRX1 & 1.62 \\
Hot spot & KLPRX1 & 3.248 \\
\hline
\end{tabular}


These factors are slightly different from those used in the latest version of the HFIR fuel element steady state heat transfer code (also referred to as the HFIR thermal analysis code). 30 They are based on data in Table 9 and Table 10 of ORNL/TM-11647, draft, by D. G. Morris and M. W. Wendel. The referred report includes a RELAP5 model of HFIR. A small fraction of the hot channel fuel surface area belongs to the hot spot. The fraction of the hot fuel channel surface area assigned to the hot plate is defined by KHSRX1; (KHSRX1 $=0.99995808$ for the hot plate). The hot spot surface area is equal to (fuel plate surface area $) *(1-$ KHSRX1).

The flow rates through average, hot fuel, and bypass channels are calculated using the standard MMS momentum equation, Eq. (4). Flow rates through different regions in the core are calculated from

average fuel channel:

$$
\frac{\mathrm{d} \mathrm{w}_{\mathrm{a}}}{\mathrm{dt}}=1.66924810^{7} \frac{\mathrm{A}_{\mathrm{a}}}{\mathrm{L}_{\mathrm{a}}}\left[\mathrm{P}_{\mathrm{s}}-\mathrm{P}_{1}+\frac{\rho_{\mathrm{a}}+\rho_{\mathrm{s}}}{2144} \Delta \mathrm{Z}_{\mathrm{c}}-\frac{\mathrm{w}_{\mathrm{a}}\left|\mathrm{w}_{\mathrm{a}}\right|}{\mathrm{K}_{\mathrm{ca}}^{2}} \frac{2}{\rho_{\mathrm{a}}+\rho_{\mathrm{s}}}\right]
$$

hot channel:

$$
\frac{d w_{h}}{d t}=1.66924810^{7} \frac{A_{h}}{L_{h}}\left[P_{s}-P_{1}+\frac{\rho_{p}+\rho_{s}}{2144} \Delta Z_{c}-\frac{w_{h}\left|w_{h}\right|}{\left(K_{c s} K_{c h}\right)^{2}} \frac{2}{\rho_{p}+\rho_{s}}\right]
$$

and bypass channel:

$$
\frac{d w_{b}}{d t}=1.66924810^{7} \frac{A_{b}}{L_{b}}\left[P_{s}-P_{1}+\frac{\rho_{b}+\rho_{s}}{2144} \Delta Z_{c}-\frac{w_{b}\left|w_{b}\right|}{K_{c b}^{2}} \frac{2}{\rho_{b}+\rho_{s}}\right]
$$

where

$$
\begin{aligned}
A_{a}, A_{h}, A_{b}= & \text { flow cross sectional areas of average, hot and bypass channels } \\
& \text { respectively }\left(f^{2}\right), \\
K_{c a}, K_{c b}= & \text { flow conductances for average and bypass channels }\left(1 b_{m} / h\right)(p s i)-0.5 \\
& \left(1 b_{m} / f t 3\right)^{-0.5}, \\
K_{c h}= & \text { flow reduction multiplication factor for hot channels, }
\end{aligned}
$$


$L_{a}, L_{h}, L_{b}=$ length of average, hot and bypass channels ( $f t$ ),

$P_{1}=$ core exit pressure (psia),

$w_{a}, w_{h}, w_{b}=$ flow rates through average, hot and bypass channels respectively $\left(l b_{m} / h\right)$,

$\Delta \mathrm{Z}_{\mathrm{c}}=$ core height $(\mathrm{ft})$, and,

$\rho_{a}, \rho_{p}, \rho_{b}=$ exit densities for average, hot and bypass channels respectively $\left(\mathrm{lb}_{\mathrm{m}} / \mathrm{ft}^{3}\right)$.

The total core exit flow is then calculated from

$$
w_{c}=N_{a} w_{a}+N_{h} w_{h}+w_{b}
$$

where

$\mathrm{N}_{\mathrm{a}}, \mathrm{N}_{\mathrm{h}}$ = number of average and hot channels respectively.

The core is a resistive type node; that is, flow rates are calculated using core inlet and outlet pressures and no pressure calculation is performed within the core region.

Exit enthalpies of average, hot, and bypass channels are calculated from slightly different form of enthalpy derivative equation which uses core exit pressure derivative $\left(\mathrm{dP}_{1} / \mathrm{dt}\right)$ with respect to time.

The average channel enthalpy derivative is

$$
\frac{d h_{a}}{d t}=\frac{1}{V_{a} \rho_{a}}\left[\frac{w_{a} h_{s}-w_{a} h_{a}+Q_{a}+Q_{f c}}{3600}+0.185 V_{a} \frac{d P_{1}}{d t}\right]
$$

The hot channel enthalpy derivative is

$$
\frac{d h_{p}}{d t}=\frac{1}{V_{h} \rho_{p} K_{h a}}\left[\frac{w_{h} h_{t}-w_{h} h_{p}+Q_{p}+Q_{t c} K_{b}}{3600}+0.185 V_{h} \frac{d P_{1}}{d t}\right] \text {, }
$$

and the bypass channel enthalpy derivative is

$$
\frac{\mathrm{dh}_{\mathrm{b}}}{\mathrm{dt}}=\frac{1}{\mathrm{~V}_{\mathrm{b}} \rho_{\mathrm{b}}}\left[\frac{\mathrm{w}_{\mathrm{b}} \mathrm{h}_{\mathrm{s}}-\mathrm{w}_{\mathrm{b}} \mathrm{h}_{\mathrm{b}}+\mathrm{Q}_{\mathrm{b}}}{3600}+0.185 \mathrm{~V}_{\mathrm{b}} \frac{\mathrm{dP}_{1}}{\mathrm{dt}}\right]
$$


where

$h_{a}, h_{p}, h_{b}=\begin{aligned} & \text { exit enthalpies of average, hot and bypass channels respectively } \\ & \left(B \text { tu } / \mathrm{b}_{m}\right)\end{aligned}$

$\mathrm{K}_{\mathrm{hs}}=$ surface area fraction not including hot spot (0.99995808),

$\mathrm{Q}_{\mathrm{a}}, \mathrm{Q}_{\mathrm{p}}, \mathrm{Q}_{\mathrm{b}}=$ heat transfer rates for average, hot and bypass channels respectively $(\mathrm{Btu} / \mathrm{h})$,

$\mathrm{Q}_{\mathrm{fc}}=$ heat generated in the coolant per channel $(\mathrm{Btu} / \mathrm{h})$, and

$V_{a}, V_{h}, V_{b}=$ volumes of average, hot and bypass channels respectively $\left(f^{3}{ }^{3}\right)$.

The heat generated in the hot spot located at the exit of the hot channel is added to the hot channel enthalpy:

$$
h_{h}=h_{p}+\frac{Q_{s}+Q_{f c}\left(1-K_{h s}\right)}{W_{h}}
$$

where

$$
\begin{aligned}
& h_{h}=\text { hot channel exit enthalpy including hot spot }\left(B t u / b_{m}\right) \text {, and } \\
& Q_{s}=\text { hot spot heat transfer rate }(B t u / h)
\end{aligned}
$$

The calculated flow rate through the average channel is multiplied by the number of average channels to obtain the total core flow through average channels. The same thing is done for the hot channels if more than one hot channel is considered. A flow reduction factor is used to increase friction (or reduce flow conductance) so that less flow goes through the hot channel. The magnitude of the flow conductance terms are shown in Table 12.

Table 12. Values of the flow conductance terms of hot, bypass and average channels

\begin{tabular}{lll}
\hline \multicolumn{1}{c}{ Core region } & \multicolumn{1}{c}{$\begin{array}{c}\text { Flow conductance } \\
\text { (name) }\end{array}$} & \multicolumn{1}{c}{ Value } \\
\hline Average channel & KCARX1 & 153.1 \\
Hot channel & KCARX1*KCHRX1 & 92.53 \\
Bypass channel & KCBRX1 & 19378.0 \\
\hline
\end{tabular}


The flow conductance terms, the $k_{c f}$ term in Eq. (5), have the units of $\left(\mathrm{lb}_{\mathrm{m}} / \mathrm{h}\right)(\mathrm{psi})-0.5$ $\left(\mathrm{lb}_{\mathrm{m}} / \mathrm{ft} \mathrm{t}^{3}\right)-0.5$.

A hot spot is modelled at the exit of the core where the fluid temperature is the highest and pressure is the lowest. The onset of nucleate boiling (ONBR) and the departure from nucleate boiling (DNBR) ratios are calculated for the hot spot. The forced convection heat transfer coefficient is calculated from the Hausen correlation:

$$
\mathrm{Nu}=\mathrm{U}_{8} 0.0235\left(\operatorname{Re}^{0.8}-230\right)\left(1.8 \operatorname{Pr}^{0.3}-0.8\right)\left(\frac{\mu_{b}}{\mu_{w}}\right)^{0.14}
$$

where

$$
\begin{aligned}
\mathrm{Nu} & =\text { Nusselt number }=h \mathrm{D}_{h} / \mathrm{k}, \\
\mathrm{U}_{8} & =\text { uncertainty factor }=0.9,30 \\
\mathrm{Re} & =\text { Reynolds number, } \\
\mathrm{Pr} & =\text { Prandtl number, } \\
\mu_{\mathrm{b}} & =\text { water viscosity at the bulk fluid temperature, and } \\
\mu_{\mathrm{w}} & =\text { water viscosity at the wall temperature. }
\end{aligned}
$$

The entry region effects, which are included in the previous studies, 30 are neglected. 24 The Bergles-Rohsenow correlation is used to calculate nucleate boiling heat flux:31

$$
(q / A)_{b}=15.6 P_{1}^{1.156}\left(T_{o}-T_{\text {sat }}\right)^{a}
$$

where

$$
a=\frac{2.3}{P_{1}^{0.0234}}
$$

$(\mathrm{q} / \mathrm{A})_{\mathrm{b}}=$ heat flux $\left(\mathrm{Btu} / \mathrm{h} \mathrm{ft} \mathrm{f}^{2}\right)$,

$P_{1}=$ core exit pressure (psia),

$\mathrm{T}_{0}=$ hot spot surface temperature $\left({ }^{\circ} \mathrm{F}\right)$, and

$\mathrm{T}_{\text {sat }}=$ saturation temperature $\left({ }^{\circ} \mathrm{F}\right)$. 
If calculated heat flux for the hot spot using the Hausen correlation is equal to the heat flux calculated from the Bergles-Rohsenow correlation (i.e., $O N B R=1$ ), boiling conditions will prevail. The critical heat flux is calculated using the Gambill's correlation developed for HFIR. 32 Since the incipient boiling is used as the safety limit, the critical heat flux is only used as an indicator. A previous report by T. L. Wilson includes information on the vessel and core models also. 24

\subsubsection{The Core Exit Region Model}

The core exit is a mixing region for flows from average, hot and bypass flow channels. It is a storage type node; that is, only pressure and enthalpy are calculated. The equations are

core exit region pressure derivative:

$$
\frac{\mathrm{dP}}{\mathrm{dt}}=\frac{\rho_{1}\left(w_{c}-w_{1}\right)-\left.\frac{\partial \rho}{\partial h}\right|_{p} w_{c}\left(h_{c}-h_{1}\right)}{3600 V_{1}\left(\left.\rho_{1} \frac{\partial \rho}{\partial P}\right|_{h}+\left.0.185 \frac{\partial \rho}{\partial h}\right|_{p}\right)}
$$

where

$$
\begin{aligned}
& w_{1}=\text { flow rate from the core exit region to vessel outlet plenum }\left(\mathrm{lb}_{\mathrm{m}} / \mathrm{h}\right), \\
& \rho_{1}=\text { core exit region density }\left(\mathrm{lb} / \mathrm{m} / \mathrm{ft}^{3}\right), \text { and }
\end{aligned}
$$

core exit enthalpy $\left(h_{c}\right)$ :

$$
h_{c}=\frac{w_{b} h_{b}+N_{1} w_{1} h_{c}+N_{h} w_{h} h_{h}}{w_{c}}
$$

The core exit region enthalpy derivative is

$$
\frac{d h_{1}}{d t}=\frac{0.185\left(w_{c}-w_{1}\right)+\left.\frac{\partial \rho}{\partial p}\right|_{b} w_{c}\left(h_{c}-h_{1}\right)}{3600 V_{1}\left[\left.\rho_{1} \frac{\partial \rho}{\partial p}\right|_{b}+\left.0.185 \frac{\partial \rho}{\partial h}\right|_{p}\right]_{b}}
$$


The core exit pressure and the vessel outlet plenum pressure are then used to calculate flow from the core exit region to the vessel outlet plenum:

$$
\frac{d w_{1}}{d t}=1.66924810^{7} \frac{A_{0}}{L_{0}}\left[P_{1}-P_{b l}+\frac{\left(\rho_{1}+\rho_{b}\right)}{2144} \Delta Z_{o}-\frac{w_{1}\left|w_{1}\right|}{K_{d}^{2}} \frac{2}{\left(\rho_{1}+\rho_{b}\right)}\right]
$$

where

$\mathrm{A}_{0}=$ average flow cross sectional area $\left(\mathrm{ft}^{2}\right)$,

$\mathrm{L}_{\mathrm{O}}=$ combined flow length $(\mathrm{ft})$,

$\mathrm{K}_{\mathrm{cl}}=$ flow conductance $\left(\mathrm{lb}_{\mathrm{m}} / \mathrm{h}\right)(\mathrm{psi})^{-0.5}\left(\mathrm{lb}_{\mathrm{m}} / \mathrm{ft}^{3}\right)^{-0.5}$,

$\mathrm{P}_{\mathrm{hl}}=$ vessel outlet plenum (exit) pressure (psia), and

$\Delta Z_{\mathrm{o}}=$ elevation difference between core outlet and vessel outlet $(\mathrm{ft})$.

\subsubsection{The Vessel Outlet Plenum Model}

The equations for the outlet plenum are very similar to those of the inlet plenum. The equations are vessel outlet plenum pressure derivative:

$$
\frac{\mathrm{dP}_{\mathrm{h} 1}}{\mathrm{dt}}=\frac{\frac{\rho_{1}+\rho_{\mathrm{hl}}}{2}\left(\mathrm{w}_{1}-\mathrm{w}_{\mathrm{h} 1}\right)-\left.\frac{\partial \rho}{\partial \mathrm{h}}\right|_{\mathrm{p}} \mathrm{w}_{1}\left(\mathrm{~h}_{1}-\mathrm{h}_{\mathrm{h} 1}\right)}{3600 \mathrm{~V}_{\mathrm{o}}\left[\left.\frac{\rho_{1}+\rho_{\mathrm{h} 1}}{2} \frac{\partial \rho}{\partial \mathrm{P}}\right|_{\mathrm{h}}+\left.0.185 \frac{\partial \rho}{\partial \mathrm{h}}\right|_{\mathrm{P}}\right]}
$$

and vessel outlet plenum enthalpy derivative:

$$
\frac{d h_{h 1}}{d t}=\frac{0.185\left(w_{1}-w_{h 1}\right)+\left.\frac{\partial \rho}{\partial P}\right|_{h} w_{1}\left(h_{1}-h_{h 1}\right)}{3600 V_{0}\left[\left.\frac{\rho_{1}+\rho_{h 1}}{2} \frac{\partial \rho}{\partial P}\right|_{h}+\left.0.185 \frac{\partial \rho}{\partial h}\right|_{p}\right]}
$$

where,

$$
\begin{aligned}
h_{h l} & =\text { vessel exit (hot leg) enthalpy }\left(B t u / b_{m}\right) \\
V_{0} & =\text { vessel outlet plenum volume }\left(\mathrm{ft}^{3}\right) \\
w_{h l} & =\text { vessel exit flow }\left(l_{\mathrm{m}} / \mathrm{h}\right)
\end{aligned}
$$




$$
\begin{aligned}
& P_{h l}=\text { vessel outlet plenum (exit) pressure }(\mathrm{psia}) \text {, and } \\
& \rho_{\mathrm{hl}}=\text { vessel exit density }\left(\mathrm{lb}_{\mathrm{m}} / \mathrm{ft} 3\right)
\end{aligned}
$$

The structural expansion/contraction is not considered. The pressure and enthalpy are provided to the hot leg pipe as the outlet plenum pressure and enthalpy. In turn the flow from the vessel outlet plenum to the hot leg $\left(w_{h l}\right)$ is calculed in the hot leg pipe module. No heat transfer across the solid boundaries of the outlet plenum is considered.

\subsubsection{Heat Exchangers (Coolers)}

A new COOLER module has been developed at ORNL. The main heat exchangers, coolers, are parallel-counter-flow (shell and U-tube type) and mounted vertically. A schematic drawing of the coolers is shown in Fig. 15. Only three coolers are required for full-power operation. There is liquid water in the shell (secondary coolant) and tube (primary coolant) sides. The effectiveness method has been used in modeling of the coolers. The shell and tube sides are represented by single nodes. There are advantages of the effectiveness method over the logarithmic mean temperature difference (LMTD) method. 33 The effectiveness $(E)$ is defined by

$$
E=\frac{C_{w e}\left(T_{w e}-T_{w l}\right)}{C_{\min }\left(T_{w e}-T_{d e}\right)}=\frac{C_{d e}\left(T_{d l}-T_{d e}\right)}{C_{\min }\left(T_{w e}-T_{d e}\right)}
$$

where

$$
\begin{aligned}
\mathrm{C}_{\mathrm{de}} & =\mathrm{w}_{\mathrm{de}} \mathrm{Cp}_{\mathrm{de}},\left(\mathrm{Btu} / \mathrm{h}^{\circ} \mathrm{F}\right) \text { the shell side, } \\
\mathrm{C}_{w e} & =\mathrm{w}_{\mathrm{we}} \mathrm{Cp}_{\mathrm{we}},\left(\mathrm{Btu} / \mathrm{h}^{\circ} \mathrm{F}\right) \text { the tube side, } \\
\mathrm{C}_{\max } & =\max \left(\mathrm{C}_{\mathrm{we}}, \mathrm{C}_{\mathrm{de}}\right) \\
\mathrm{C}_{\min } & =\min \left(\mathrm{C}_{\mathrm{we}}, \mathrm{C}_{\mathrm{de}}\right), \\
\mathrm{C}_{\mathrm{p}} & =\text { specific heat }\left(\mathrm{Btu} / \mathrm{h}^{\circ} \mathrm{F}\right), \\
\mathrm{w}_{\mathrm{de}} & =\text { shell side flow rate }\left(\mathrm{lb}_{\mathrm{m}} / \mathrm{h}\right), \\
\mathrm{w}_{\mathrm{we}} & =\text { tube side flow rate }\left(\mathrm{lb}_{\mathrm{m}} / \mathrm{h}\right), \\
\mathrm{T}_{\mathrm{de}} & =\text { shell side inlet temperature }\left({ }^{\circ} \mathrm{F}\right), \\
\mathrm{T}_{\mathrm{dl}} & =\text { shell side outlet temperature }\left({ }^{\circ} \mathrm{F}\right), \\
\mathrm{T}_{\mathrm{we}} & =\text { tube side inlet temperature }\left({ }^{\circ} \mathrm{F}\right), \text { and } \\
\mathrm{T}_{\mathrm{wl}} & =\text { tube side outlet temperature }\left({ }^{\circ} \mathrm{F}\right) .
\end{aligned}
$$


Independent of outlet temperatures, the effectiveness for parallel-counter-current (shell-and-tube) heat exchanger is calculated from 34

$$
\begin{aligned}
& \text { If } C_{\text {ritin }}=C_{w e} \text { and } C_{\max }=C_{d e} \text {, } \\
& E=\frac{\left(1+G+2 C^{\circ} G\right)+\left(2 C^{*}+1\right) D e^{-\alpha}-e^{-\alpha}}{\left(1+G+2 C^{\circ} G\right)+2 C^{*}(1-D)+2 C^{*} D e^{-\alpha}}
\end{aligned}
$$

where

$$
\begin{aligned}
& D=\frac{1-e^{-a}}{2 C^{*}+1}, \\
& G=\frac{1-e^{-\beta}}{2 C^{*}+1}, \\
& \alpha=\frac{1}{4} N T U\left(2 C^{*}+1\right), \\
& t=\frac{1}{2} N T U\left(2 C^{*}-1\right), \\
& C^{*}=C_{\min } / C_{\max }, \\
& N T U=\frac{U A}{C_{\min }}, \text { and } \\
& U A=\text { overall heat transfer coefficient *heat transfer area. } \\
& \text { If } C_{n . i n}=C_{d e} \text { and } C_{\max }=C_{w e}, \text { then replace } \\
& C^{*} \text { by } 1 / C^{*} \\
& N T U \text { by } N T U C^{*}, \text { and } \\
& e \text { by eC* }
\end{aligned}
$$

in Eq. (36). 
The net heat transfer rate $(Q)$ is calculated from

$$
Q=E C_{\min }\left(T_{w e}-T_{d e}\right) \text {. }
$$

Calculation of effectiveness requires the knowledge of UA; UA is calculated from an overall heat transfer coefficient equation for coolers: 4

$$
\begin{aligned}
& U A=\frac{w_{w e} w_{d e}}{k_{d l} w_{d e} w_{w e}^{0.2}+k_{d f} w_{w e} w_{d e}+k_{d s} w_{d e}^{0.4} w_{w e}} \\
& k_{d t}=\frac{w_{\text {we }}^{0.8}\left(D_{o} / D_{i}\right) N_{h}^{-0.2}}{0.023\left(k / D_{i}\right) \operatorname{Re}^{0.8} \operatorname{Pr}^{0.4} A_{t}}, \\
& k_{d f}=\frac{R_{\text {fouling }}}{A_{t}}+\frac{\left(D_{0}-D_{i}\right) / 2 N_{h}}{k_{\text {tube }} A_{t}}, \\
& k_{d s}=w_{d e}^{0.6}\left(\frac{1}{U A}-\frac{k_{d t}}{w_{w e}^{0.8}}-k_{d r}\right) N_{h}^{-0.4}, \\
& A_{\mathfrak{l}}=\text { total heat transfer area }\left(\mathrm{ft}^{2}\right) \text {, } \\
& D_{0}=\text { outer diameter of tubes }(\mathrm{ft}) \text {, } \\
& D_{i}=\text { inner diameter of tubes }(\mathrm{ft}) \text {, } \\
& \mathrm{k}=\text { fluid thermal conductivity }\left(\mathrm{Btu} / \mathrm{ft} \mathrm{h}^{\circ} \mathrm{F}\right) \text {, } \\
& \mathrm{k}_{\text {wbe }}=\text { tube metal thermal conductivity }\left(\mathrm{Btu} / \mathrm{ft} \mathrm{h}^{\circ} \mathrm{F}\right) \text {, } \\
& \mathrm{N}_{\mathrm{h}} \text { = number of parallel heaters, } \\
& \operatorname{Re}=\text { Reynolds number, } \\
& \mathbf{R}_{\text {fouling }} \text { = fouling factor for shell and tube sides, zero for new heat exchangers (if } \\
& \operatorname{Pr}=\text { Prandtl number. }
\end{aligned}
$$

The parameter $k_{d s}$ is calculateu from the steady state value of $U A, k_{d t}$ and $k_{d f}$. Using plant data steady state value of UA is calculated from

$$
\mathrm{UA}=\frac{\mathrm{Q}}{\Delta \mathrm{T}}
$$


where

$$
\begin{aligned}
& Q=\text { heat transfer rate, and } \\
& \Delta T=\text { average temperature difference. }
\end{aligned}
$$

A value for $\mathbf{k}_{\mathbf{d s}}$ is calculated from Eq. (41) using the value of $U A$ from Eq. (42). The values of these parameters for a single heat exchanger are found in Table 13.

Table 13. Steady state values of $k_{d t}, k_{d f}$ and $k_{d s}$ for single (CL1) and double (CL2) heat exchanger models

\begin{tabular}{ccll}
\hline Parameter & HFIRSYS-name & & \multicolumn{1}{c}{ Value } \\
\hline$k_{d t}$ & KDT CL1 & $7.110^{-3}$ & $\left(\mathrm{lb}_{\mathrm{m}} / \mathrm{h}\right)^{0.8}\left(\mathrm{Btu} / \mathrm{h}^{\circ} \mathrm{F}\right)^{-1}$ \\
$\mathrm{k}_{\mathrm{df}}$ & KDF CL1 & $2.5110^{-7}$ & $\left(\mathrm{Btu} / \mathrm{h}^{\circ} \mathrm{F}\right)^{-1}$ \\
$\mathrm{k}_{\mathrm{ds}}$ & KDS CL1 & $1.0510^{-3}$ & $(\mathrm{lb} / \mathrm{h} /)^{-0.2}\left(\mathrm{Btu} / \mathrm{h}^{\circ} \mathrm{F}\right)^{-1}$ \\
$\mathrm{k}_{\mathrm{dt}}$ & KDT CL2 & $6.210^{-3}$ & $(\mathrm{lb} / \mathrm{h})^{0.8}\left(\mathrm{Btu} / \mathrm{h}^{\circ} \mathrm{F}\right)^{-1}$ \\
$\mathrm{k}_{\mathrm{df}}$ & KDF CL2 & $1.25510^{-8}$ & $\left(\mathrm{Btu} / \mathrm{h}^{\circ} \mathrm{F}\right)^{-1}$ \\
$\mathrm{k}_{\mathrm{ds}}$ & KDS CL2 & $8.010^{-4}$ & $(\mathrm{lb} / \mathrm{h} /)^{-0.2}\left(\mathrm{Btu} / \mathrm{h}^{\circ} \mathrm{F}\right)^{-1}$ \\
\hline
\end{tabular}

The cooler module is a resistive-storage type; the tube side inlet flow rate $w_{w e}$ and outlet pressure and enthalpy are calculated in the module. The MMS momentum equation, Eq. (4), is used to calculate the tube-side inlet flow rate and reverse flow is not allowed. The pressure and enthalpy derivatives are calculated from Eq. (13) and Eq. (14) including structural elasticity terms. The shell side flow rate is calculated from steady state momentum equation not including elevation terms, Eq. (10). The flow conductance term in this equation is controlled to change the secondary flow rate. A proportional-integral (pi) controller controls the flow conductance term (KCD_ID) to keep the reactor inlet temperature at about $120^{\circ} \mathrm{F}$. This is a simplified representation of the secondary flow control by T. L. Wilson of ORNL. 24 Pump coastdown is calculated from an exponential curve which determines the shell side inlet pressure after the pumps are tripped.

$$
P_{s e}=P_{s w 1 m} f_{s w 1}+\left(1-f_{s w 1}\right) P_{s w l a}+P_{s w 11}
$$

where

$$
\begin{aligned}
\hat{\mathbf{I}}_{\text {SWl }}= & \mathrm{e}^{-\frac{1-t_{1}}{T_{\mathrm{c}}}} \text { for pump irip, exponentialiy decaying to zero. This factor uses EXPF } \\
& \text { function of ACSL. }
\end{aligned}
$$




$$
\begin{aligned}
\mathrm{t} & =\text { time }(\mathrm{s}), \\
\mathrm{t} & =\text { time of trip }(\mathrm{s}), \\
\mathrm{T}_{\mathrm{c}} & =\text { time constant, (default is } 0.5 \mathrm{~s}), \\
\mathrm{P}_{\text {se }} & =\text { shell side inlet pressure }(\mathrm{psia}), \\
\mathrm{P}_{\text {sw } 1 \mathrm{~m}} & =\text { main secondary pump head (psia), } \\
\mathrm{P}_{\text {swla }} & =\text { auxiliary secondary pump head (psia), and } \\
\mathrm{P}_{\text {sw1l }} & =\text { shell side outlet pressure (psia). }
\end{aligned}
$$

This equation is in the main portion of the HFIRSYS program. The shell side inlet pressure is provided to the cooler modules for calculation of shell side flow rate using Eq. (10). Those transients for which secondary side response is important, an actuator, picontroller for controlling valve position and pump head and coastdown curves need to be incorporated into the model.

In the HFIRSYS model, two of the coolers are combined into a single COOLER and the remaining cooler is represented as a single COOLER.

\subsubsection{Circular Horizontal Tank}

The MMS library does not include a circular horizontal tank model. For a given net out flow rate, water level will drop at a constant rate in a tank with a uniform cross sectional area. In a tank with a circular cross sectional area, the level drops faster as the cross sectional area becomes smaller. The primary coolant head tank, a circular horizontal tank, provides the necessary suction head for the pressurizer pumps. It receives letdown return flow and flows from other sources in the plant. A new tank module has been developed (CTANK) to represent the primary head tank. A schematic of the tank is shown in Fig. 16. The water temperature and tank pressure are constant. Three separate flow streams into the tank and one from the tank can be specified. The pressure at the outlet of the tank is calculated using tank pressure and water level. The water level is calculated from water inventory in the tank. 33 The area of the shaded segment of the circle in Fig. 16 is

$$
A=\frac{1}{2} r^{2}(\phi-\sin \phi)
$$

and the volume of water is

$$
\mathrm{V}=\mathrm{A} \mathbf{L},
$$


where

$L=$ length of the tank ( $f t)$,

$r$ = radius of the tank $(\mathrm{ft})$, and

$\phi=$ two times angle $\theta$ shown in Fig. 16.

Then the angle is computed from

$$
\phi=\sin \phi+\frac{2 V}{L r^{2}}
$$

This equation is solved using a trial and error method. The distance between the water surface and the center of the tank cross sectional area $(y)$ is

$$
y=r \cos \frac{\phi}{2}
$$

Water level $\left(l_{v}\right)$ is calculated as a function of $y$

$$
1_{v}=r-y
$$

A control valve on the line coming from the demineralizer system maintains a water level corresponding to $90 \%$ capacity (1875 gal.). The controller is modelled in a simplistic way by T. L. Wilson of ORNL. 24 The flow from the demineralizer system is controlled by the following equation:

$$
\mathrm{w}_{\mathrm{dm}}=\max \left\{0 ., \min \mathrm{w}_{100},\left[\frac{\mathrm{w}_{100}}{5.0}\left(1_{\mathrm{veet}}-1_{\mathrm{v}}\right)\right]\right\}
$$

where

$\mathrm{w}_{\mathrm{dm}}=$ demineralizer system flow rate $\left(\mathrm{lb}_{\mathrm{m}} / \mathrm{h}\right)$,

$\mathrm{w}_{100}=$ maximum demineralizer system flow rate $\left(\mathrm{lb}_{\mathrm{m}} / \mathrm{h}\right)$, and

$\mathrm{l}_{\mathrm{vset}}=$ level set point $(\mathrm{ft})$.

This equation is in the main part of HFIRSYS and $w_{d m}$ is an input flow to the tank model. 


\subsubsection{Combined Pony Motor and AC Motor Model}

The main circulation pumps are driven by two motors connected to the same shaft, Fig. 3. When the main ac motors are tripped, small dc pony motors continue to run. In simulation of pump trips, motor torque is assumed to decrease to zero immediately. 35 Since the dc pony motors continue to run after the main motors are tripped, the motor torque decreases to the dc pony motor torque. The only modifications made to the standard MOTOR module are inclusion of dc pony motor torque and $\mathrm{N}^{2}$ in friction torque instead of $\mathrm{N}$ in calculation of motor speed during coastdown. The motor speed derivative is

$$
\frac{d N}{d t}=307.39 \frac{\left(T_{m}-T_{f}-T_{1}\right)}{I}
$$

where

$$
\begin{aligned}
N & =\text { motor speed }(\mathrm{rpm}), \\
\mathrm{t} & =\text { time }(\mathrm{s}), \\
\mathrm{I} & =\text { inertia of pump, ac and pony motors }\left(\mathrm{lb}_{\mathrm{m}} \mathrm{ft}^{2}\right) \\
\mathrm{T}_{\mathrm{m}} & =\text { motor torque }\left(\mathrm{lb}_{\mathrm{f}} \mathrm{ft}\right) \\
\mathrm{T}_{1} & =\text { hydraulic torque }\left(\mathrm{lb}_{\mathrm{f}} \mathrm{ft}\right) \\
\mathrm{T}_{\mathrm{f}} & =\mathrm{k}_{\mathrm{fr}} \mathrm{N}^{2}=\text { friction torque }\left(\mathrm{lb}_{\mathrm{f}} \mathrm{ft}\right) \\
\mathrm{k}_{\mathrm{fr}} & =\text { friction factor }(\mathrm{lb} f \mathrm{ft} / \mathrm{rpm}), \text { and } \\
\mathrm{g}_{\mathrm{c}} \frac{60}{2 \pi} & =307.39, \text { a conversion factor. }
\end{aligned}
$$

The friction factor, $\mathrm{k}_{\mathrm{fr}}$, is adjusted such that when the ac motors are tripped the calculated flow coastdown profile matches the measured primary flow coastdown profile $(\mathrm{KFRCP} 1=0.0005$ and $\mathrm{KFRCP} 2=0.0010)$. There is no dc pony motor representation other than including its torque in calculation of the coastdown speed. The dc pony motor torque data are given in Table $14 .{ }^{36}$ 
Table 14. The dc pony motor torque as a function of speed

\begin{tabular}{cc}
\hline Speed $(\mathrm{rpm})$ & torque $\left(\mathrm{lb}_{\mathrm{f}} \mathrm{ft}\right)$ \\
\hline 145 & 129 \\
225 & 77.2 \\
305 & 47.6 \\
425 & 25.4 \\
532 & 15.8 \\
\hline
\end{tabular}

To set dc pony motor torque equal to zero, the parameter KLPCP1 for one heat exchanger loop and KLPCP2 for two heat exchanger loop need to be set equal to FALSE at run time or in command files.

The pump speed is about $1800 \mathrm{rpm}$ during normal operation and moment of inertia of the motors and the pump are shown in Table 15.6

Table 15. Moment of inertia of the main circulation pump and its motors

\begin{tabular}{lc}
\hline Component & $\begin{array}{c}\text { Moment of Inertia } \\
\left(\mathrm{lb}_{\mathrm{m}} \mathrm{ft}^{2}\right)\end{array}$ \\
\hline ac motor & 421.0 \\
dc pony motor & 9.5 \\
Pump & 37.5 \\
\hline
\end{tabular}

The MOTOR module is connected to the MMS PUMP4Q module that includes four quadrant homologous pump curves. The pump homologous curves for the main circulation pumps were calculated from the manufacturer pump performance curves and implemented into MMS PUMP4Q module to replace the normal operational quadrant of the homologous curves.

\subsubsection{Pressurizer Pumps Model}

There are two main pressurizer pumps and an emergency pressurizer pump. The pressurizer pumps are described in Sect. 2.5. The emergency pump is represented by tabulated data: flow rate as a function of pump head implemented in an ACSL function 
table named KWEPZP. Two remaining pumps are called main (operating) and standby (in standby) pressurizer pumps. There is a variable speed magnetic drive between each pump and its motor (Fig. 8); however, the operating pump runs at a constant speed during normal operation. Available information on inertia of these pumps are provided in Sect. 2.5. Coastdown and startup pump speed is calculated from a torque balance:

$$
T_{m}-T_{p}=I \frac{d N}{d t}
$$

where

$$
\begin{aligned}
T_{m} & =\text { motor torque }\left(l b_{f} f t\right) \\
T_{p} & =\text { pump torque }\left(l b_{f} f t\right) \\
I & =\text { inertia of magnetic clutch, couplings, shaft, pump impeller and water }\left(l_{m} f t^{2}\right), \\
N & =\text { pump speed (rpm), and } \\
t & =\text { time }(s) .
\end{aligned}
$$

During coastdown pump torque can be represented as a function of pump speed and a loss coefficient (c): 37

$$
T_{p}=c N^{2}
$$

Then derivative of the pump speed either for startup or coastdown is calculated from

$$
\frac{\mathrm{dN}}{\mathrm{dt}}=\frac{1}{\mathrm{I}}\left(307.39 \mathrm{~T}_{\mathrm{m}}-\mathrm{c} \mathrm{N^{2 }}\right)
$$

where

$$
\begin{aligned}
c & =0.0111 \mathrm{lb}_{\mathrm{m}} \mathrm{ft}^{2} / \mathrm{rpm} \mathrm{s} \text { (calculated from pressurizer pump test data), } \\
\mathrm{N} & =\mathrm{rpm}, \\
\mathrm{I} & =120.0 \mathrm{lb}_{\mathrm{m}} \mathrm{ft}^{2} \\
\mathrm{~T}_{\mathrm{m}} & =\mathrm{lb}_{\mathrm{f}} \mathrm{ft}, \text { and } \\
\mathrm{g}_{\mathrm{c}} \frac{60}{2 \pi} & =307.39
\end{aligned}
$$


Motor torque values at different speeds for steady state operation can be calculated from this equation. The motor torque is assumed to be zero during coastdown 35,37 leading to a simple expression for hand calculation of pump speed:

$$
N=\frac{N_{0}}{1+\frac{c N_{0} t}{I}}
$$

where

$$
\begin{aligned}
N_{0} & =\text { steady state pump speed (rpm), and } \\
t & =\text { time after pump trip (s). }
\end{aligned}
$$

In HFIRSYS, the speed derivative, Eq. (51) is integrated using a central integrator for coastdown and standby pump startup. Steady state motor torque calculated from Eq. (51) yields desired pump speed. The main pressurizer pumps are assumed to be identical. Figure 25 includes a comparison of Eq. (52) to the pressurizer pump speed coastdown data. 8 The pressures at the inlet and discharge of the pressurizer pumps are calculated. If these pressures reach any of the trip set points listed in Sect. 2.7, the main pressurizer pump will be tripped. For high discharge pressure trip, no time delay is considered. If suction pressure is as low as $0.5 \mathrm{psig}$, the pumps do not trip immediately. Trip is delayed about $5 \mathrm{~s}$ and at the end of the $5 \mathrm{~s}$ if the pressure is still low enough then the pumps are tripped. This has been handled by use of ACSL SCHEDULE and DISCRETE commands. No time delay between generation of a trip signal and tripped pumps is considered. The motor torque data for the main pressurizer pump are in function table KMOTM. The estimated total inertia $(\mathrm{I}=120.0 \mathrm{l} \mathrm{m} f)$ and loss coefficient $(c=0.0111$ $\mathrm{lb}_{\mathrm{m}} \mathrm{ft} 2 / \mathrm{rpm} \mathrm{s}$ ) are used for the pump. 8

The main pressurizer pump uses the MMS PUMP module. The flow rate (Q), head $(\mathrm{H})$, hydraulic horse power $\left(\mathrm{BHP}_{\mathrm{f}}\right), \mathrm{Q} / \mathrm{N}, \mathrm{H} / \mathrm{N}^{2}$, and $\mathrm{BHP}_{\mathrm{f}} / \mathrm{N}^{3}$ were calculated from the pressurizer pump performance curve at $2616 \mathrm{rpm}$ rated speed and implemented into HFIRSYS. Appendix A includes the pressurizer pump performance curves at different speeds.

The component modules, their connections, and flow stream names are shown in a block diagram, Fig. 10, and a schematic drawing representing the current configuration of HFIRSYS, Fig. 11. All of the pressurizer pumps are connected to the same suction and discharge line in the model. The emergency pressurizer pump has a different flow path in HFIR; it feeds seal water to the main circulation pump seals. Since the leakage into the 
primary coolant system and the pump seals are not modelled separately, the current configuration is considered satisfactory. The auxiliary pressurizer pump starts if the pressurizer pump discharge flow rate is below $75 \mathrm{gpm}$; however, it is capable of providing coolant into the primary system if the system pressure is below 228 psia.

\subsubsection{Flow Model for Pipe Breaks}

Small breaks in the primary coolant system in HFIRSYS are modelled using valves in fully open position. Flow conductance terms are determined depending on diameters of breaks. Flow rate through orifices is accurately determined from the incompressible single phase flow equation: 25

$$
\mathrm{w}=\mathrm{C} \frac{\pi \mathrm{D}^{2}}{4}\left[2 \mathrm{~g}_{\mathrm{c}} \rho 144\left(\mathrm{P}_{\mathrm{s}}-\mathrm{P}_{\mathrm{b}}\right)\right]^{0.5}
$$

where

$$
\begin{aligned}
C & =\text { coefficient, } \\
D & =\text { break diameter }(\mathrm{ft}), \\
\mathrm{P}_{\mathrm{S}} & =\text { system pressure }(\mathrm{psia}), \\
\mathrm{P}_{\mathrm{b}} & =\text { back pressure }(\mathrm{psia}), \\
\mathrm{w} & =\text { flow rate }(\mathrm{lb} / \mathrm{b} / \mathrm{s}), \text { and } \\
\rho & =\text { density }\left(\mathrm{lb}_{\mathrm{m}} / \mathrm{ft} 3\right) .
\end{aligned}
$$

For a given loss coefficient, Eq. (53) is identical to the valve flow equation including valve flow coefficient $C_{v}: 38$

$$
\mathrm{Q}_{\mathrm{v}}=\mathrm{C}_{\mathrm{v}}\left[62.4 \frac{\left(\mathrm{P}_{\mathrm{S}}-\mathrm{P}_{\mathrm{b}}\right)}{\rho}\right]^{0.5}
$$

where

$$
\begin{aligned}
\mathrm{C}_{\mathrm{v}} & =\mathrm{gpm} / \mathrm{psi} 0.5 \\
\mathrm{Q}_{\mathrm{v}} & =\text { volumetric flow rate }(\mathrm{gpm}), \\
\mathrm{P}_{\mathrm{s}} & =\text { system pressure }(\mathrm{psia}), \\
\mathrm{P}_{\mathrm{b}} & =\text { back pressure }(\mathrm{psia}), \text { and } \\
\rho & =\text { density }\left(\mathrm{l} \mathrm{b}_{\mathrm{m}} / \mathrm{ft} 3\right) .
\end{aligned}
$$


The parameter $\mathrm{C}_{\mathrm{v}}$ incorporates flow cross sectional area and a loss coefficient; thus, it can be written as a function of break diameter. In previous small break loss of coolant studies for HFIR, breaks are identified by $C_{v}$ 's. ${ }^{11}$ In the current study $C_{v}=17.67 D^{2}$ is utilized and converted into MMS flow conductance term. ${ }^{4} \mathrm{D}$ is in inches in this equation. This corresponds to a loss coefficient (C) equal to 0.593 . The flow conductance of breaks $(\mathrm{KCV})$ and $\mathrm{C}_{\mathrm{v}}$ are related to each other by

$$
\mathrm{KCV}=63.34 \mathrm{C}_{\mathrm{v}} \text {. }
$$

The flow rate through the fully open valve representing a break is

$$
w=\operatorname{KCV}\left(\rho_{\mathrm{e}} \Delta P\right)^{0.5}
$$

where

$$
\begin{aligned}
w & =\text { break flow rate }\left(\mathrm{lb}_{\mathrm{m}} / \mathrm{h}\right) \\
\Delta \mathrm{P} & =\text { pressure drop through the valve }(\mathrm{psi}), \text { and } \\
\rho_{\mathrm{e}} & =\text { density }\left(\mathrm{lb}_{\mathrm{m}} / \mathrm{ft}^{3}\right)
\end{aligned}
$$

In Fig. (10), VALVEI modules representing breaks are located at main circulation pump discharge (BK1), main circulation pump inlet (BK2), at cooler inlet (BK3) and at the vessel (BK4).

\subsubsection{Relief Valves}

There are two pressure relief paths each having a rupture disk and a relief valve. They are not modeled separately instead a flow conductance for the relief valve and a rupture disk combination was calculated based on the information in Sect. 6.11.3 of "HFIR FSAR Chap. 6 - Interfaces With Other Chapters," by H. G. O'Brien (April 8, 1991). Each path has a capacity of $296 \mathrm{gpm}$ at an overpressure of $682 \mathrm{psi}$ including the 0.8 rupture disk combination factor. Then the flow conductance for one path is

$$
\operatorname{KCVSRV}=\frac{w}{(\rho \Delta P)^{0.5} f(y)}
$$




$$
\begin{aligned}
f(y) & =1 \text { when reactor pressure }>\text { set pressure, } \\
\rho & =62 \mathrm{lb}_{\mathrm{m}} / \mathrm{ft}^{3}, \\
\Delta P & =682 \mathrm{psi}, \text { and } \\
w & =296 \mathrm{gpm} \\
\text { KCVSRV } & =715.94 \frac{\mathrm{lb}}{\mathrm{h}}\left(\frac{\mathrm{lb}}{\mathrm{ft}^{3}} \mathrm{psi}\right)^{-0.5} .
\end{aligned}
$$

The parameter KNSRV can either be set at 1 or 2 depending on the number of paths open.

The default value for KNSRV is 2. The back pressure (PSRVL) is set at 14.7 psia and the pressure set point (PRVSET) is 658.45 psia. The set pressure for the relief valves is $625 \pm 3 \%$ psig; thus, the pressure set point in HFIRSYS is

$$
625+0.03 \times 625+14.7=658.45 \text { psia }
$$

The flow conductance (KCVSRV) is automatically set at zero when reactor pressure falls below the pressure set point.

\subsection{CONTROL SYSTEM MODEL}

Transients to be studied include control actions. Consistent with modeling details, control system has been modelled. The following parameters in HFIRSYS are continuously controlled:

1. letdown control valve position to keep primary system pressure at $482.7 \mathrm{psia}$,

2. secondary flow control to keep reactor inlet temperature at $120^{\circ} \mathrm{F}$, and

3. demineralizer flow control to keep primary head tank level at $90 \%$ capacity.

\subsubsection{Letdown Valve Controller}

Letdown control valve positions are controlled using an actuator, and a proportional-integral-derivative controller. The controller and actuator are modelled using the standard MMS modules named PIDCNT and ACT.4 The error signal to the letdown valve controller $\mathrm{LC} 1$ is the difference between the reactor inlet pressure (PCLRX) and the pressure set point $(\mathrm{PSET}=482.7 \mathrm{psia})$. A proportional-integral-derivative controller is represented by 39 


$$
Y=k_{c} e+\frac{k_{c}}{t_{i}} \int_{0}^{t} e d t+k_{c} t_{d} \frac{d e}{d t}+Y_{s}
$$

where

$$
\begin{aligned}
\mathrm{Y} & =\text { position signal (controller output), } \\
\mathrm{Y}_{\mathbf{s}} & =\text { steady state value of signal, } \\
\mathbf{e} & =\text { error signal, } \\
\mathrm{k}_{\mathbf{c}} & =\text { proportional constant (gain), } \\
\mathrm{t}_{\mathbf{d}} & =\text { derivative time, } \\
\mathrm{t}_{\mathrm{i}} & =\text { integral time }\left(1 / \mathrm{t}_{\mathrm{i}}\right. \text { is reset rate), and } \\
\mathrm{t} & =\text { time }(\mathrm{s})
\end{aligned}
$$

The term $\mathrm{k}_{\mathrm{c}} / \mathrm{t}_{\mathrm{i}}$ is called integral constant. Proportional, integral, and derivative constants need to be specified by users for a pi-controller in MMS. The following values are repetition of what is reported about these constants in ORNL/TM-11647 (draft) by D. G. Morris and M. W. Wendel:

proportional band setting $=100 \%($ gain $=1.0)$,

reset setting $=12 \mathrm{~s}$, and

derivative setting $=9 \mathrm{~s}$.

The actual gain is indicated to be $0.08333 \mathrm{psi}^{-1}$ because of the signal conversion from the controller output to valve stem position at the valve. The pid-controller settings in HFIRSYS are

proportional gain $(\mathrm{CPGLC1})=0.08333 \mathrm{psi}^{-1}$,

integral gain (CIGLC1) $=\frac{0.08333 \mathrm{psi}^{-1}}{12 \mathrm{~s}}=0.0069 \mathrm{psi}^{-1} \mathrm{~s}^{-1}$

derivative gain $(\mathrm{CDGLC} 1)=0.0833 \mathrm{psi}^{-1}$,

inverse time constant (KTDLC1) $=\frac{1}{9 \mathrm{~s}}=0.111 \mathrm{~s}^{-1}$,

low limit of controller output $(\mathrm{KLLLCl})=0.0$,

high limit of controller output (KHLLC1) $=1.0$,

limiter gain $(\mathrm{KLGLC1})=100.0$, 
initial controller output $(\mathrm{Z} 1 \mathrm{CLC} 1)=0.629$

initial integral output $(\mathrm{Z} 1 \mathrm{DLC} 1)=0.0$, and

set point $(\mathrm{PSET})=482.7 \mathrm{psia}$

The parameter $Y$ is valve position demand and named CYLV1 in HFIRSYS and transferred to the actuator ACT. Since letdown control valves in three letdown lines are controlled simultaneously and are identical, the signal CYLV1 is the same for both of the letdown lines. The actuator output is the new valve position YLV1, same for both of the letdown valves. The value of the time constant equal to $5.0 \mathrm{~s}$ for the actuator is taken from Ref. 2 .

\subsubsection{Secondary Flow Control}

Secondary flow is controlled by a simplified control system. There are two heat exchanger loops one of which includes a cooler representing combination of two coolers, and the other representing a single cooler. The secondary side control model was developed by T. L. Wilson of ORNL24 in a simplistic way. The control system includes two proportional-integral controllers and does not include actuators and valves. The controllers change the conductance of the secondary coolant to control the flow rather than changing valve position; that is, the output signal $Y$ of Eq. (55) represents flow conductance $\left(k_{c d}\right)$ in the equation:

$$
w_{d c}=\frac{k_{c d}}{\left[\rho\left(P_{d c}-P_{d 1}\right)\right]^{0.5}}
$$

where

$$
\begin{aligned}
\mathrm{k}_{\mathrm{od}} & =\text { flow conductance }\left(\mathrm{lb}_{\mathrm{m}} / \mathrm{h}\right)(\mathrm{psi})^{-0.5}\left(\mathrm{lb}_{\mathrm{m}} / \mathrm{ft}^{3}\right)^{-0.5} \\
\mathrm{P}_{\mathrm{dc}} & =\text { shell side inlet pressure }(\mathrm{psia}) \\
\mathrm{P}_{\mathrm{dl}} & =\text { shell side outlet pressure }(\mathrm{psia}) \\
\mathrm{w}_{\mathrm{de}} & =\text { shell side inlet flow rate }\left(\mathrm{lb}_{\mathrm{m}} / \mathrm{h}\right), \text { and } \\
\rho & =\text { density }\left(\mathrm{lb}_{\mathrm{m}} / \mathrm{ft}^{3}\right)
\end{aligned}
$$

The error signal (e) is the temperature difference between reactor inlet temperature and the set point. The proportional and integral constants are artificially large for this simplified representation of the secondary flow control system. 
Upon a reactor trip, the main secondary cooling pumps are tripped and the tower bypass vaive operis slowly in about $87 \mathrm{~s}$. The secondary return flow mixes with the 400,000 gallons of coolant in the basin. In HFIRSYS this is accomplished by linearly increasing the flow fraction going through the tower bypass valve. At $87 \mathrm{~s}$, the secondary return flow entirely bypasse: the tower. The enthalpy of the coolant in the basin and its mass are allowed to change. The tower is not modelled; however, it is assumed to reduce the coolani temperature to the normal operational value set by the user. The derivative equations for basin coolant mass and enthalpy are

$$
\begin{aligned}
& \frac{d M_{b}}{d t}=\frac{1}{3600} \sum_{i=1}^{2}\left(w_{i e}-w_{i l}\right), \\
& \frac{d h_{r}}{d t}=\frac{f_{v}}{3600 M_{B}}\left[w_{1 e}\left(h_{1 e}-h_{B}\right)+w_{2 e}\left(h_{2 e}-h_{B}\right)\right] \text {, and } \\
& f_{v}=\frac{t}{87} \text { for } 0 s \leq t \leq 87 s \text { and } \\
& f_{v}=1 \text { for } t>87 s
\end{aligned}
$$

where

$$
\begin{aligned}
f_{v} & =\text { factor representing fractional diversion of flow through bypass } \\
h_{B} & =\text { basin coolant enthalpy }\left(B t u / l b_{m}\right), \\
h_{1 e}, h_{2 e} & =\text { entering flow enthalpies }\left(B t u / b_{m}\right) \\
M_{B} & =\text { basin water mass }\left(l_{m}\right), \\
w_{i e}, w_{i l} & =\text { entering and leaving flows }\left(l b_{m} / h\right), \text { and } \\
t & =\text { time }(s) .
\end{aligned}
$$

A detailed control system with pumps, pipes, valves, and control system has been developed but it is not available with this version.

\subsubsection{Primary Head Tank Level Control}

Prima:y head tank water level is controlled by a simple equation in HFIRSYS, Ea. (47). At HFIR, the letdown flow returning to the primary head tank is not controlled but the flow from the demineralizer system is controlled by a controller, actuator and a 
control valve. Maximum demineralizer flow is about $90-100 \mathrm{gpm}$ and Eq. (47) is a simple substitute for the controller.

\subsubsection{Trips}

The reactor, main circulation pumps, pressurizer pumps, and secondary pumps are trippef $>t$ their trip set points. The reactor and main circulation pump trips use MMS TRIP module which handles time delays as well as creating trip signals. The scram related parameters and their values are shown in Table 16.

Table 16. Parameters related to scram in HFIRSYS

\begin{tabular}{cll}
\hline HFIRSYS name & \multicolumn{1}{c}{ Definition } & \multicolumn{1}{c}{ Value } \\
\hline PCLRX & Inlet pressure & Variable \\
RTSET & Trip set point & $382.7 \mathrm{psia}$ \\
DTRTRP & Trip time delay & $0.04 \mathrm{~s}$ \\
\hline
\end{tabular}

The author is not able to provide references for the delay times. The values of delay times were gathered by T. L. Wilson of ORNL. 24 The main circulation pump trip related parameters and their values are found in Table 17.

Table 17. Parameters related to the main circulation pump trip in HFIRSYS

\begin{tabular}{cll}
\hline HFIRSYS name & \multicolumn{1}{c}{ Definition } & \multicolumn{1}{c}{ Value } \\
\hline PCLRX & Inlet pressure & Variable \\
PTSET & Trip set point & 249.7 psia \\
DTPTRP & Trip time delay & $0.1 \mathrm{~s}$ \\
\hline
\end{tabular}

The main and standby pressurizer pump trips do not utilize the TRIP module. Control actions related to pressurizer pumps in HFIRSYS consist of

1. low suction pressure $(0.5 \mathrm{psig})$ that trips the main and standby pressurizer pumps,

2. high discharge pressure (532.7 psia) that trips the main and standby pressurizer pumps,

3. low head tank capacity (less than $25 \%$ capacity) that trips the main and standby pressurizer pumps,

4. standby pressurizer pump startup (432.7 psia), and

5. emergency pressurizer pump startup (low pressurizer pump flow of $75 \mathrm{gpm}$ ). 
Number (1) makes use of ACSL's SCHEDULE and DISCRETE commands. The SCHEDULE command generates an indication of low pressure. However, there is $5 \mathrm{~s}$ time delay for the trip action to occur and at the end of $5 \mathrm{~s}$ if the suction pressure is still below 0.5 psig then pump trip occurs. The DISCRETE command schedules trip action $5 \mathrm{~s}$ into the future. However, the ACSL 9A version doesn't activate this function if the calculation is started from a restart file. Number (4) includes about $7.2 \mathrm{~s}$ delay in HFIRSYS. Other trips do not include any time delay. Pressurizer pump trip parameters and their values are given in Table 18.

Table 18. Parameters related to the pressurizer pump trip in HFIRSYS

\begin{tabular}{|c|c|c|}
\hline HFIRSYS name & Definition & Value \\
\hline KPZMS & Low suction pressure & $15.2 \mathrm{psia}$ \\
\hline KPZMD & High discharge pressure & 532.7 psia \\
\hline KLOPZS & Low head tank capacity (standby) & 0.25 \\
\hline KLOPZM & Low head tank capacity (main) & 0.25 \\
\hline PLOW & Low reactor pressure (standby) & $432.7 \mathrm{psia}$ \\
\hline LOGPZM & Pump status (main) & $\begin{array}{l}\text { true. is on } \\
\text {.false. is off }\end{array}$ \\
\hline LOGPZS & Pump status (standby) & $\begin{array}{l}\text { true. is on } \\
\text {.false. is off }\end{array}$ \\
\hline LEPZP & Pump status (auxiliary) & $\begin{array}{l}\text { true. is on } \\
\text {.false. is off }\end{array}$ \\
\hline
\end{tabular}

The secondary coolant pump trip is accomplished by setting logical variable KONSW1 to FALSE. Whenever the reactor is tripped, the secondary side is automatically tripped. 


\section{VERIFICATION AND VALIDATION OF HFIRSYS}

The HFIRSYS code was built with MMS-modules and modules and coding developed in-house. The fundamental equations used in the development of modules are presented in this report. The in-house developed coding has been reviewed to verify that the coding accurately portrays intended mathematical models.

\subsection{COMPARISON TO HFIR DEPRESSURIZATION EXPERIMENTS}

Accurate calculation of the system pressure in computer simulations of HFIR is important especially for those operational transients and small break loss of coolant events for which simulation results indicate no threat to the fuel. The depressurization calculations have been performed to test predictive capabilities of HFIRSYS and the results are compared to the Dixon's depressurization test data. 5 Before comparisons between the HFIRSYS predictions and the test data can be made, the test data are analyzed in Sects. 4.1.1 through 4.1.5.

A pressurized light water research reactor, HFIR, does not have a conventional pressurizer with gas space. There is no gas space in the primary coolant system; therefore, its pressure rapidly responds to changes in coolant temperature and inventory due to fluid compressibility. An additional effect on system pressure is due to changes in structural volume. (A contracting structure will tend to keep system pressure up during a loss of coolant event.) Structural elasticity and fluid compressibility form "system elasticity." Their effects on system elasticity were quantified by using the Dixon's depressurization test data 5 and analytical techniques. 40 More specifically, the contribution of structural elasticity to the overall system elasticity was separated from that of fluid compressibility so that a "structural elasticity constant" and a "system elasticity coefficient " which provides change in the system pressure per gallon of water added or removed from the system, can be calculated. Additionally, reduction in the fluid temperature due to fluid expansion during an adiabatic depressurization of the primary coolant system was calculated. The system elasticity constants for the primary coolant system with four and thres heat exchanger loops need to be determined before validation tests are performed. 
The conservation of mass equation for the primary coolant system is

$$
\frac{d(\rho V)}{d t}=w_{i}-w_{o}
$$

where

$$
\begin{aligned}
\rho & =f(P, T)=\text { fluid density, } \\
V & =f(P, T)=\text { volume of the primary coolant system, } \\
w_{i} & =\text { net mass flow rate in, } \\
w_{0} & =\text { net mass flow rate out, } \\
t & =\text { time, } \\
T & =\text { temperature, and } \\
P & =\text { pressure. }
\end{aligned}
$$

The left hand side of the equation can be expanded as follows:

$$
\frac{d(\rho V)}{d t}=\rho\left(\frac{\partial V}{\partial P} \frac{d P}{d t}+\frac{\partial V}{\partial T} \frac{d T}{d t}\right)+V\left(\frac{\partial \rho}{\partial P} \frac{d P}{d t}+\frac{\partial \rho}{\partial T} \frac{d T}{d t}\right)
$$

Net loss of coolant $\left(\mathrm{m}_{\mathrm{l}}\right)$ during a small time interval $\Delta t$ over which the flow rates and density remain constant is

$$
\mathrm{m}_{1}=\left(\mathrm{w}_{\mathrm{o}}-\mathrm{w}_{1}\right) \Delta \mathrm{t},
$$

and also

$$
\mathrm{m}_{1}=-\rho \Delta \mathrm{V}_{\mathrm{d}}
$$

The change in pressure and $(\Delta \mathrm{P})$ discharge of liquid volume $\left(\Delta \mathrm{V}_{\mathrm{d}}\right)$ in $\Delta t$ seconds can be related to each other by

$$
-\rho \Delta V_{d}=\rho\left(\frac{\partial V}{\partial P} \Delta P+\frac{\partial V}{\partial T} \Delta T\right)+V\left(\frac{\partial \rho}{\partial P} \Delta P+\frac{\partial \rho}{\partial T} \Delta T\right)
$$

Calculation of pressure includes evaluation of the four terms: 
1. Volume expansion and contraction due to temperature,

2. Volume expansion and contraction due to pressure,

3. Change in water density due to temperature, and

4. Change in water density due to pressure.

The main purpose is to calculate the contribution of the structural elasticity of the system to the system elasticity constant of HFIR by analyzing the Dixon's HFIR test results. Dixon's tests can be considered adiabatic and the fluid temperature was uniform throughout the system. (The system elasticity constant is the same as "Dixon's spring constant.") An analysis of the Dixon's spring constant measurement tests is provided in the following section.

\subsubsection{Dixon's Depressurization Experiments at HFIR}

The main purpose of the Dixon's depressurization tests at HFIR was to calculate "a system elasticity constant" for HFIR. The system elasticity constant represents combined elasticity of the structure and water for the cold isothermal primary coolant system with four heat exchanger loops (i.e., no power generation in the core and uniform fluid temperature throughout the system). The tests were performed by pressuring HFIR up to about 1000 psia and by bleeding off small volumes of water; the pressure and the amount of water removed were measured. Prior to the tests, the system was leak-rated; the system depressurized in $90 \mathrm{~min}$ from 950 psig to the atmospheric pressure. 5 Between five to ten minutes were required for each test and the amount of water lost through leakage was neglected in the measurement of the total amount of water removed from the system. In this study, the system elasticity constant has been calculated in psi/gal as gross, adjusted ${ }_{1}$, and adjusted ${ }_{2}$ for every data point in Dixon's measurements and shown in Table 19.

The water temperature was $88^{\circ} \mathrm{F}$ in Runs 1 and $2,94^{\circ} \mathrm{F}$ in Run 3 , and $92^{\circ} \mathrm{F}$ in Run 4. The amount of water lost through leakage was estimated by assuming a pressureindependent uniform leakage rate. (The leakage was neglected in the original paper.) $)^{5}$ From Run 2, a pressure-independent uniform leakage rate is calculated: 
Table 19. Dixon's data and calculated system elasticity constants

\begin{tabular}{|c|c|c|c|c|c|c|}
\hline \multirow[b]{2}{*}{$\begin{array}{l}\text { Run } \\
\text { No. }\end{array}$} & \multirow{2}{*}{$\begin{array}{c}\text { Pressure } \\
\text { (psig) }\end{array}$} & \multirow{2}{*}{$\begin{array}{c}\text { Discharged } \\
\text { water mass } \\
(1 \mathrm{bm})\end{array}$} & \multicolumn{3}{|c|}{$\begin{array}{c}\text { System elasticity constant } \\
\mathbf{K}_{\mathrm{fs}}(\mathrm{ps} / \mathrm{gal})\end{array}$} & \multirow{2}{*}{$\begin{array}{c}\mathbf{K s} \\
\text { (psi/gal) }\end{array}$} \\
\hline & & & Gross & Adjusted $_{1}$ & Adusted $_{2}$ & \\
\hline $\begin{array}{l}1 \\
1 \\
1 \\
1 \\
1\end{array}$ & $\begin{array}{l}970-772 \\
772-550 \\
550-345 \\
345-145 \\
145-10\end{array}$ & $\begin{array}{r}85.5 \\
94.0 \\
90.5 \\
88.5 \\
+78.0 \\
436.5\end{array}$ & $\begin{array}{l}19.29 \\
19.66 \\
18.85 \\
18.79 \\
14.38\end{array}$ & $\begin{array}{l}17.88 \\
18.25 \\
17.44 \\
17.38 \\
12.97\end{array}$ & $\begin{array}{l}18.15 \\
18.52 \\
17.71 \\
17.65 \\
13.24\end{array}$ & $\begin{array}{l}72.84 \\
78.77 \\
65.94 \\
65.12 \\
29.22\end{array}$ \\
\hline $\begin{array}{l}2 \\
2 \\
2 \\
2 \\
2\end{array}$ & $\begin{array}{l}952-772 \\
772-565 \\
565-345 \\
345-165 \\
165-10\end{array}$ & $\begin{array}{r}76.0 \\
92.0 \\
95.0 \\
78.0 \\
+87.0 \\
428.0\end{array}$ & $\begin{array}{l}19.73 \\
18.73 \\
19.27 \\
19.19 \\
14.51\end{array}$ & $\begin{array}{l}18.32 \\
17.32 \\
17.86 \\
17.78 \\
13.10\end{array}$ & $\begin{array}{l}18.59 \\
17.59 \\
18.13 \\
18.05 \\
13.37\end{array}$ & $\begin{array}{l}80.05 \\
64.31 \\
72.17 \\
70.91 \\
29.86\end{array}$ \\
\hline $\begin{array}{l}3 \\
3 \\
3 \\
3 \\
3\end{array}$ & $\begin{array}{l}935-715 \\
715-545 \\
545-332 \\
332-160 \\
160-10\end{array}$ & $\begin{array}{r}89.0 \\
62.0 \\
92.5 \\
72.0 \\
+70.0 \\
386.0\end{array}$ & $\begin{array}{l}20.57 \\
22.80 \\
19.14 \\
19.84 \\
17.29\end{array}$ & $\begin{array}{l}19.16 \\
21.39 \\
17.73 \\
18.43 \\
15.88\end{array}$ & $\begin{array}{l}19.43 \\
21.66 \\
18.00 \\
18.70 \\
16.15\end{array}$ & $\begin{array}{r}98.36 \\
205.42 \\
70.15 \\
82.13 \\
48.50\end{array}$ \\
\hline $\begin{array}{l}4 \\
4 \\
4 \\
4 \\
4 \\
4\end{array}$ & $\begin{array}{l}972-765 \\
765-555 \\
555-315 \\
315-160 \\
160-58 \\
58-10\end{array}$ & $\begin{array}{r}84.0 \\
89.5 \\
97.0 \\
70.0 \\
45.5 \\
+25.0 \\
410.5\end{array}$ & $\begin{array}{l}20.51 \\
19.52 \\
20.57 \\
18.40 \\
18.62 \\
15.92\end{array}$ & $\begin{array}{l}19.10 \\
18.11 \\
19.16 \\
16.99 \\
17.21 \\
14.51\end{array}$ & $\begin{array}{l}19.37 \\
18.38 \\
19.43 \\
17.26 \\
17.48 \\
14.78\end{array}$ & $\begin{array}{l}96.84 \\
76.30 \\
98.36 \\
60.11 \\
62.86 \\
37.94\end{array}$ \\
\hline
\end{tabular}

$$
\begin{aligned}
& \mathrm{L}_{\mathrm{rm}}=428.0 \mathrm{lb} / 90 \mathrm{~min}=4.76 \mathrm{lb} / \mathrm{min} \text { or } \\
& \mathrm{L}_{\mathrm{Tv}}=428.0 \mathrm{lb} / \mathrm{m} 0.01607 \mathrm{ft} 3 / 1 \mathrm{~b}_{\mathrm{m}} 1 \mathrm{gal} / 0.1337 \mathrm{ft} 3 / 90 \mathrm{~min} \\
& \mathrm{~L}_{\mathrm{rv}}=0.57 \mathrm{gal} / \mathrm{min} .
\end{aligned}
$$

On the average, each test took about $7.5 \mathrm{~min}$. Therefore, the amount of unaccounted mass leaked from the system (i.e., estimated error in the total amount of water removed from the system) is

$$
\mathrm{m}_{\mathrm{e}}=\mathrm{L}_{\mathrm{rm}} 7.5 \mathrm{~min}=35.7 \mathrm{lb} \mathrm{m} \text {. }
$$


The same error in terms of volume of water is 4.3 gallons. Then an approximate variation in the system elasticity constants is calculated by computing system elasticity constants with and without the leakage water mass for Run 2 and by taking the difference. The difference is $1.41 \mathrm{psi} / \mathrm{gal}$. The system elasticity constants shown as adjusted ${ }_{1}$ in Table 19 are adjusted by this amount.

No temperature decrease was recorded during depressurization of the system. Decrease in liquid temperature during depressurization and its effect on the system elasticity constant are calculated in the next section.

\subsubsection{Change in Water Temperature During Depressurization}

The first law of thermodynamics is applied to the primary coolant system, a control volume with moving boundaries. The equation is

$$
\frac{d U}{d t}=\frac{d Q}{d t}+\frac{d W}{d t}+U_{i}-U_{0}
$$

where

$$
\begin{aligned}
U & =\text { total system energy, } \\
U_{i} & =\text { rate of energy coming in }=w_{i} u_{i} \\
U_{0} & =\text { rate of energy going out }=w_{0} u_{0} \\
Q & =\text { net heat transfer } \\
W & =\text { external work }+ \text { flow work, } \\
W & =\text { flow rate, and } \\
u & =\text { internal energy. }
\end{aligned}
$$

The process is adiabatic; thus,

$$
\mathrm{dQ} / \mathrm{dt}=0 .
$$

Then changes in internal energy is equal to the net work done on the system and by the system,

$$
\mathrm{dU}=\mathrm{dW}-\mathrm{U}_{\mathrm{o}} \mathrm{dt} \text {. }
$$


The external work is done by the structure on the primary coolant. The energy equation becomes

$$
\int_{1}^{2} d U=-\int_{1}^{2} P d V-\int_{1}^{2} w_{0} h_{0} d t
$$

where

$$
\begin{aligned}
w_{i} & =0.0=\text { flow rate into the system, } \\
P & =\text { system pressure }(p s i a), \\
h_{0} & =\text { water enthalpy }\left(B t u / b_{m}\right) .
\end{aligned}
$$

Ir. Eq. (61), the term $d V$ represents an incremental change in the HFIR primary coolant system volume. The change in the volume of a conduit due to the radial expansion or contraction is given by Eq. (11).

The structural elasticity cefficient $\left(\mathrm{k}_{\mathrm{pv}}\right)$ for HFIR in Eq. (11) is

$$
k_{p v}=\frac{2 r}{e E} \text { having units of }\left(\mathrm{psi}^{-1}\right)
$$

and in terms of change in the system volume and pressure is

$$
k_{p v}=\frac{1}{V} \frac{d V}{d P}
$$

Equation (61) can be integrated to compute change in the total internal energy for a depressurization event:

$$
\begin{aligned}
& \int_{1}^{2} d U=\int_{1}^{2} P V k_{p v} d P-\int_{1}^{2} w_{o} h_{o} d t \\
& U_{2}-U_{1}=\frac{0.185}{2} V k_{p v}\left(P_{1}^{2}-P_{2}^{2}\right)-m_{1} \frac{\left(h_{1}+h_{2}\right)}{2}
\end{aligned}
$$

where the initial conditions are designated by the subscript 1 and final conditions by 2 , the unit conversion factor $(0.185)$ is inserted, and 


$$
\begin{aligned}
h & =u+P v=\text { enthalpy }\left(B t u / / b_{m}\right), \\
h_{0} & =\left(h_{1}+h_{2}\right) / 2=\text { average enthalpy of discharge flow }\left(B t u / l b_{m}\right) .
\end{aligned}
$$

The primary coolant system volume assumes an average value. The internal energy based on per unit mass is

$$
u_{2}=\frac{0.0925 V k_{p v}\left(P_{1}^{2}-P_{2}^{2}\right)-m_{1} \frac{\left(h_{1}+h_{2}\right)}{2}+M_{1} u_{1}}{M_{1}-m_{1}}
$$

where

$$
M_{1}=\text { total initial primary coolant mass before discharge }\left(l_{m}\right) \text {. }
$$

Definition of enthalpy provides a second equation:

$$
u_{2}=h_{2}-0.185 P_{2} \quad v_{2}
$$

where

$$
v_{2}=\text { specific volume }\left(\mathrm{ft}^{3} / \mathrm{b}_{\mathrm{m}}\right)
$$

The terms $v_{2}, h_{2}$, and $u_{2}$ are unknown. Once a structural elasticity coefficient is calculated, change in the primary coolant system volume is calculated from Eq. (62) using known pressures:

$$
V_{2}=V_{1}-V k_{p v}\left(P_{1}-P_{2}\right)
$$

where

$$
\begin{aligned}
\mathrm{V} & =\text { average primary coolant system volume }(\mathrm{ft} 3), \\
\mathrm{V}_{1} & =\text { initial primary coolant system volume }\left(\mathrm{ft}^{3}\right), \text { and } \\
\mathrm{V}_{2} & =\text { final primary coolant system volume }(\mathrm{ft} 3) .
\end{aligned}
$$


Second, an iterative solution is set up; the magnitude of $m_{1}$ is assumed and $v_{2}$ is calculated

$$
\mathrm{v}_{2}=\frac{\mathrm{V}_{2}}{\mathrm{M}_{1}-\mathrm{m}_{1}}
$$

Then Eqs. (64) and (65) are solved for $h_{2}$ at $P_{2}$ and $v_{2}$. Calculated value of $h_{2}$ is compared to its corresponding value at $P_{2}$ and $v_{2}$ in ASME steam tables. The iteration continues until a correct value for $m_{1}$ is determined. A computer program (SPRING.CSL) has been developed to perform this task. This programs is added to Appendix D. Values for $k_{p v}$ have been calculated by T. L. Wilson and M. W. Wendel separately41 using known constants for materials and component dimensions. In this study, it is calculated from Dixon's depressurization data.

The temperature drop and system elasticity constants for ten different depressurization cases were calculated and shown in Table 20. In each case, the system depressurizes down to 24 psia. The volumes of the primary coolant system with four and three heat exchanger loops respectively were calculated to be about $1844 \mathrm{ft}^{3}$ and $1626 \mathrm{ft}^{3}$. The structural elasticity coefficent $\left(k_{\mathrm{pv}}\right)$ is set equal to zero so that the system elasticity constants based on liquid compressibility alone can be calculated, which is explained in the next section. The initial temperature is $90^{\circ} \mathrm{F}$. The temperature drop increases as the pressure drop increases; the maximum temperature drop is about $0.293^{\circ} \mathrm{F}$ for $976 \mathrm{psi}$ pressure drop. Additional liquid water discharge due to structural contraction resulting from $0.3^{\circ} \mathrm{F}$ drop in structure temperature is about $0.174 \mathrm{lb}_{\mathrm{m}} \cdot{ }^{41} \mathrm{Small}$ and large break loss of coolant accidents cause HFIR to depressurize rapidly; however, the structure temperature will cool at a slower rate than the depressurization rate because of the large thermal capacity of the structure and conduction heat transfer. The contribution of temperature dependent structure term in the calculation of system pressure is neglected. The sensitivity of water density with respect to temperature is determined to be about $\left(-0.0132 \mathrm{lb}_{\mathrm{m}} / \mathrm{ft}^{3} /{ }^{\circ} \mathrm{F}\right)$ by Wendel.41 The additional liquid water mass needed to keep $1844.0 \mathrm{ft}^{3}$ full as liquid water contracts due to $0.293^{\circ} \mathrm{F}$ temperature drop is

$$
1844.0 \mathrm{ft}^{3}\left(-0.0132 \mathrm{lb}_{\mathrm{m}} / \mathrm{ft}^{3} /{ }^{\circ} \mathrm{F}\right) 0.293^{\circ} \mathrm{F}=-7.13 \mathrm{lb}_{\mathrm{m}}
$$

the negative number indicates flow into the system. Inclusion of the temperature affect in the estimated amount of leakage water in Run 2 will increase adjusted 1 values of the system 
elasticity constant in Table 19 by $0.27 \mathrm{psi} / \mathrm{gal}$ on the average. The column named adjusted 2 in Table 19, reflects the modified values of adjusted ${ }_{1}$ column by $0.27 \mathrm{psi} / \mathrm{gal}$.

\subsubsection{System Elasticity Constant Based on Fluid Compressibility}

Calculation of presswie for an adiabatic depressurization event in which the primary coolant system volume does not change and temperature effects are neglected includes only water compressibility term. Equation (59) reduces to

$$
\mathrm{K}_{\mathrm{f}}=\left(-\frac{\Delta \mathrm{P}}{\Delta \mathrm{V}_{\mathrm{d}}}\right)_{\mathrm{V}, \mathrm{T}}=\frac{1}{\frac{\mathrm{V}}{\rho} \frac{\partial \rho}{\partial \mathrm{P}}}
$$

where

$\mathrm{K}_{\mathrm{f}}=$ system elasticity constant based on water compressibility (psi/gal).

This approach yields the most conservative bound for the system elasticity constant. The $\mathrm{K}_{\mathrm{f}}$ values that are calculated for different initial pressures, $90^{\circ} \mathrm{F}$ initial water temperature, $1844 \mathrm{ft}^{3}$ and $1626 \mathrm{ft}^{3}$ representing primary system coolant volume with four and three heat exchanger loops are shown in Table 20. The variation in $\mathrm{K}_{\mathrm{f}}$ is small and arithmetic averages of system elasticity constants based on water compressibility are

$$
\begin{aligned}
& \mathrm{K}_{\mathrm{f}}=27.47 \mathrm{psi} / \mathrm{gal} \text { for } 1626 \mathrm{ft}^{3} \text {, and } \\
& \mathrm{K}_{\mathrm{f}}=24.23 \mathrm{psi} / \mathrm{gal} \text { for } 1844 \mathrm{ft}^{3} \text {. }
\end{aligned}
$$


Table 20. Adiabatic depressurization tests and the calculated reductions in the liquid water temperature

\begin{tabular}{|c|c|c|c|}
\hline \multirow{2}{*}{$\begin{array}{c}\text { Pressure range } \\
\text { (psia) }\end{array}$} & \multirow{2}{*}{$\begin{array}{c}\text { Temperature drop } \\
\left({ }^{\circ} \mathrm{F}\right) \\
\end{array}$} & \multicolumn{2}{|c|}{$\begin{array}{c}\text { System elasticity } \\
\text { constant } \\
\left(\mathrm{K}_{\mathrm{f}}=\mathrm{psi} / \mathrm{gal}\right)\end{array}$} \\
\hline & & $1844 \mathrm{ft}^{3}$ & $1626 \mathrm{ft}^{3}$ \\
\hline $\begin{array}{r}100-24 \\
200-24 \\
300-24 \\
400-24 \\
500-24 \\
600-24 \\
700-24 \\
800-24 \\
900-24 \\
1000-24\end{array}$ & $\begin{array}{l}0.026 \\
0.054 \\
0.082 \\
0.109 \\
0.137 \\
0.174 \\
0.201 \\
0.229 \\
0.256 \\
0.293\end{array}$ & $\begin{array}{l}24.19 \\
24.15 \\
24.16 \\
24.17 \\
24.19 \\
24.24 \\
24.26 \\
24.27 \\
24.29 \\
24.33\end{array}$ & $\begin{array}{l}27.42 \\
27.39 \\
27.40 \\
27.41 \\
27.43 \\
27.49 \\
27.51 \\
27.53 \\
27.55 \\
27.59\end{array}$ \\
\hline
\end{tabular}

\subsubsection{System Elasticity Constant Based on Structural Elasticity}

Previous discussions indicate that the temperature effect can be neglected. Then Eq. (59) reduces to:

$$
\mathrm{K}_{\mathrm{fs}}=\left(-\frac{\Delta \mathrm{P}}{\Delta \mathrm{V}_{\mathrm{d}}}\right)_{\mathrm{T}}=\frac{1}{\frac{\partial \mathrm{V}}{\partial \mathrm{P}}+\frac{\mathrm{V}}{\rho} \frac{\partial \rho}{\partial \mathrm{P}}}=\frac{1}{\frac{1}{\mathrm{~K}_{\mathrm{s}}}+\frac{1}{\mathrm{~K}_{\mathrm{f}}}}
$$

where the left hand side of the equation represents the calculated system elasticity constants using Dixon's data and right hand side combines elasticity of the structure and liquid water,

$$
\begin{aligned}
\mathrm{K}_{\mathrm{S}}= & \partial \mathrm{P} / \partial \mathrm{V}=\text { system elasticity constant based on structural elasticity alone } \\
& (\mathrm{psi} / \mathrm{gal}), \text { and } \\
\mathrm{K}_{\mathrm{fS}}= & \text { system elasticity constant based on structural elasticity and water } \\
& \text { compressibility (psi/gal). }
\end{aligned}
$$

The $\mathrm{K}_{\mathrm{S}}$ term can then be calculated from:

$$
\mathrm{K}_{\mathrm{s}}=\frac{1}{\frac{1}{\mathrm{~K}_{\mathrm{fs}}}-\frac{1}{\mathrm{~K}_{\mathrm{f}}}}
$$


The $\mathrm{K}_{\mathrm{fs}}$ values in adjusted 2 column of Table 19 and $\mathrm{K}_{\mathrm{f}}=24.23 \mathrm{psi} / \mathrm{gal}$ were used to calculate the $\mathrm{K}_{\mathrm{S}}$ values listed in the last column of Table 19. The constant decreases as the pressure decreases indicating a larger change in the primary coolant system volume due to structural elasticity at lower pressures. The arithmetic average of these values is

$$
\mathrm{K}_{\mathrm{S}}=74.56 \mathrm{psi} / \mathrm{gal} \text {. }
$$

An average value for the structural elasticity coefficient $k_{p v}\left(p^{-1} i^{-1}\right)$ is then calculated from the experimental data using $\mathrm{k}_{\mathrm{pv}}=\frac{1}{\mathrm{~V}} \frac{\mathrm{dV}}{\mathrm{dP}}$ :

$$
\mathrm{k}_{\mathrm{pv}}=9.7210^{-7} \mathrm{psi}^{-1} \text { for } 1844 \mathrm{ft}^{3} \text { volume }
$$

The coefficient for the primary coolant system with three heat exchanger loops is

$$
\mathrm{k}_{\mathrm{pv}}=9.7210^{-7} \mathrm{psi}^{-1} \text { for } 1626 \mathrm{ft}^{3} \text { volume, }
$$

and $\mathrm{K}_{\mathrm{S}}=74.561844 / 1626=84.56 \mathrm{psi} / \mathrm{gal}$. In applying the experimental results to 1626 $\mathrm{ft}^{3}$, the change in the volume per unit change in pressure is assumed to be proportional to the volume.

\subsubsection{System Elasticity Constant Based on Fluid Compressibility and Structural Elasticity}

The HFIR system elasticity constants based on fluid compressibility and structural elasticity and structural elasticity constants for the primary coolant system with four heat exchanger loops (1844 $\left.\mathrm{ft}^{3}\right)$ and with three heat exchanger loops (1626 ft 3 ) were calculated using Dixon's data. The results are summarized in Table 21. The system elasticity constants $\left(\mathrm{K}_{\mathrm{fs}}\right)$ were calculated from Eq. (67) using the average values of $\mathrm{K}_{\mathrm{f}}$ and $\mathrm{K}_{\mathrm{s}}$ :

$$
\begin{aligned}
& \mathrm{K}_{\mathrm{fs}}=18.3 \mathrm{psi} / \mathrm{gal} \text { for } 1844 \mathrm{ft}^{3} \text {, and } \\
& \mathrm{K}_{\mathrm{fs}}=20.74 \mathrm{psi} / \mathrm{gal} \text { for } 1626 \mathrm{ft}^{3} \text {. }
\end{aligned}
$$


Table 21. HFIR system elasticity constants based on water compressbility $\left(\mathrm{K}_{\mathrm{f}}\right)$, structural elasticity $\left(\mathrm{K}_{\mathrm{s}}\right)$, structural elasticity and water compressibility $\left(\mathrm{K}_{\mathrm{fs}}\right)$; and the structural elasticity coefficient $\left(\mathrm{k}_{\mathrm{pv}}\right)$

\begin{tabular}{|c|c|c|c|c|c|c|c|}
\hline \multicolumn{3}{|c|}{$\begin{array}{c}\text { HFIR with } 4 \mathrm{HX} \text {-loop } \\
\left(1844 \mathrm{ft}^{3}\right)\end{array}$} & \multicolumn{5}{|c|}{$\begin{array}{c}\text { HFIR with } 3 \mathrm{HX} \text {-loop } \\
\left(1626 \mathrm{ft}^{3}\right)\end{array}$} \\
\hline $\mathbf{K}_{\mathbf{f}}$ & $=24.23 \mathrm{psi} / \mathrm{gal}$ & $\mathrm{K}_{\mathrm{fs}}=18.3 \mathrm{psi} / \mathrm{gal}$ & $\mathrm{K}_{\mathbf{f}}$ & $=27.47 \mathrm{psi} / \mathrm{gal}$ & $\mathrm{K}_{\mathrm{fs}}$ & $=$ & 20.74 psi/gal \\
\hline $\mathrm{K}_{\mathbf{S}}$ & $=74.56 \mathrm{psi} / \mathrm{gal}$ & $\mathrm{k}_{\mathrm{p}:}:=9.7210^{-7} \mathrm{psi}^{-1}$ & $\mathbf{K}_{\mathbf{S}}$ & $84.56 \mathrm{psi} / \mathrm{gal}$ & $k_{p v}$ & $=$ & $9.7210^{-7} \mathrm{psi}^{-1}$ \\
\hline
\end{tabular}

\subsubsection{Comparison of HFIRSYS Depressurization Predictions to Test Data}

Depressurization tests were run using HFIRSYS and the calculated reactor inlet pressure is compared to the pressure calculated using measured system elasticity constants in the previous section. Two separate depressurization tests for primary coolant system with four heat excha..yer loops and primary coolant system with three heat exchanger loops were run. The HFIRSYS model has been configured to operate with three heat exchanger loops. The volumes of hot leg, cold leg, and reactor vessel were increased to represent the system with four heat exchanger loops. In the first test, the code response is compared to the pressure calculated based on fluid compressibility alone $\left(k_{p v}=0.0\right.$ and $\left.K_{f s}=K_{f}\right)$. In the second test, the code response is compared to the pressure calculated using the measured HFIR system elasticity constant based on structural elasticity and fluid compressibility. In the second test, the structural elasticity coefficient $\left(k_{p v}\right)$ is set equai to $9.7210^{-7} \mathrm{psi}^{-\mathrm{i}}$.

Initial conditions for the four tests were the same: only three dc pony motors operate; pressurizer pumps are off; letdown valves are closed; no heat generation occurs in the core; coolant temperature is about $90.6^{\circ} \mathrm{F}$; primary coolant pressure is $593.3 \mathrm{psia}$. The depressurization tests were started by forming a small opening at the discharge side of the main circulation pumps. Discharged water mass was compo:nded in $\mathrm{lb}_{\mathfrak{m}}$. The system pressure is represented as a function of the accumulated discharged water mass and time.

The resuits from four heat exchanger loop case are presented in Figs. 17 and 18. Figure 17 shows a comparison of the HFIRSYS response with no structural elasticity $\left(\mathrm{k}_{\mathrm{pv}}=0\right)$ to the two pressure traces calculated using system elasticity constants $\mathrm{K}_{\mathrm{fs}}=$ $18.3 \mathrm{psi} / \mathrm{gal}$ and $\mathrm{K}_{\mathrm{fs}}=24.23 \mathrm{psi} / \mathrm{gal}$. If the HFIRSYS response is correct, it should follow the pressure trace calculated using $\mathrm{K}_{\mathrm{fs}}=24.23 \mathrm{psi} / \mathrm{gal}$; that is, no structural elasticity case. The HFIRSYS reactor inlet pressure does follow closely the pressure trace calculated using $\mathrm{K}_{\mathrm{fs}}=24.23 \mathrm{psi} / \mathrm{gal}$. The HFIRSYS reactor inlet pressure calculated by 
including structural elasticity $\left(k_{\mathrm{pv}}=9.7210^{-7} \mathrm{psi}{ }^{1}\right)$ is presented in Fig. 18. In this case, the HFIRSYS reactor inlet pressure follows closely the pressure trace calculated using $\mathrm{K}_{\mathrm{fs}}=18.3 \mathrm{psi} / \mathrm{gal}$. Because of squeezing action of the structure in the second case, more discharged water is accumulated for the same pressure drop. The discharged mass is $188.1 \mathrm{lb}_{m}$ in the first case (no structural elasticity) and $248.7 \mathrm{lb}_{\mathrm{m}}$ in the second case. The temperature drop in both cases is about $2.05^{\circ} \mathrm{F}$ which is larger than the expected values shown in Table 2. Comparisons of the time dependent behavior of the HFIRSYS reactor inlet pressure are presented in Figs. 19 and 20. Satisfactory agreement between the HFIRSYS predictions and the system pressures calculated using measured system elasticity constants are achieved.

The same calculations $\mathrm{v}$ re repeated for the primary coolant system with three heat exchanger loops. The results are shown in Figs. 21 and 22. Figure 21 corresponds to Figs. 17 and Fig. 22 corresponds to Fig. 18. Note that the system elasticity constants are different for this case: $\mathrm{K}_{\mathrm{fs}}=\mathrm{K}_{\mathrm{f}}=27.47 \mathrm{psi} / \mathrm{gal}$ when $\mathrm{k}_{\mathrm{pv}}=0 \mathrm{psi}-1$ and $\mathrm{K}_{\mathrm{fs}}=20.74 \mathrm{psi} / \mathrm{gal}$ when $k_{p v}=9.7210^{-7} \mathrm{psi}^{-1}$. The results are satisfactory. Total amount of discharged mass is $218.6 \mathrm{lb}_{\mathrm{m}}$ when structural elasticity is included and $165 \mathrm{lb}_{\mathrm{m}}$ when structural elasticity is not included. Decrease in the temperature drop is $2.05^{\circ} \mathrm{F}$.

\subsection{COMPARISON TO MEASURED PUMP COASTDOWN DATA}

G. J. Dixon performed exprriments to measure primary and secondary coolant flow rates at HFIR.5 A dummy core that did not generate any heat was used during the experimei،s. Measured steady state flow rates for one, two, three and four dc pony motor operations are reported in Sect. 2.1 . Three main circulation pumps were tripped and flow rate was allowed to decay to three dc pony motor flow rate. The flow coastdown profile is shown with a solid line in Fig. 23. A similar test was performed using HFIRSYS and the results of the test are shown with a dotted line in the same figure. The coastdown flow rate calculated using motor friction factors $\left(\mathrm{k}_{\mathrm{fr}}\right)$ in the following table closely match the experimentally measured coastdown flow rate:

\begin{tabular}{ll} 
HFIRSYS name & $\frac{\text { Value }}{\text { KFRCP1 }}$ \\
$\begin{array}{l}\text { (one-pump loop) } \\
\text { KFRCP2 } \\
\text { (two-pump loop) }\end{array}$ & 0.0005 \\
\hline
\end{tabular}

With these friction factors, the primary coolant flow rate decays to about $2,700 \mathrm{gpm}$ at $9 \mathrm{~s}$ ( $142 \mathrm{gpm}$ of that is provided by the main pressurizer pump). The steady 
flow rate is about $2,650 \mathrm{gpm}$ ( $163 \mathrm{gpm}$ is provided by the main pressurizer pump). The HFIRSYS coastdown flow profile up to $10 \mathrm{~s}$ is shown in Fig. 23. The primary flow coastdown was calculated with no power generation in the core, the main pressurizer pump on and at coolant temperature equal to about $90^{\circ} \mathrm{F}$. The measured steady flow rate for three dc pony motor operation is about $2,525 \mathrm{gpm}$. The calculated steady flow rate through the pump for one dc pony motor operation is about $1370 \mathrm{gpm}$.

A flow coastdown profile of the main secondary coolant pumps was measured from a steady state flow of $22,500 \mathrm{gpm}$. Flow rate decreased to the half of 22,500 in about $2.94 \mathrm{~s}$ and became negligible in about $5.29 \mathrm{~s}$. An exponentially decaying flow coastdown was assumed in the model of secondary side by T. L. Wilson 24 as mentioned in Sect. 3.2.2. The main secondary coolant pumps, pipes and valves are not modelled. The shell side exit pressure is fixed and whenever the main secondary coolant pumps are tripped the shell side inlet pressure is calculated from Eq. (43). In HFIRSYS, the secondary side flow rate is increased to match $22,500 \mathrm{gpm}$ steady state flow. The secondary side was tripped to calculate flow coastdown profile. A time constant of $0.5 \mathrm{~s}$ in Eq. (43) renders the flow to become zero in about $6 \mathrm{~s}$. The coastdown flow rate calculated using this time constant is compared to the experimentally measured profile in Fig. 24. The predicted secondary coastdown flow rate is much smaller than the measured flow rate.

The pressurizer pump speed was recorded during its ccastdown in a separate test. 8 In Fig. 25, the test results are shown with closed circles and the HFIRSYS prediction with a solid line. Agreement is good at high speeds. Between $400 \mathrm{rpm}$ and $100 \mathrm{rpm}$ HFIRSYS underpredicts the pressurizer pump speed; however, at this low speed the pump generates no flow or low flow depending on the primary coolant system pressure. 


\subsection{COMPARISON TO MEASURED FLOW RATES THROUGH DEPRESSURIZATION VALVES}

Flow rates through the depressurization valves were measured during system pressure checks/depressurization system by HFIR maintenance personnel.12 There are two depressurization valves connected to the same line. The valves are connected to the inlet plenum of the vessel and the discharge point of the line is connected to the letdown header. The tests were conducted to measure flow through each valve and through both valves. During the test the reactor did not generate any heat and the pressurizer pump speed was increased to keep the system pressure at about 214.7 psia. While the system was at steady state at 214.7 psia, the pressurizer pump flow rate was measured by the flow meter in the pressurizer pump discharge line. The measured flow rates, as indicated in Sect. 2.6, are

\section{4-96 gpm at $214.7 \mathrm{psia}$, and}

$138-143 \mathrm{gpm}$ at $484.7 \mathrm{psia}$.

The measured flow rates show very little increase in the case of two open valves over one open valve indicating that most of the pressure drop is in the line. The depressurization line including the valves has been modelled using a single valve in HFIRSYS. The combined fuw conductance of the valve (KBKRX1) and the line is set equal to $\left.410.0\left(\mathrm{lb}_{\mathrm{m}} / \mathrm{h}\right)\left(\mathrm{lb}_{\mathrm{f}} / \mathrm{ft}^{2}\right)^{-0.5}\left(\mathrm{lb}_{\mathrm{m}} / \mathrm{ft}\right)^{3}\right)^{-0.5}$ to yield the closest flow rate values to those measured during the test. In a similar manner to the tests, pressurizer pump speed was increased to sustain the system pressure aboli 214.7 psia and 484.7 psia and flow rate through the depressurization valve was calculattid at steady state. The calculated flow rates through the depressurization valve by HFIRSYS are

$$
\begin{aligned}
& 92.5 \mathrm{gpm} \text { at } 214.7 \mathrm{psia} \text {, and } \\
& 141.1 \mathrm{gpm} \text { at } 484.7 \mathrm{psia} \text {. }
\end{aligned}
$$

The agreement between these values and the measured flow rates are considered satisfactory. 


\section{REFERENCES}

1. F. T. Binford and E. N. Cramer, The High-Flux Isotope Reactor, Vol. 1, ORNL3572, May 1964.

2. S. J. Ball, "HFIR Process Control System Studies," ORNL/CF 61-10-65, Oct. 18, 1961.

3. N. Hilvety and T. G. Chapman, HFIR Fuel Element Steady State Heat Transfer Analysis, ORNL/TM-1903, Dec. 1967.

4. Modular Modeling System (MMS): A Code for the Dynamic Simulation of Fossil and Nuclear Power Plants, Volume 1: Theory Manual, Babcock \& Wilcox, March 1985.

5. G. J. Dixon, Preliminary HFIR Hydraulic Tests, ORNL/CF 64-12-43, Dec. 18, 1964.

6. H. A. McLain to T. E. Cole, "Coastdown Times Following an Electrical Failure of All Three Pumps Neglecting the Effects of the Pony Motor," internal memorandum, Sept. 25, 1962.

7. Rolf Hohmann to A. Sozer, "Subject: Allis-Chalmers 4 × 3 HD-9 Pressurizer Pumps Serial Nos. 69037-38," October 20, 1988.

8. A. Sozer, "Main Pressurizer Pump Coastdown Prediction and Comparison to HFIR Test Data," ORNL internal memorandum, March 16, 1989.

9. L. P. Smith, R. R. Dixon and S. W. W. Shor, "Modular Modeling System (MMS): A Code for the Dynamic Simulation of Fossil and Nuclear Power Plants, Overview and General Theory," EPRI CS/NP-2989, March 1983.

10. W. R. Csborn to E. C. Miller, correspondence on HFIR Pressurizer Pumps-Allis Chalmers, Purchase Order 74X-47504, IR-4580, Feb. 19, 1963.

11. O. W. Burke to M. W. Kohring, "Analog Computer Analysis of Loss of Pressurize Accidents in the HFIR," internal memorandum, March 6, 1985.

12. B. L. Corbett, "System Pressure Checks/depressurization System," internal document, Jari. 18, 1988.

13. S. W. W. Shor, "Modular Modeling System Validation: Transients in Fossil and Nuclear Power Plants," EPRI CS/NP-2945, March 1983.

14. S. W. W. Shor and B. J. Winkelman, "Modular Modeling System (MMS) Volume 4A: Applications-1983 Code Release Workshop Proceedings," EPRI CS/NP-3016, Volume 4A, February 1985. 
15. P. Bartells, "Modular Modeling System (MMS) Volume 4B: Applications-1984 Code Release Workshop Proceedings," EPRI CS/NP-3016, Volume 4B , April 1987.

16. "Modular Modeling System (MMS): A Code for the Dynamic Simulation of Fossil and Nuclear Power Plants, Volume 3: ACSL-Based MMS User's Manual," March 1985.

17. S. W. W. Shor, "Modular Modeling System (MMS), Volume 5: Summary Report," EPRI CS/NP-3016, April 1987.

18. R. D. Schaack, "MMS-EASEt: A Pre- and Post-Processor for the Modular Modeling System (MMS)," Babcock \& Wilcox, June 1985.

19. Conference on Power Plant Training Simulators and Modeling, hosted by Duke Power Company and sponsored by EPRI, Charlotte, North Carolina, June 15-17, 1988.

20. Advanced Continuous Simulation Language (ACSL) Reference Manual, Mitchell and Gauthier Associates, Concord, Mass. 01742.

21. M. E. Davis, Numerical Methods and Modeling for Chemical Engineers, John Wiley \& Sons, Inc., 1984.

22. M. Hanif Chaudry, Applied Hydraulic Transients, Van Hostrand Reinhold, Co., 1987.

23. Flow of Fluids Through Valves, Fittings, and Pipe, CRANE, Technical Paper No. 410, 1979.

24. T. L. Wilson, "HFIR Systems Transient Model," ORNL/RRD/INT-25, O-t. 30, 1987.

25. M. M. El-Wakil, Nuclear Heat Transport, American Nuclear Society, La Grange Park, Illinois, August 1981.

26. W. E. Thomas, "Best Estimate for High Flux Isotope Reactor (HFIR) PostShutdown Decay Heat Source," ORNL Internal Memorandum, Nov. 14, 1989.

27. W. E. Thomas, "HFIR Decay Heat at Very Short Times After Reactor Scram," ORNL Internal Memorandum, March 16, 1990.

28. H. A. McLain, HFIR Fuel Element Steady State Heat Transfer Analysis Revised Version, ORNL/TM-1904, December 1967.

29. N. Ozisik, Basic Heat Transfer, McGraw-Hill Book Company, pp. 195, 1977.

30. W. E. Thomas, "Bases for the Scram Setpoints, Limiting Safety System Settings, and Safety Limits of the HFIR for Mode 1 Operation at $85 \mathrm{MW}(\mathrm{th}), "$ ORNL/RRD/INT-22, Dec. 22, 1987. 
31. W. M. Rohsenow and J. P. Hartnett, "Handbook of Heat Transfer," McGraw-Hill, 1973.

32. W. R. Gambill, Design Curves for Burnout Heat Flux in Forced Convection Subcooled Light Water Systems, ORNL/TM-2421, November 14, 1968.

33. A. Sozer, Component and System Simulation Models for High Flux Isotope Reactor, ORNL/TM-11033, August 1989.

34. W. M. Rohsenow, J. P. Hartnett and E. N. Ganic, Handbook of Heat Transfer Applications, 2nd edition, McGraw-Hill, 1985.

35. E. B. Wylie, Course Notes on Fluid Transient Analysis by Microcomputers, University of Michigan, July 11-25, 1988.

36. H. A. McLain, Revised Flow Coast-down Times in the HFIR Primary Coolant System Following an Electrical Failure of All Three Pumps Neglecting the Effects of the Pony Motor, Intra-Laboratory Correspondence to T. E. Cole, September 25, 1962.

37 E. E. Lewis, Nuclear Power Reactor Safety, John Wiley \& Sons, 1977.

38. J. W. Hutchison, ISA Handbook of Control Valves, Instrument Society of America, Pittsburg, Pennsylvania, 1971.

39. D. R. Coughanowr, L. B. Koppel, Process Systems Analysis and Control, McGraw-Hill Kogakuska, Ltd., 1965.

40. A. Sozer, "Calculation of HFIR System Elasticity Constant and Structural Elasticity Coefficient from HFIR Hydraulic Test Data," ORNL Internal Memorandum, April 11, 1989.

41. M. W. Wendel, "Analysis of HFIR Primary Coolant System Elasticity," ORNL Internal Memorandum, March 13, 1989. 


\section{Appendix A}

\section{PUMP PERFORMANCE CURVES}

Pump performance curves are one of the vital constituents of a system simulation model. The pump performance curves of the pumps included in the HFIRSYS computer model are presented in this section.

The main circulation pump curves are exhibited in Figs. A.1 through A.3. Figure A.2 is a reproduction of Fig. 6.2.7 (Ref. 1) including pump head as a function of flow rate for ac motor at $1780 \mathrm{rpm}$ and dc motor operation at $270 \mathrm{rpm}$. Figure A.3 provides experimentally measured flow coastdown profile for the main circulation pumps.

The pressurizer pump curves are exhibited in Fig. A.4 for the pump speed equal to $2616 \mathrm{rpm}$ and in Fig. A.5 for $3485 \mathrm{rpm}$. Figure A.6 is a reproduction of Fig. 6.2 .9 that includes four curves representing pump head as a function of flow rate at 3500, 3074, 2616, and $1500 \mathrm{rpm}$. Only coastdown data available for the pump speed are given in Fig. A.7 that is based on data in Ref. 8. The emergency pressurizer pump is a new pump and its characteristics at $3541 \mathrm{rpm}$ are provided in Fig. A.8.

The secondary coolant pumps are not modelled using pump curves as explained in Sect. 3.2.2; however, their characteristics and the coastdown profile are shown in Fig. A.9 and A.10 for comparison and future improvement purposes. Note that the auxiliary pump (PU-14) has two winding speeds: normal and emergency. The data indicates that the secondary flow diminishes in about $5 \mathrm{~s}$ after the pumps are tripped.

A general percent torque vs percent speed curve applicable to any centrifugal, axial, or mixed flow pump provided by Allis-Chalmers, manufacturer of the pressurizer pumps, is shown in Fig. A.11. 


\section{Appendix B}

\section{RUNNING THE HFIRSYS MODEL}

Running HFIRSYS requires two files: command file and model definition file. The ACSL manual provides information on the use of command files and various commands. Becoming familiar with the following document may enhance use of various run time commands when performing calculations with HFIRSYS:

Advanced Continuous Simulation Language (ACSL),

Reference Manual,

Mitchell and Gauthier Associates, Concord, Mass. 01742

The model definition file which makes calls to MMS macros (standard MMS modules representing various system components) also includes values for constants and initial conditions, and minor level of coding. An ACSL feature, debug output, provides values of all the state variables, their initial conditions and derivatives, and algebraic variables in an organized way and alphabetical order.

To Compile HFIRSYS on VAX machines at \$ prompt, the following needs to be done:

\$ACSL HFIRSYS.CSL/OUT $=$. LST $/ L I B=$ MMSIVAT.

If the file is succesfully translated and compiled, these files will be generated:

HFIRSYS.EXE

HFIRSYS.FOR

HFIRSYS.LST

HFIRSYS.OBJ

HFIRSYS.LOG

HFIRSYS.RRR

To run the model, the following command is issued at $\$$ prompi:

\$RUN HFIRSYS 
This will generate ACSL prompt at which the command file is accessed by typing:

ACSL > SET CMD $=99$

This command will prompt the user for the command file name. After the command file name is provided, one can procede by restoring an initialization file:

ACSL > RESTOR 'HINI' (HINI is a file name)

ACSL> CONTIN

If an initialization file is not available, then at ACSL prompt START command is used:

\section{ACSL $>$ START}

If an initialization file is to be made at any point during the calculation, SAVE command is used:

ACSL > SAVE 'filename'. 


\section{Appendix C}

\section{HFIRSYS MODULES}

Information on the standard MMS modules can be found in the following documents:

Modular Modeling System (MMS): A Code for the Dynamic Simulation of Fossil and Nuclear Power Plants, Volume 1: Theory Manual, Babcock \& Wilcox, March 1985.

Modular Modeling System (MMS): A Code for the Dynamic Simulation of Fossil and Nuclear Power Plants, Volume 3: ACSL-Based MMS User's Manual, Babcock \& Wilcox, March 1985.

This document by Ahmet Sozer is the primary source of the information on the modifications and in-house developed routines for HFIRSYS.

Description of the in-house developed HFIR module input parameters is provided in the following list. 


\begin{tabular}{|c|c|c|c|}
\hline CONSTANT PARAMETER & UNITS & NAME & VALUE \\
\hline $\begin{array}{l}\text { Logical parameter for heat transfer coefficient } \\
\text { calculation }\end{array}$ & $(-)$ & FHTRX1 & TRUE or FALSE \\
\hline Vessel pool check valve flow enthalpy & $\left(B T U / b_{m}\right)$ & HCVP & 47.97 \\
\hline Heat transfer surface area for average fuel plate & $\left(\mathrm{ft}^{2}\right)$ & KAARX1 & 0.7941 \\
\hline Heat transfer surface area for bypass channel & $\left(\mathrm{ft}^{2}\right)$ & KABRX1 & 82.60 \\
\hline Heat transfer surface area for hot fuel plate & $\left(\mathrm{ft}^{2}\right)$ & KAFIRX1 & 0.7941 \\
\hline Heat transfer surface area for vessel wall & $\left(\mathrm{ft}^{2}\right)$ & KAIRX1 & 406.26 \\
\hline Vessel outlet plenum flow cross sectional area & $\left(\mathrm{ft}^{2}\right)$ & KAORX1 & 7.15 \\
\hline Core inlet region flow cross sectional area & $\left(\mathrm{ft}^{2}\right)$ & KASRX1 & 3.79 \\
\hline Flow conductance of depressurization valves & $\left(\mathrm{lb}_{\mathrm{m}} / \mathrm{h}\right) \mathrm{psi}^{-0.5}\left(\mathrm{lb}_{\mathrm{m}} / \mathrm{ft}^{3}\right)^{-0.5}$ & KBKRX1 & 410 \\
\hline Flow conductance of average channel & $\left(\mathrm{lb}_{\mathrm{m}} / \mathrm{h}\right) \mathrm{psi}-0.5\left(\mathrm{lb}_{\mathrm{m}} / \mathrm{ft}^{3}\right)^{-0.5}$ & KCARX1 & 153.1 \\
\hline Flow conductance of bypass channel & $\left(\mathrm{lb}_{\mathrm{m}} / \mathrm{h}\right) \mathrm{psi}^{-0.5}\left(\mathrm{lb}_{\mathrm{m}} / \mathrm{ft}^{3}\right)^{-0.5}$ & KCBRX1 & 19378.0 \\
\hline Hot channel flow multiplication factor & $(-)$ & KCHRX1 & 0.5978 \\
\hline Flow conductance of core exit region & $\left(\mathrm{lb}_{m} / \mathrm{h}\right) \mathrm{psi}^{-0.5}\left(\mathrm{lb}_{\mathrm{m}} / \mathrm{ft}^{3}\right)^{-0.5}$ & KCLRX1 & 367003. \\
\hline Flow conductance of core inlet region & $\left(\mathrm{lb}_{\mathrm{m}} / \mathrm{h}\right) \mathrm{psi}-0.5\left(\mathrm{lb}_{\mathrm{m}} / \mathrm{ft}^{3}\right)^{-0.5}$ & KCSRX1 & 444295 . \\
\hline Effective thickness of average channel fuel element & (ft) & KDARX1 & $2.110^{-3}$ \\
\hline Effective thickness of bypass channel metal & (ft) & KDBRX1 & $6.47710^{-3}$ \\
\hline $\begin{array}{l}\text { Table of ratio of decay heat to reactor power at time } \\
\text { of trip vs time after trip }\end{array}$ & $(-, \sec )$ & KDCRX1 & See text \\
\hline Effective thickness of hot and hot spot fuel plate & $(\mathrm{ft})$ & KDHRX1 & $2.110^{3}$ \\
\hline Effective thickness of vessel wall & (ft) & KDIRX1 & 0.25 \\
\hline Bypass channel hydraulic diameter & (ft) & KDYRX1 & 0.01 \\
\hline Average channel hydraulic diameter & (ft) & KEARX1 & $7.94610^{-3}$ \\
\hline Hot channel hydraulic diameter & (ft) & KEHRX1 & $5.7010^{-3}$ \\
\hline $\begin{array}{l}\text { Fraction of reactor power deposited in bypass metal } \\
\text { element } 1 \text { for before trip, } \\
\text { element } 2 \text { for after trip. }\end{array}$ & $(-)$ & KFBRX1 & $0.025,0.025$ \\
\hline $\begin{array}{l}\text { Fration of reactor power deposited in fuel } \\
\text { element } 1 \text { for before trip, } \\
\text { element } 2 \text { for after trip. }\end{array}$ & $(-)$ & KFF RX1 & $0.975,0.975$ \\
\hline $\begin{array}{l}\text { Hot plate peaking factor } \\
\text { element } 1 \text { for before trip, } \\
\text { element } 2 \text { for after trip. }\end{array}$ & $(-)$ & KFPRX 1 & $1.62,1.62$ \\
\hline Clad thickness & $(\mathrm{ft})$ & KGCRX1 & $7.510^{-4}$ \\
\hline Oxide layer thickness on clad & (ft) & KGORXI & $1.010^{-4}$ \\
\hline $\begin{array}{l}\text { Heat transfer coefficient of average fuel plate } \\
\text { at rated flow conditions }\end{array}$ & $\left(\mathrm{Btu} /{ }^{\circ} \mathrm{F} \mathrm{ft}^{2} \mathrm{~h}\right)$ & KHARX1 & 15000 \\
\hline Heat transfer coefficient of bypass channe'. & $\left(B t u /{ }^{\circ} \mathrm{Fft}^{2} \mathrm{~h}\right)$ & KHBRX1 & 9052 \\
\hline $\begin{array}{l}\text { Heat transfer coefficient of hot channel fuel plate } \\
\text { at rated flow conditions }\end{array}$ & $\left(\mathrm{Btu} /{ }^{\circ} \mathrm{F} \mathrm{ft} 2 \mathrm{~h}\right)$ & KHHRX1 & 15000 \\
\hline $\begin{array}{l}\text { Heat transfer coefficient of vessel wall at rated } \\
\text { flow conditions }\end{array}$ & $\left(\mathrm{Btu} /{ }^{\circ} \mathrm{F} \mathrm{ft}^{2} \mathrm{~h}\right)$ & KHIRX1 & 51.6 \\
\hline $\begin{array}{l}\text { Fraction of hot fuel channel surface area assigned } \\
\text { to hot plate }\end{array}$ & $(-)$ & KHSRX1 & 0.99995808 \\
\hline Effective conductivity of average fuel plate & $\left(\mathrm{Btu} /{ }^{\rho} \mathrm{Ffth}\right)$ & KKARX1 & 29.01 \\
\hline Effective conductivity of bypass metal & $(B t u / p f t h)$ & KKBRX1 & 80 \\
\hline Effective conductivity of hot and hot spot fuel plate & $\left(\mathrm{Btu} /{ }^{\rho} \mathrm{Ffth}\right)$ & KYHRX1 & 20.2 \\
\hline Conductivity of vessel wall & $\left(\mathrm{Btu} /{ }^{\rho} \mathrm{F} \mathrm{ft} \mathrm{h}\right)$ & KKIRג 1 & 26.4 \\
\hline Length/area of average channel & $\left(\mathrm{ft} \mathrm{t}^{-1}\right)$ & KLARX1 & 1903. \\
\hline Length/area of bypass channel & $\left(\mathrm{ft}^{-1}\right)$ & KLBRX1 & 7.665 \\
\hline Length/area of hot channel & $\left(\mathrm{ft}^{-1}\right)$ & KLHRX1 & 2695.4 \\
\hline Core length & $(\mathrm{ft})$ & KLCRX1 & 2.0 \\
\hline Core exit region length & (ft) & KLLRX i & 3.74 \\
\hline $\begin{array}{l}\text { Hot spot total peaking factor } \\
\text { element } 1 \text { for before trip, } \\
\text { element } 2 \text { for after trip. }\end{array}$ & $(-)$ & KLPRX1 & $3.248,3.248$ \\
\hline Core inlet region length & $(\mathrm{ft})$ & KLSRX1 & 3.92 \\
\hline Vessel outlet plenum length & (ft) & KLORX1 & 3.96 \\
\hline
\end{tabular}


Heigth vessel inlet to core inlet region

Heat capacity of average fuel element

Heat capacity of bypass channel

Heat capacity of vessel wall

Heat capacity of hot channel fuel plate

(hot spot + hot plate)

Number of average fuel plates

Number of hot channel fuel plates

Table of reactor power vs time prior to reactor trip

Hot channel hydraulic diameter times 3.14

Heat transfer coefficient for vessel to pool

Uncertainty factor for hot spot heat transfer coefficient

Vessel elasticity ( $\left.k_{p v}\right)$

Fluid volume of average channel

Fluid volume of bypass channel

Fluid volume of hot channel (hot spot + hot plate)

Core exit region volume

Fluid volume of inlet plenum

Vessel outet plenum volume

Core inlet region volume

Rated flow in average fuel channel

Rated flow in bypass channel

Rated flow in hot channel

Table of check valve flow vs pressure difference

Average fuel plate fuel meat half-thickness

Average fuel plate clad thickness

Average fuel plate oxide layer thickness on clad

Vessel pool temperature

Average channel flow cross sectional area

Hot channel flow cross sectional area

Bypass channel flow cross sectional area

Depressurization valve position

Elevation change (inlet - outlet) (ft)

(BTUPF)

(BTUPF)

(BTU/PF)

$(\mathrm{Btw} / \mathrm{F})$

$(-)$

$(\mathrm{Btu} / \mathrm{h}, \mathrm{s})$

(ft)

$\left(\mathrm{Btw} / \mathrm{h} \mathrm{ft}{ }^{\circ} \mathrm{F}\right)$

$(-)$

$\left(\mathrm{psi}^{-1}\right)$

$\left(\mathrm{ft}^{3}\right)$

$\left(\mathrm{ft}^{3}\right)$

$\left(\mathrm{ft}^{3}\right)$

$\left(\mathrm{ft}^{3}\right)$

$\left(\mathrm{ft}^{3}\right)$

$\left(\mathrm{ft}^{3}\right)$

$\left(\mathrm{ft}^{3}\right)$

$\left(\mathrm{lb}_{\mathrm{m}} / \mathrm{h}\right)$

$\left(\mathrm{lb}_{\mathrm{m}} / \mathrm{h}\right)$

$\left(\mathrm{lb}_{\mathrm{m}} \mathrm{h}\right)$

$\left(\mathrm{lb}_{\mathrm{m}} / \mathrm{h}, \mathrm{psi}\right)$

(ft)

(ft)

(ft)

( $\left.{ }^{\circ} \mathrm{F}\right)$

(ft)

(ft)

(ft)

$(-)$
KLURX1

KMARX1

KMBRX 1

KMIRX1

KMHRX1

KNARX1

KNHRX1

KRXRX1

KRWRX

KUWRX1

KU8RX1

KPVRX1

KVARX1

KVBRX1

KVHRX1

KVLRX1

KVIRX1

KVORX 1

KVSRX1

KWARX1

KWBRX1 1.528106

KWHRX1 12062

KWWRX1 See text

KTFRX1 $1.25 \quad 10^{-3}$

KTCRX1 $7.9210^{-4}$

$\begin{array}{lll}\text { KTORX1 } & 5.83 & 10^{-5}\end{array}$

KTWRX1 80

KXARX1 $1.051 \quad 10^{-3}$

KXHRX1 $7.4210^{-4}$

$\begin{array}{ll}\text { KXBRX1 } & 0.3379\end{array}$

YBK4 0

KZTRX1 12.5 


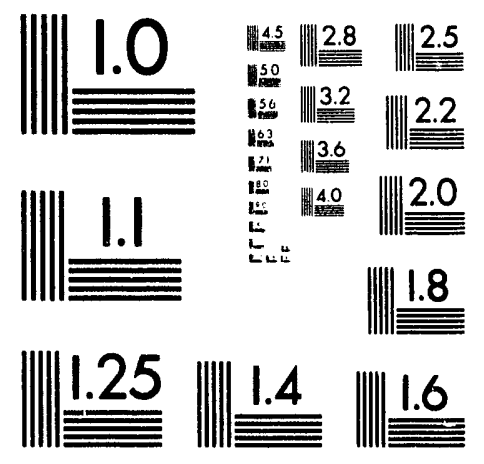



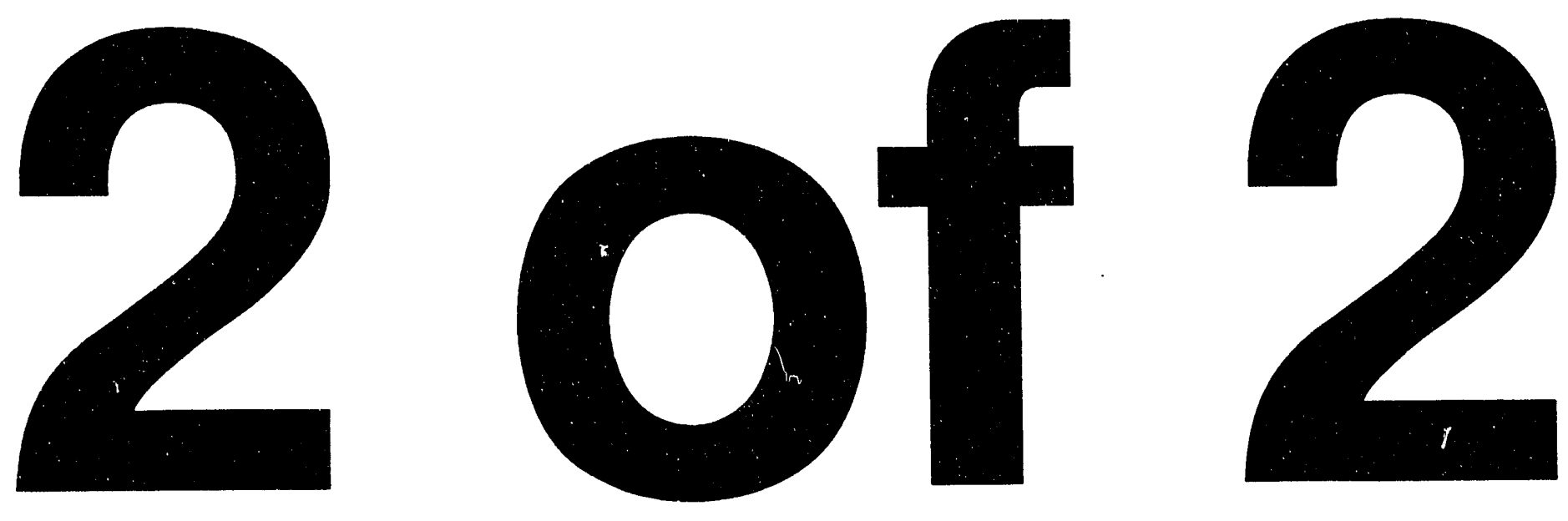


\section{Appendix D}

\section{SUPPLEMENTARY PROGRAMS USED IN VALIDATION}

As mentioned in Sect. 4.1.2, a separate routine was used in the analysis of the depressurization test data. The listing of the program for calculation of system elasticity constants (SPRING.CSL) is included in Appendix D. 
CONSTANT $\mathrm{KP}=0.927 \mathrm{E}-6, \mathrm{Pl}=650 ., \mathrm{Tl}=90.000, \mathrm{Hl}=59.7600, \ldots$

$\mathrm{V} i=0.01606682, \mathrm{VHFIR} I=1626 ., \mathrm{P} 2=24 \ldots \ldots$

$\mathrm{MLOCA}=180, \mathrm{KDM}=0.01, \mathrm{KTOL}=0.001$

DERIVATIVE

"Water enthalpy as a function of specific volume at 24 psia"

TABLE KENTAL, $1,6 / 0.01606682,0.01609750,0.01612871, \ldots$

$0.01616398,0.01620305,0.01624575, \ldots$ $48.10, \quad 58.08, \quad 68.06, \ldots$

$78.04, \quad 88.02, \quad 98.01 /$

"Water temperature as a function of enthalpy at 24 psia"

TABLE KTEMP $1,3 / 48.10,58.08,68.06, \ldots$

$80.00, \quad 90.00, \quad 100.00 /$

$\begin{array}{ll}\text { KDELP } & =\mathrm{P} 1-\mathrm{P} 2 \\ \mathrm{Ul} & =\mathrm{HI}-0.185 * \mathrm{PI} * \mathrm{VI} \\ \mathrm{MI} & =\text { VHFIRI NI }\end{array}$

VHFIR2 - VHFIRI* (I-KP*KDELP)

LO. . CONTINUE

PROCEDURAL ( $M L O C A=K D M$ )

$M L O C A=M L O C A+K D M$

END

V2 $=$ VHFIR2/(MI-MLOCA)

KPSPL $=\mathrm{KDELP} /(\mathrm{MLOCA})$

$\operatorname{KPSPG}=\operatorname{KDELP} /(\mathrm{MLOCA} \star 0.5 *(\mathrm{~V} 2+\mathrm{VI})) \star 0.1337$

$\mathrm{H} 2=((.0925 * \mathrm{VHFIRI} * \mathrm{KP} *(\mathrm{PI} * \star 2-\mathrm{P} 2 * \star 2)-.5 * \mathrm{MLOCA} * \mathrm{HI}+\ldots$ $\mathrm{MI} * \mathrm{UI}) /(\mathrm{MI}-\mathrm{MLOCA})+.185 \star \mathrm{P} 2 \star \mathrm{V} 2) / \ldots$

H2T $=$ KENTAL (V2) $(1+.5 * \mathrm{MLOCA} /(\mathrm{MI}-\mathrm{MIOCA}))$

$\mathrm{HDIFF}=\mathrm{ABS}(\mathrm{H} 2-\mathrm{H} 2 \mathrm{~T})$

IF (HDIFF. LT.KTOL) GO TO I,2

GO TO LO

L2 . . CONTINUE

TWI = KTEMP (H2)

TW2 = KTEMP (H2T)

"Cooling in F due to discharged fluid (depressurization)"

TDIFFI = TWI-Tl

TDIFF2 = TW2-T1

TERMT (HDIFF.LT.KTOL)

END

END

END 


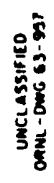

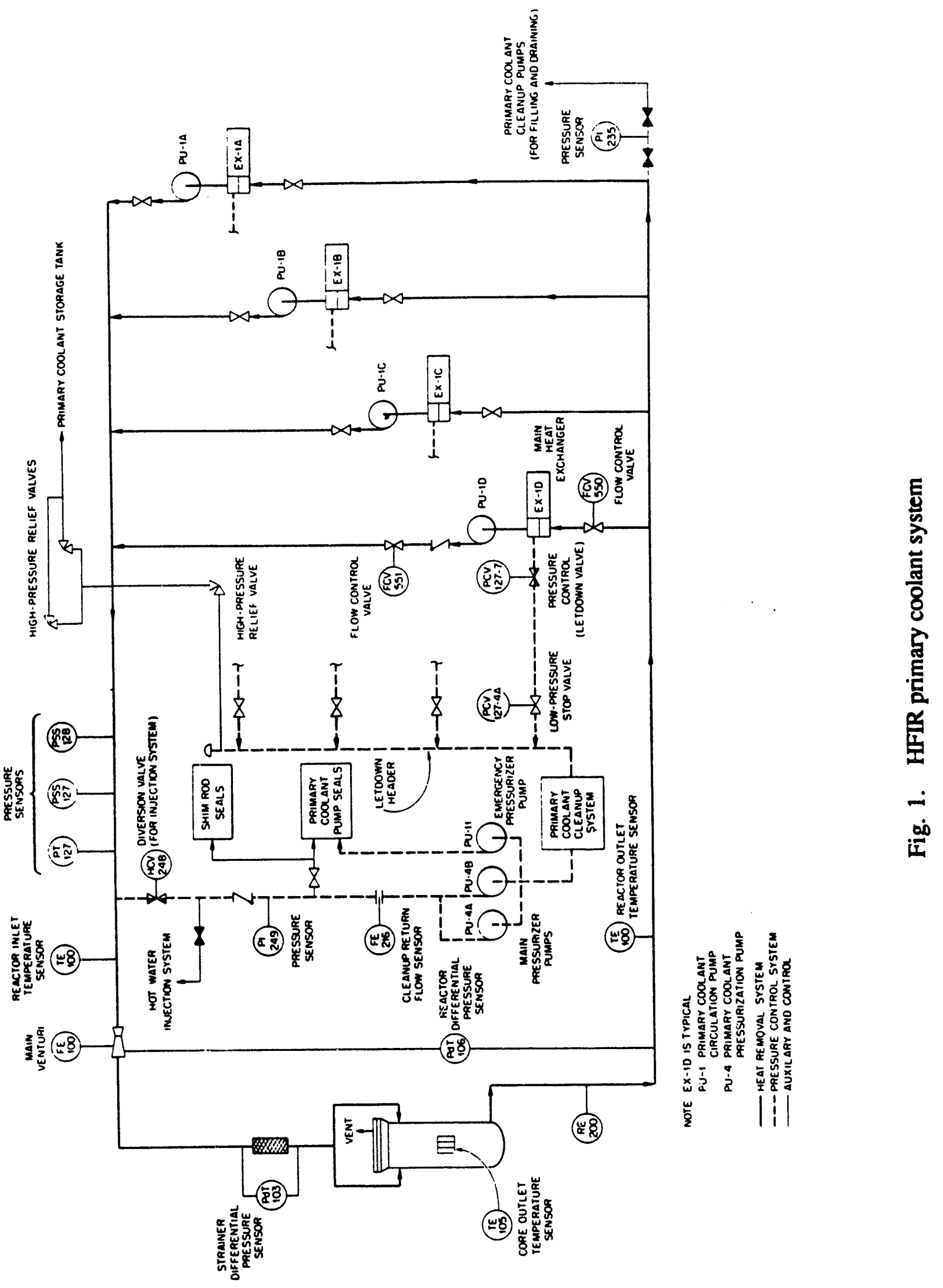




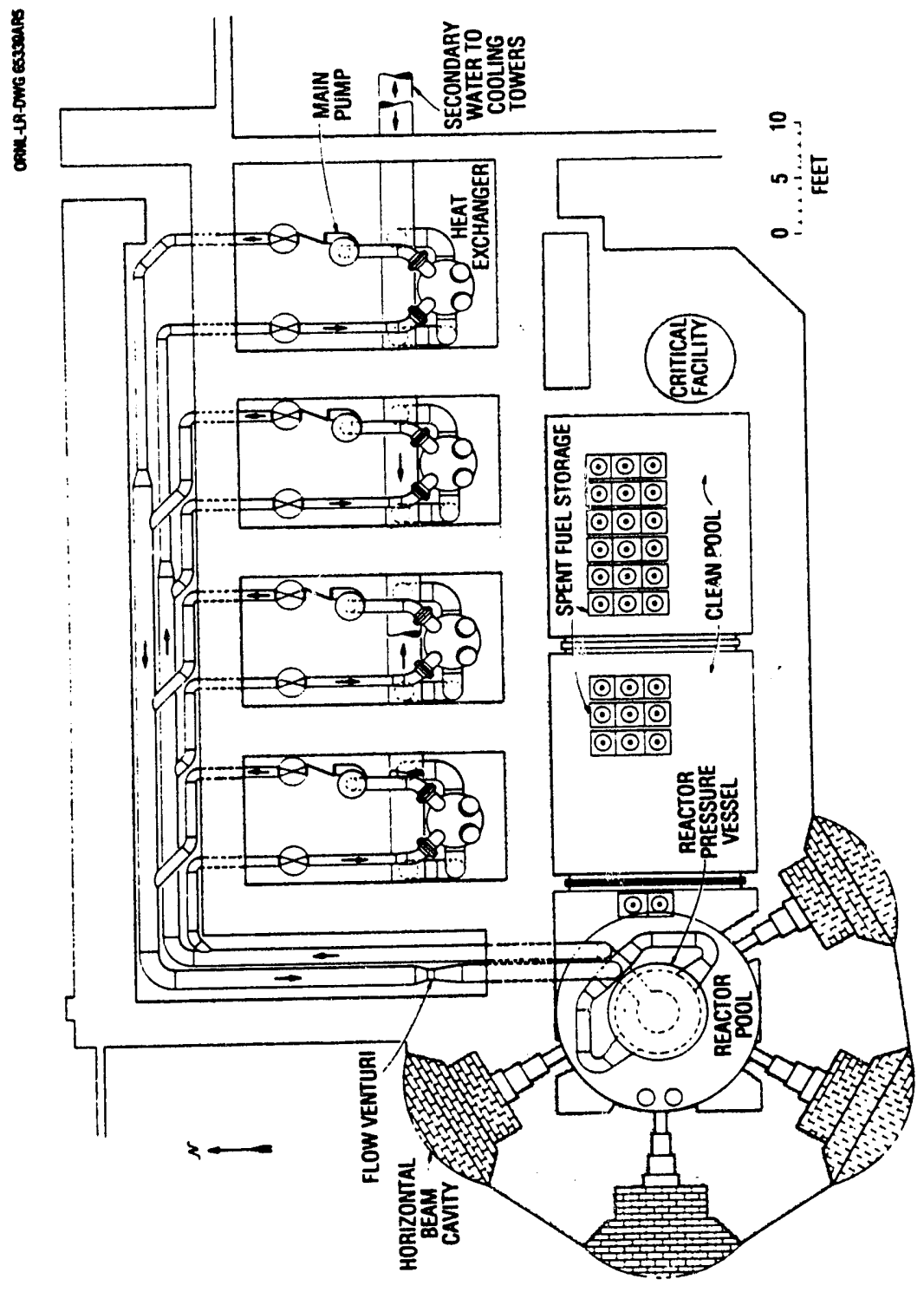

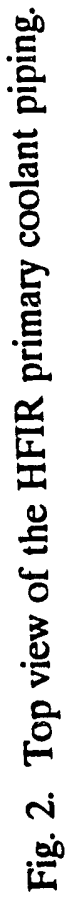




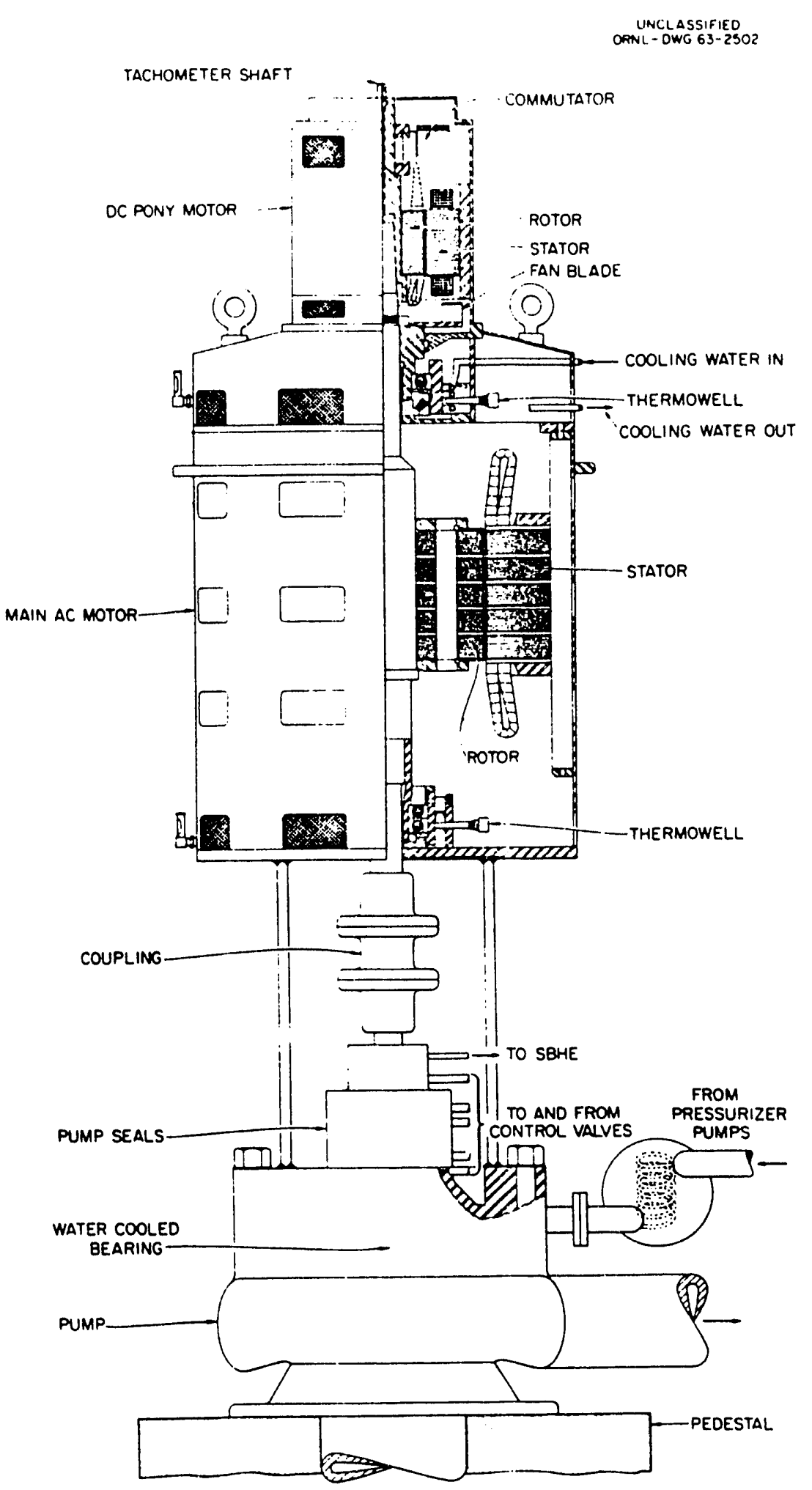

Fig. 3. Main circulation pumps with main ac and de pony motors. 
ORNL-LR-DWG 61384AR4

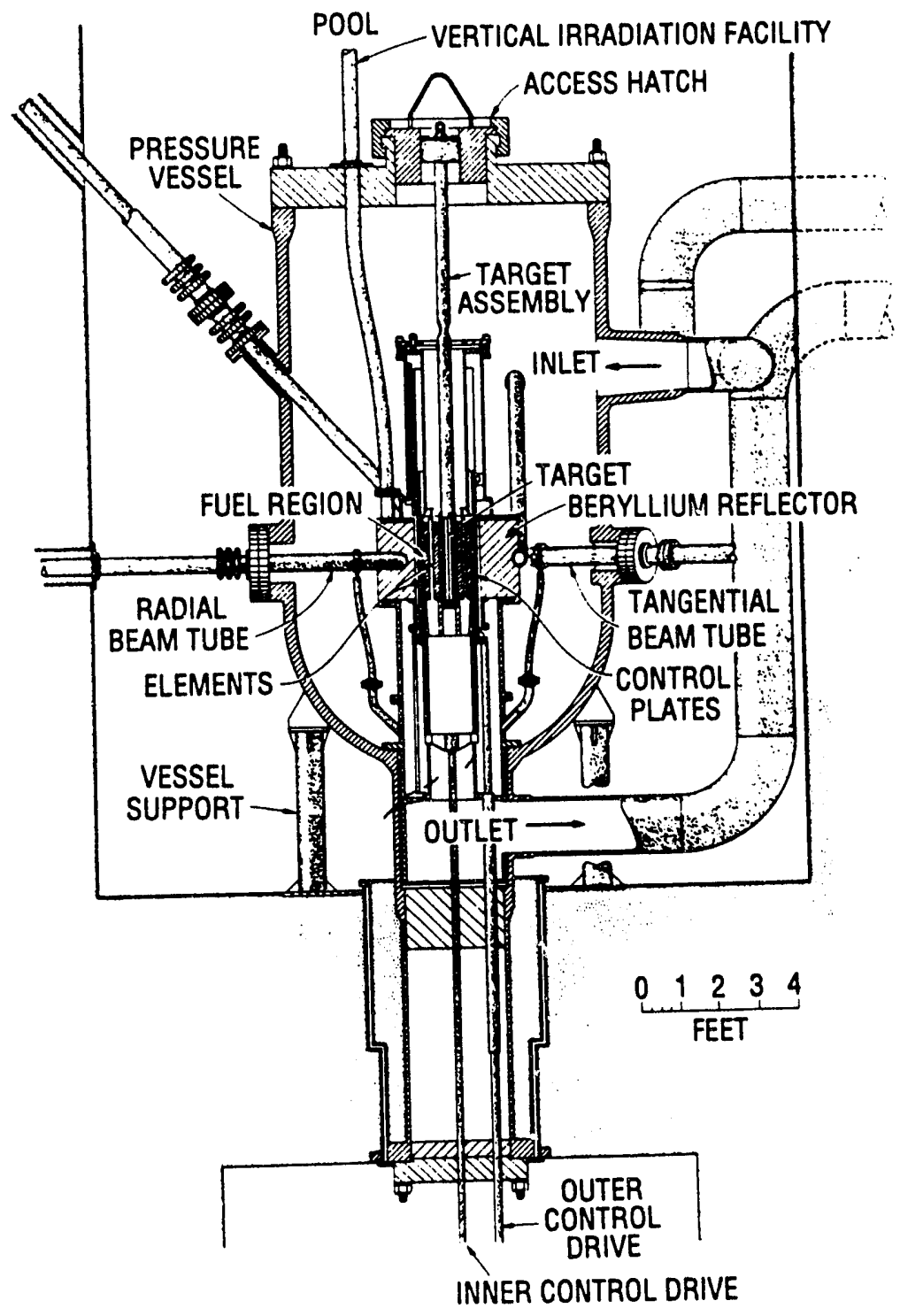

Fig. 4. Cross sectional view of the vessel and core. 


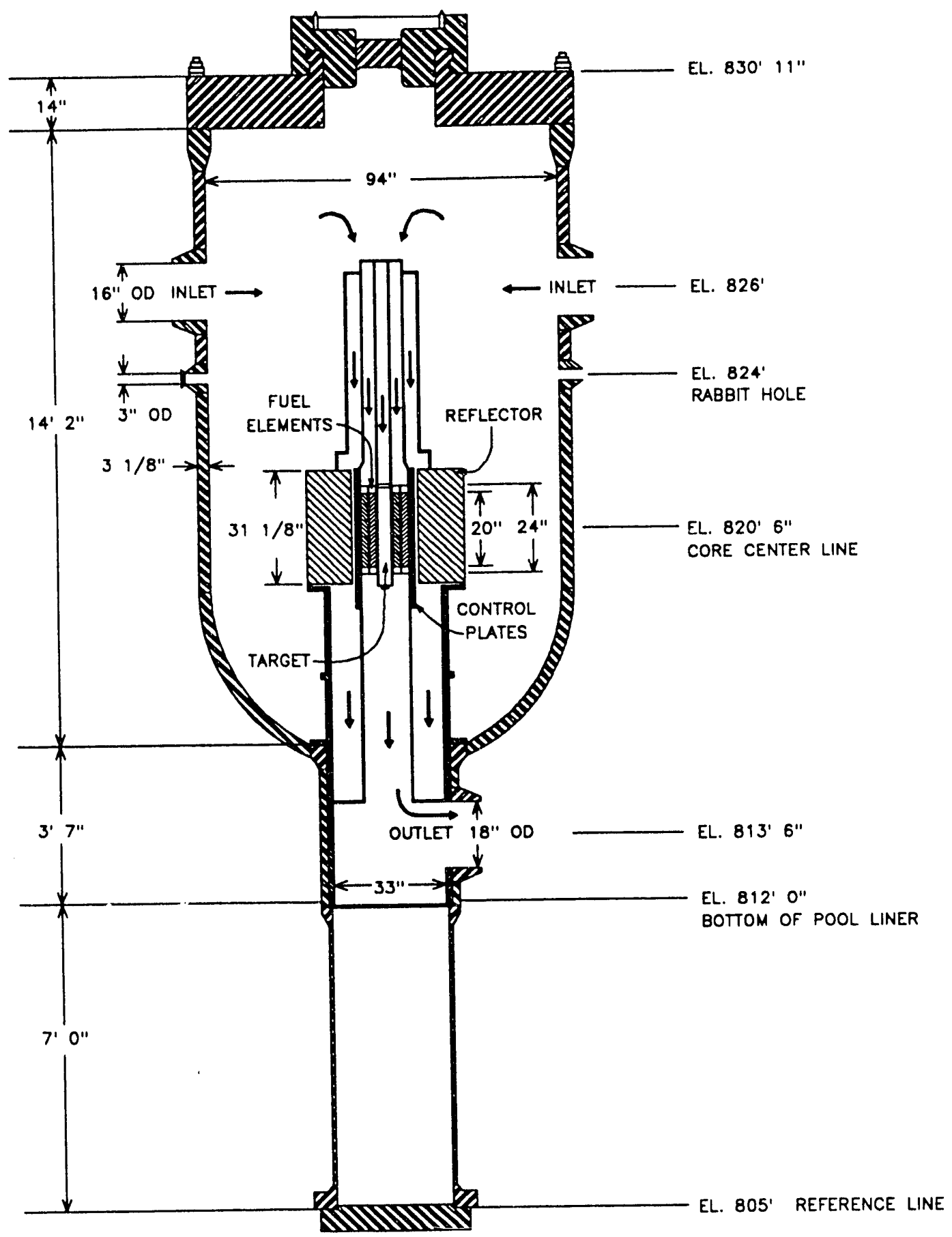

Fig. 5. Reactor vessel and core dimensions. 


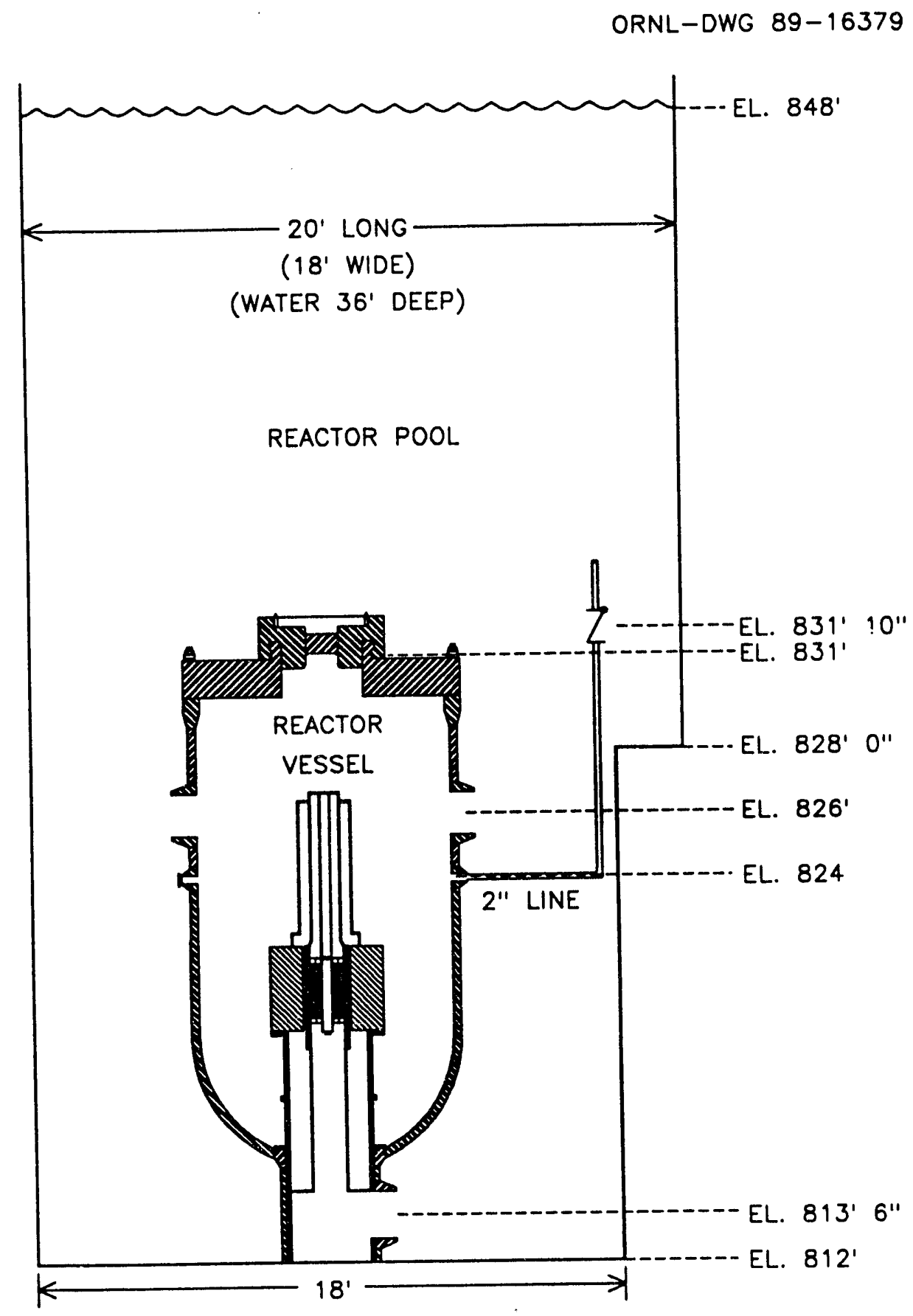

Fig. 6. The reactor pool and the vessel. 
ORNL-DWG 91M-2543A2 ETD

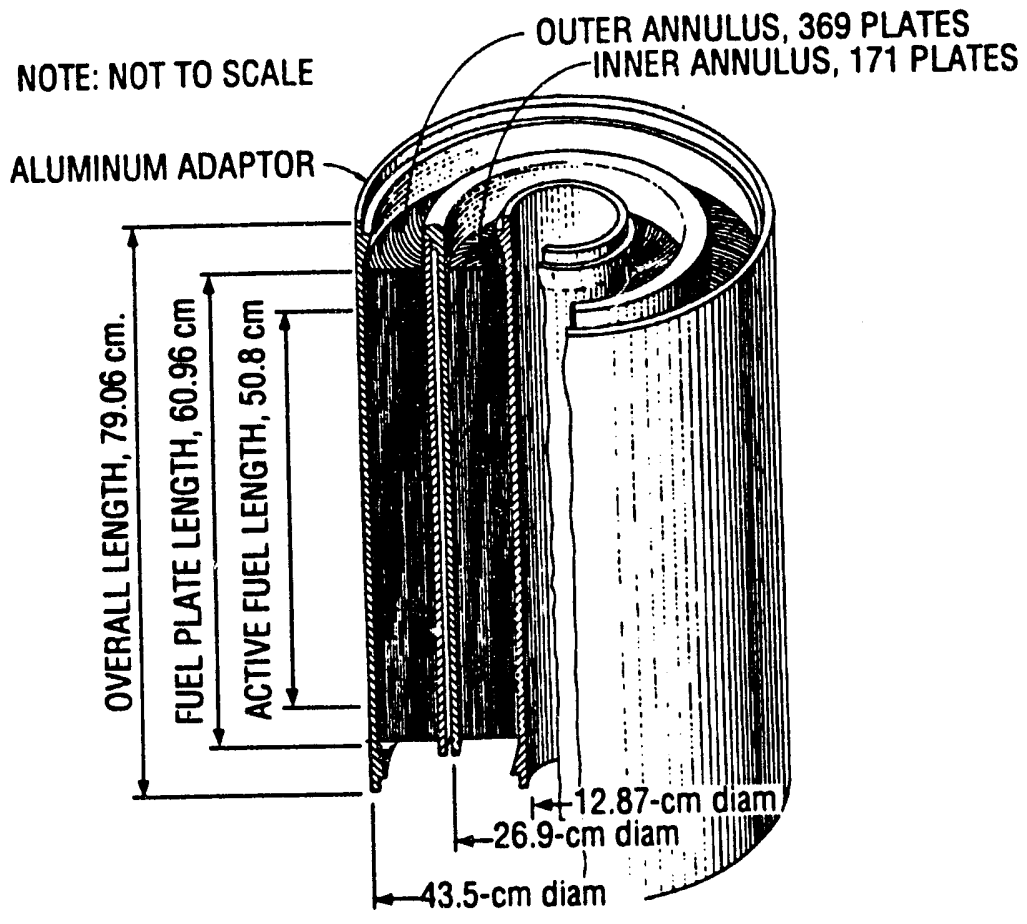

Fig. 7. Dimensions of the core and fuel elements. 


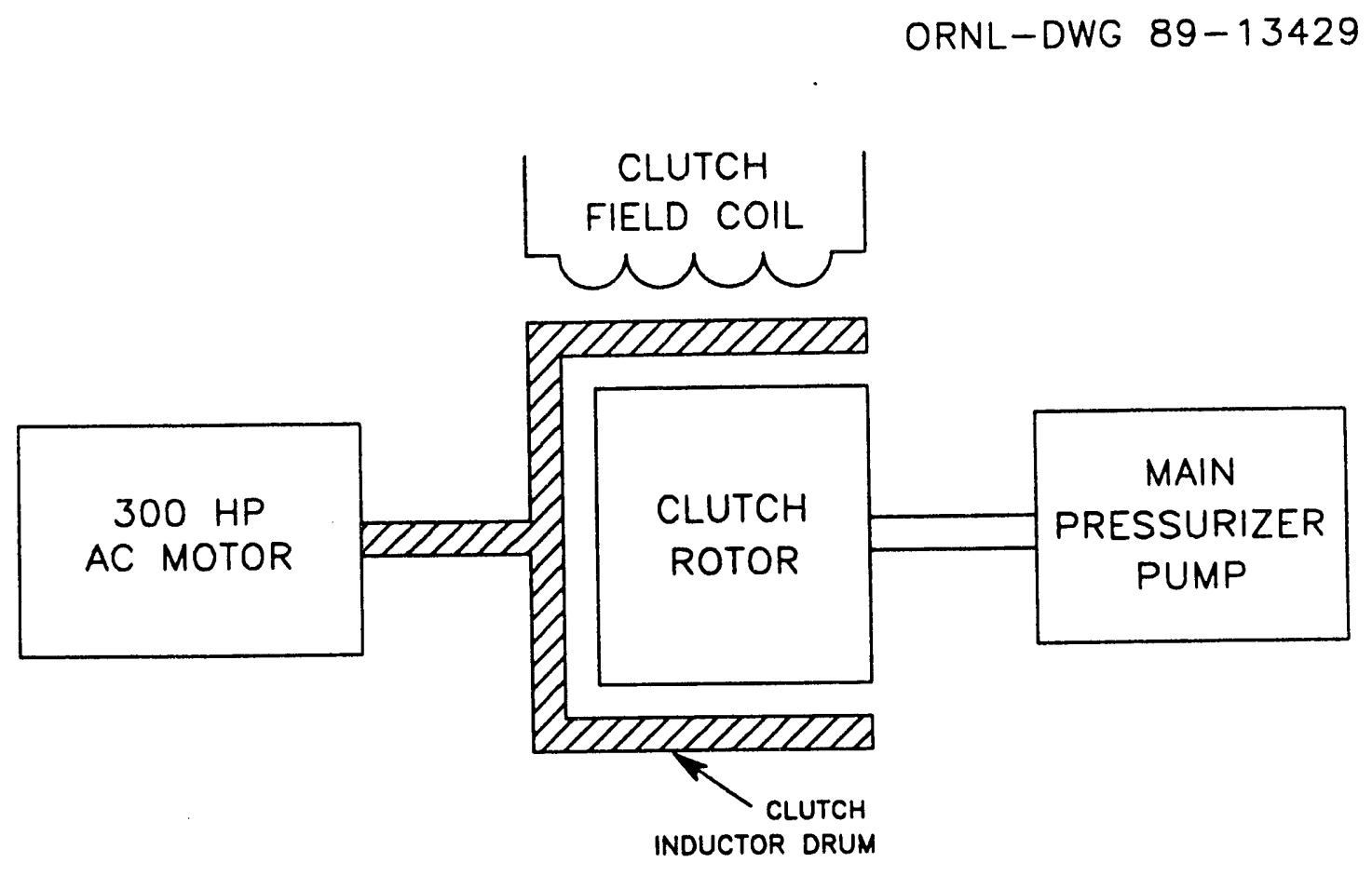

Fig. 8. A functional diagram of the magnetic drive of the main pressurizer pumps. 


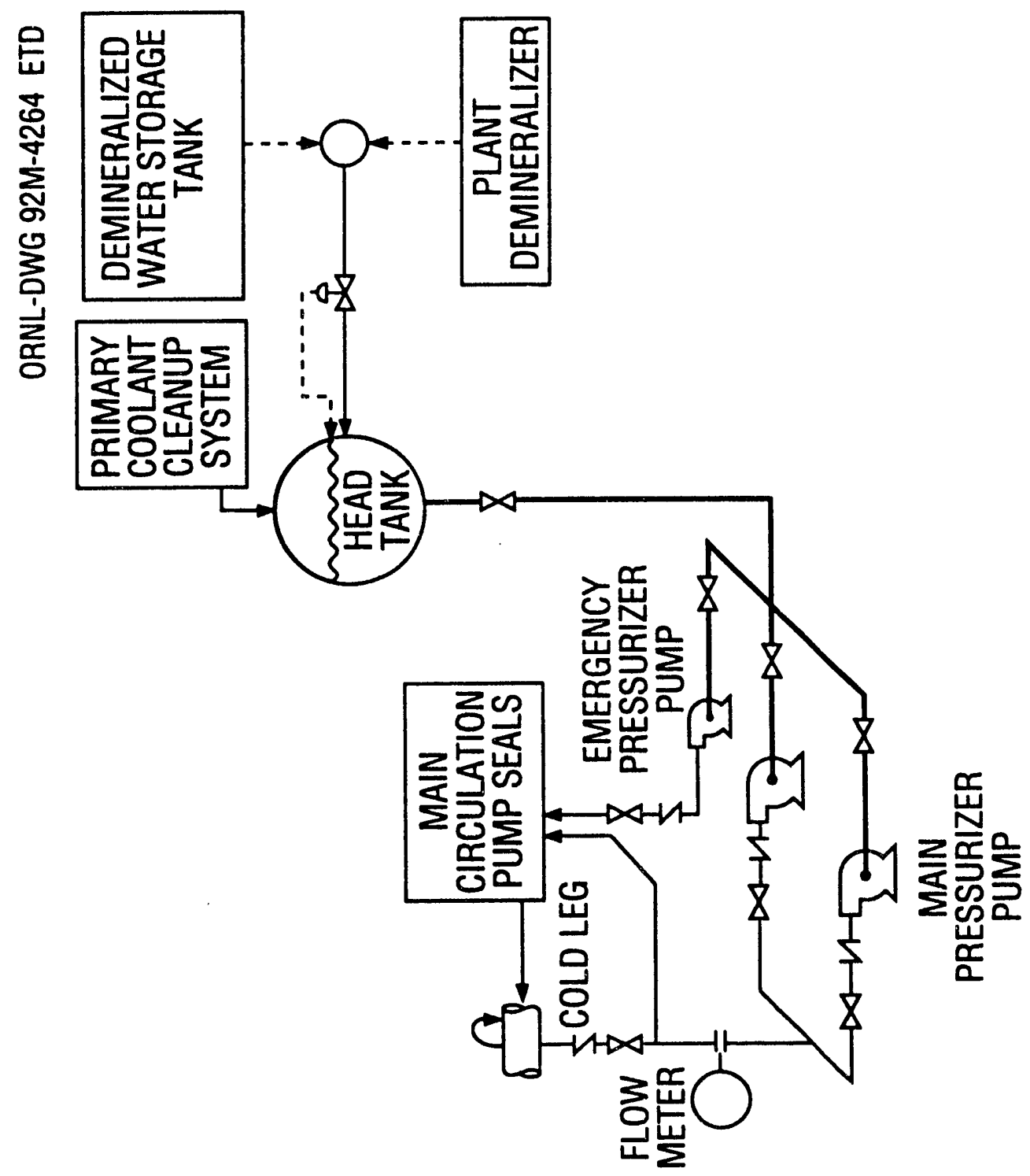

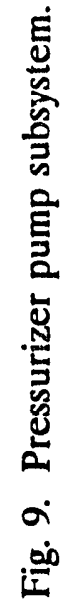




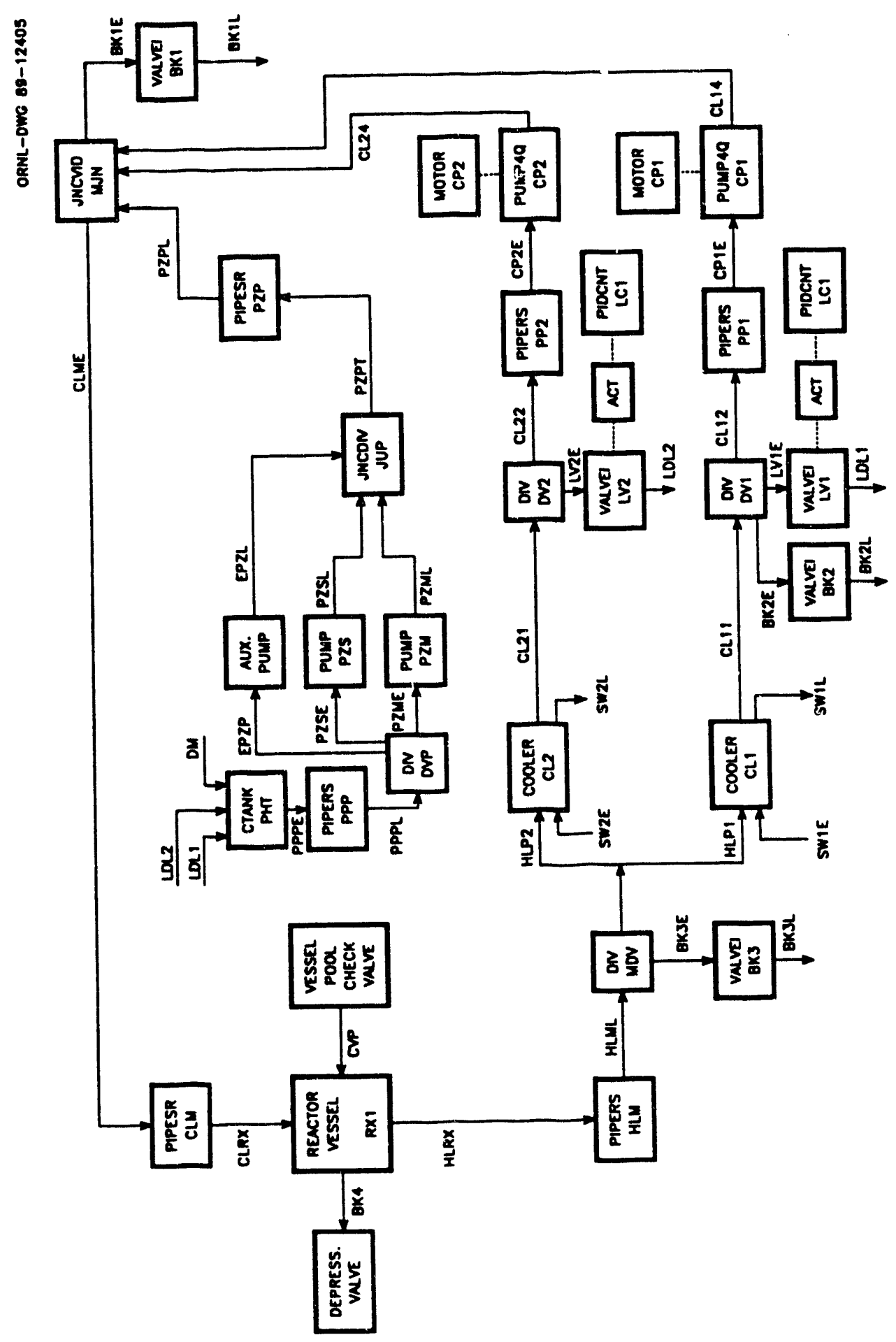

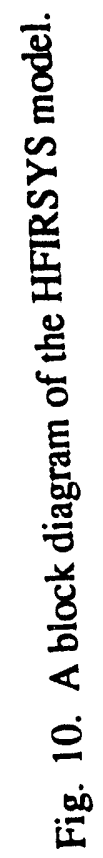




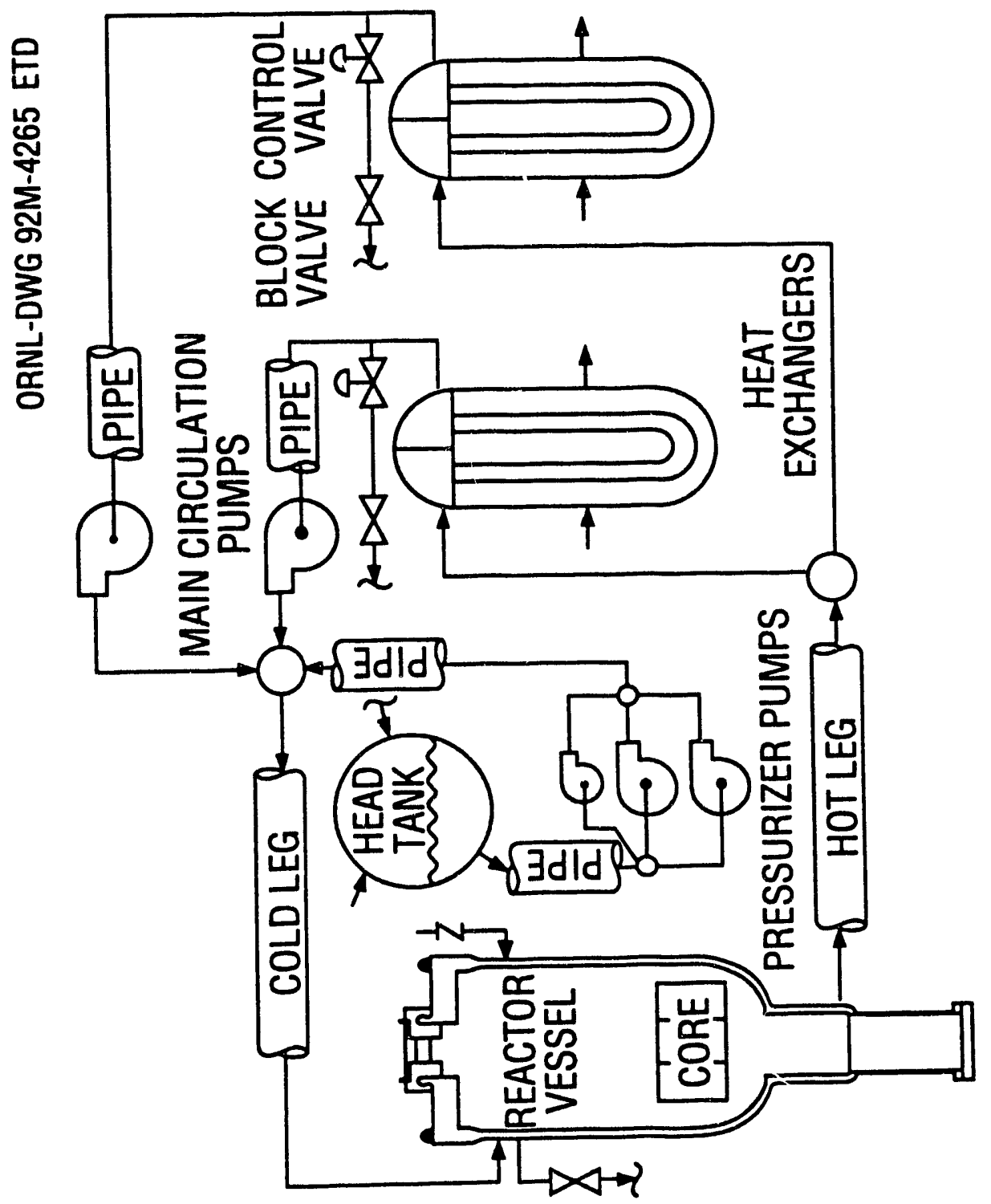

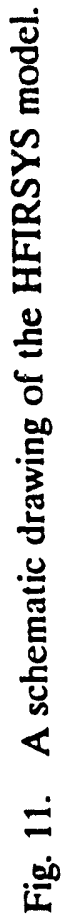




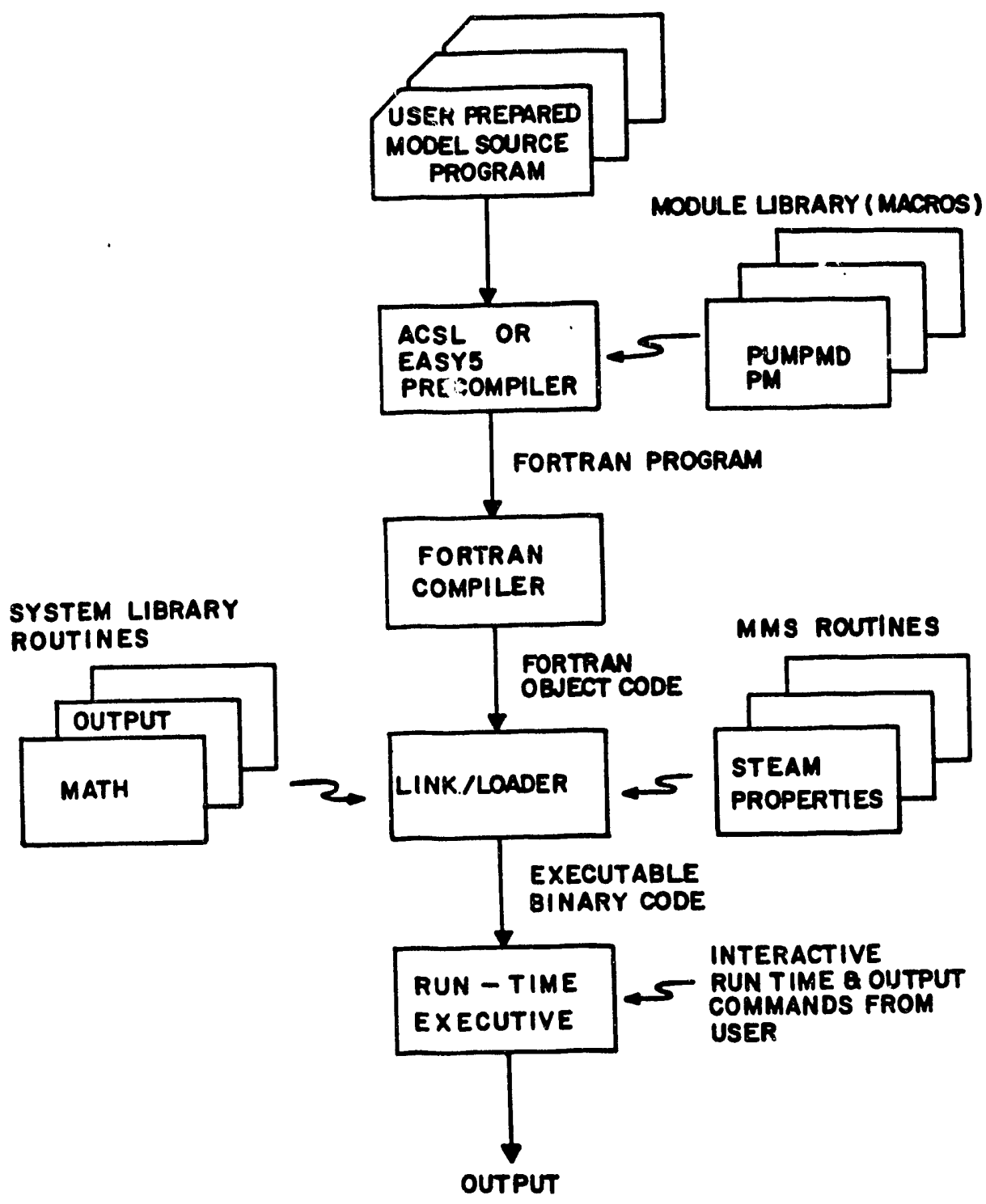

Fig. 12. A flow chart of compiling and executing an MMS program. 

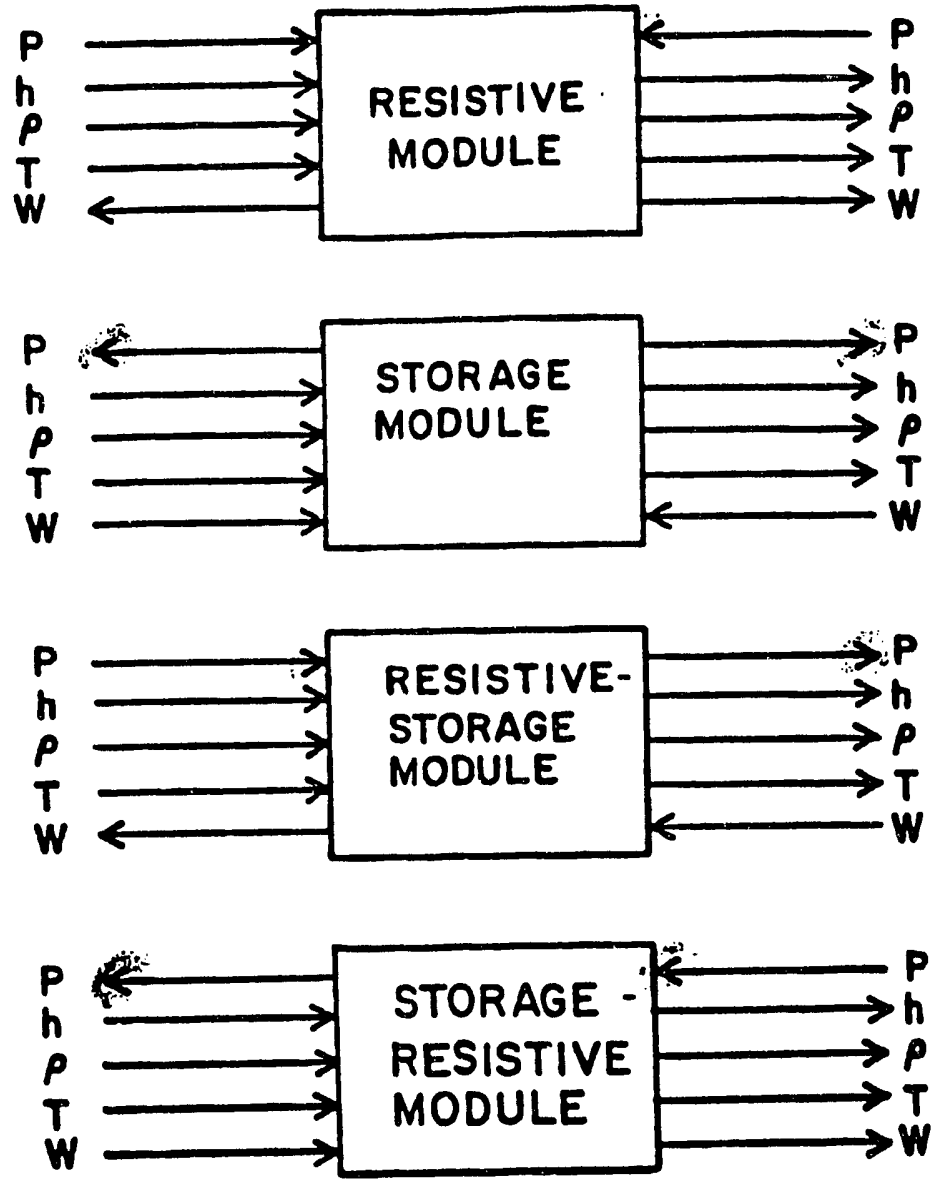

Fir. 13. Input and output variables for standard MMS modules. 


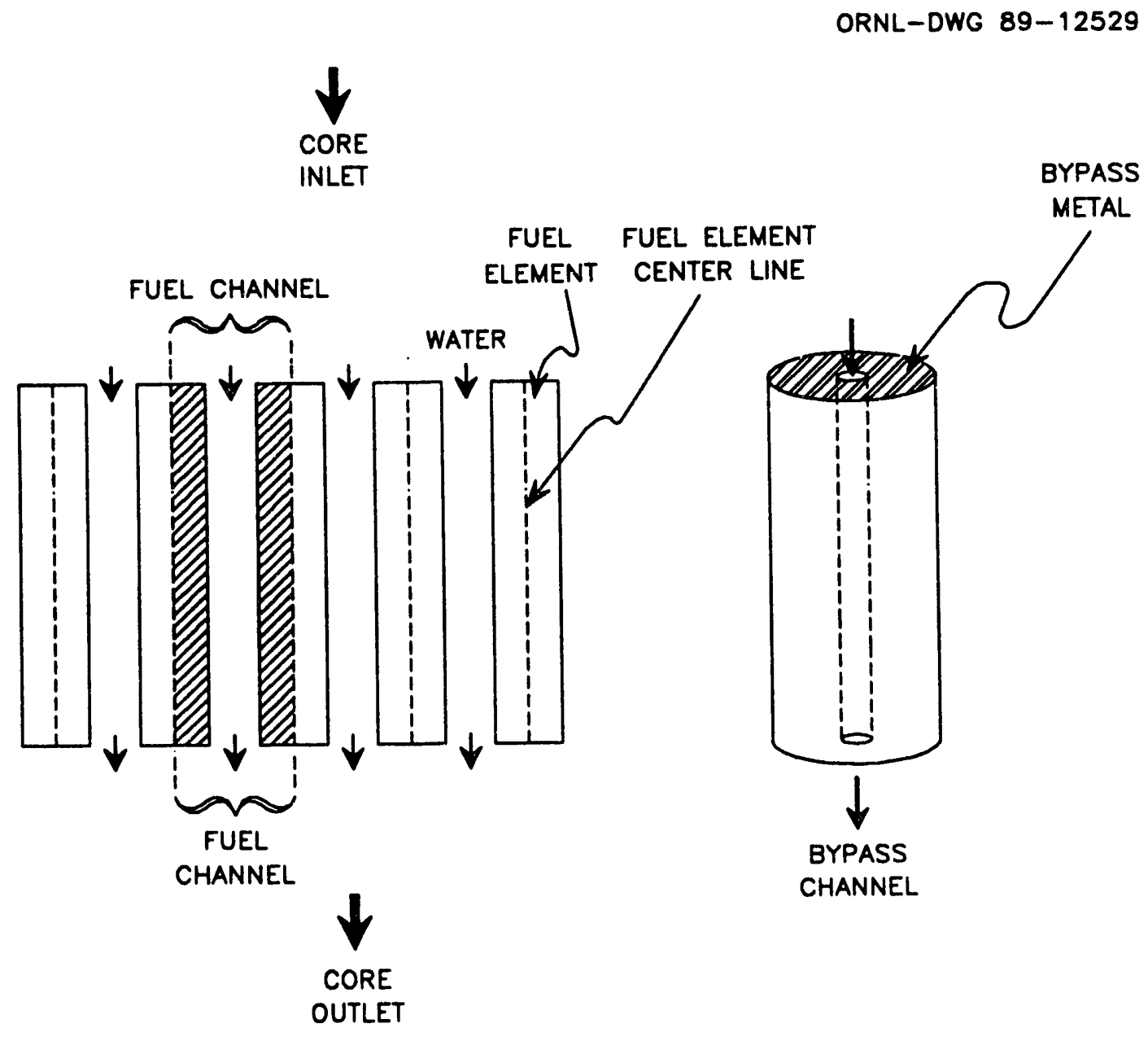

Fig. 14. A schematic drawing of the fuel and bypass channel models. 


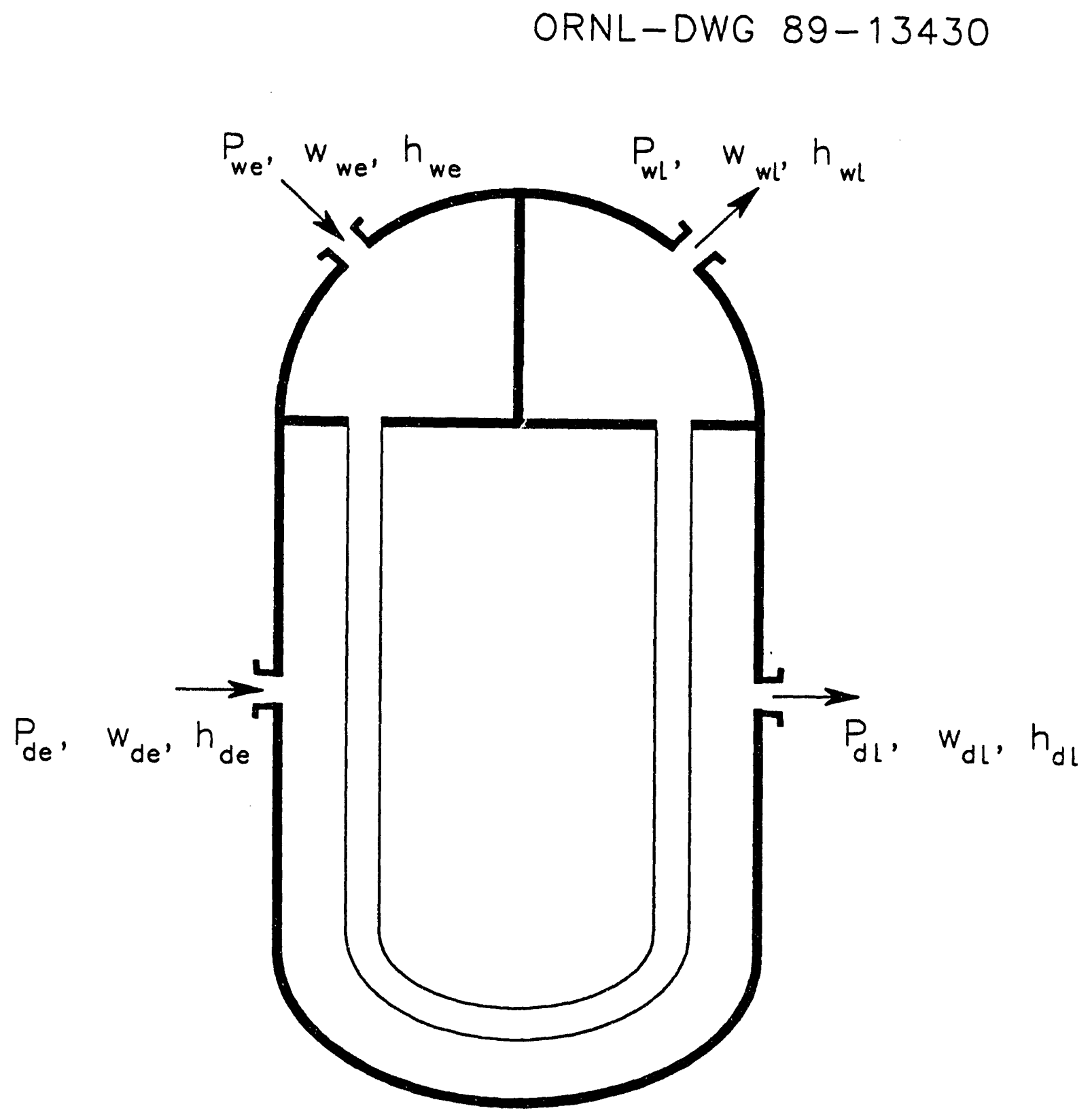

Fig. 15. A schematic drawing of the heat exchanger model. 


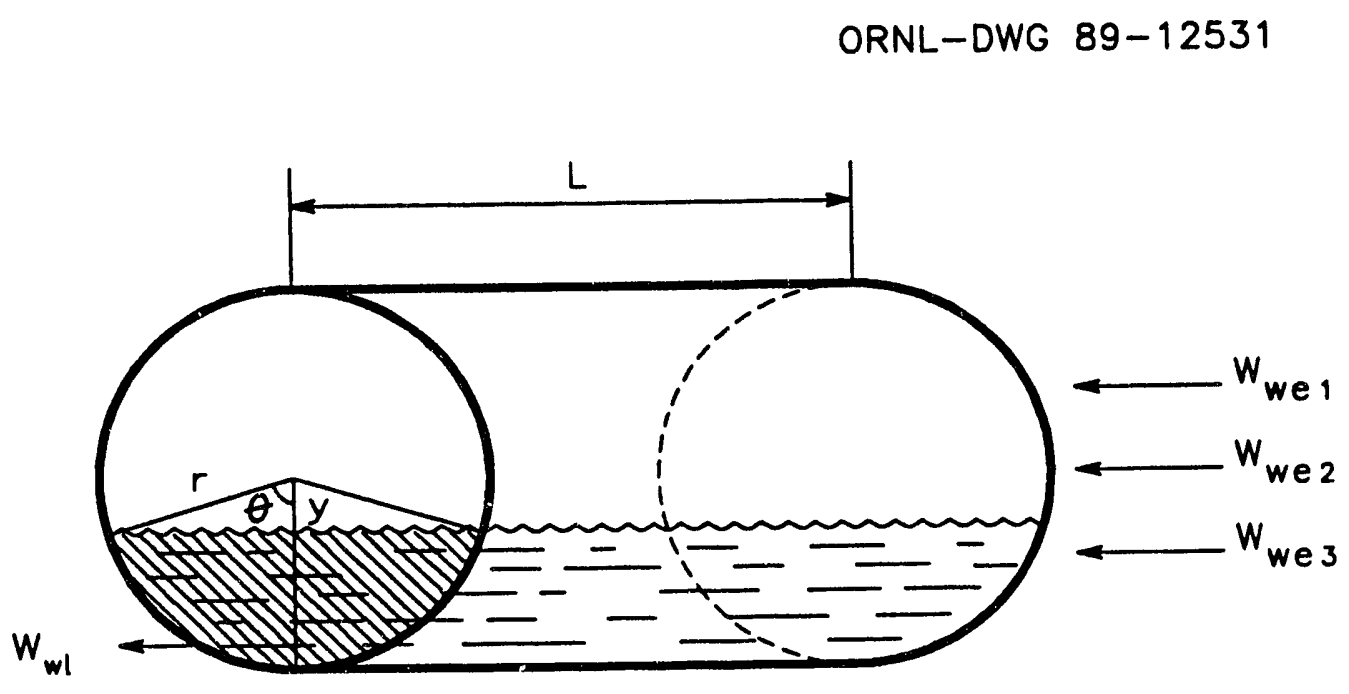

Fig. 16. A schematic drawing of the primary head tank model. 


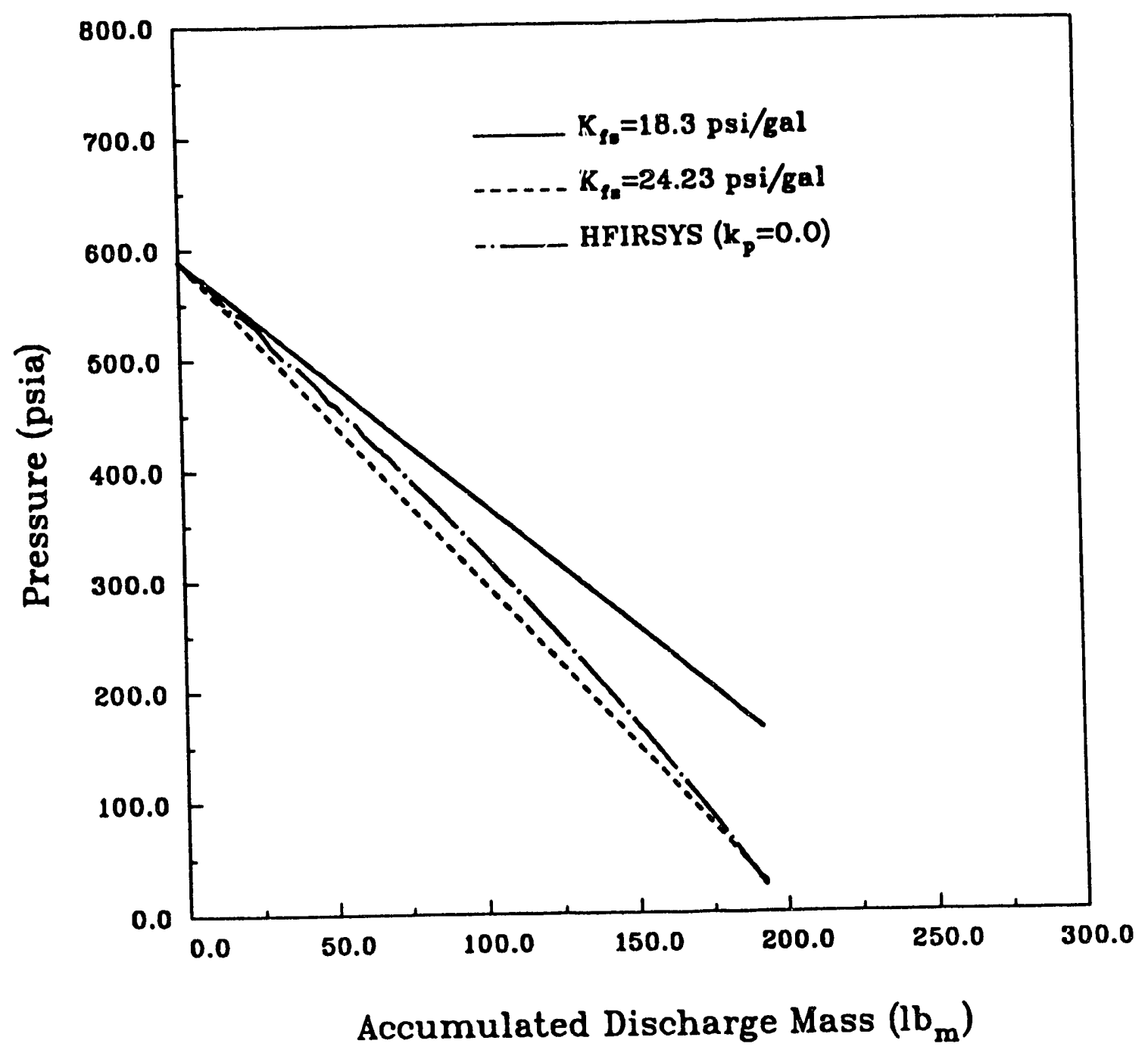

Fig. 17. Comparison of HFIRSYS reactor inlet pressure (no structural elasticity) to system pressure calculated using $\mathrm{K}_{\mathrm{fs}}=18.3 \mathrm{psi} / \mathrm{gal}$ and $\mathrm{K}_{\mathrm{fs}}=24.23 \mathrm{psi} / \mathrm{gal}$ for $1844 \mathrm{ft}^{3}$ of primary coolant system volume. 


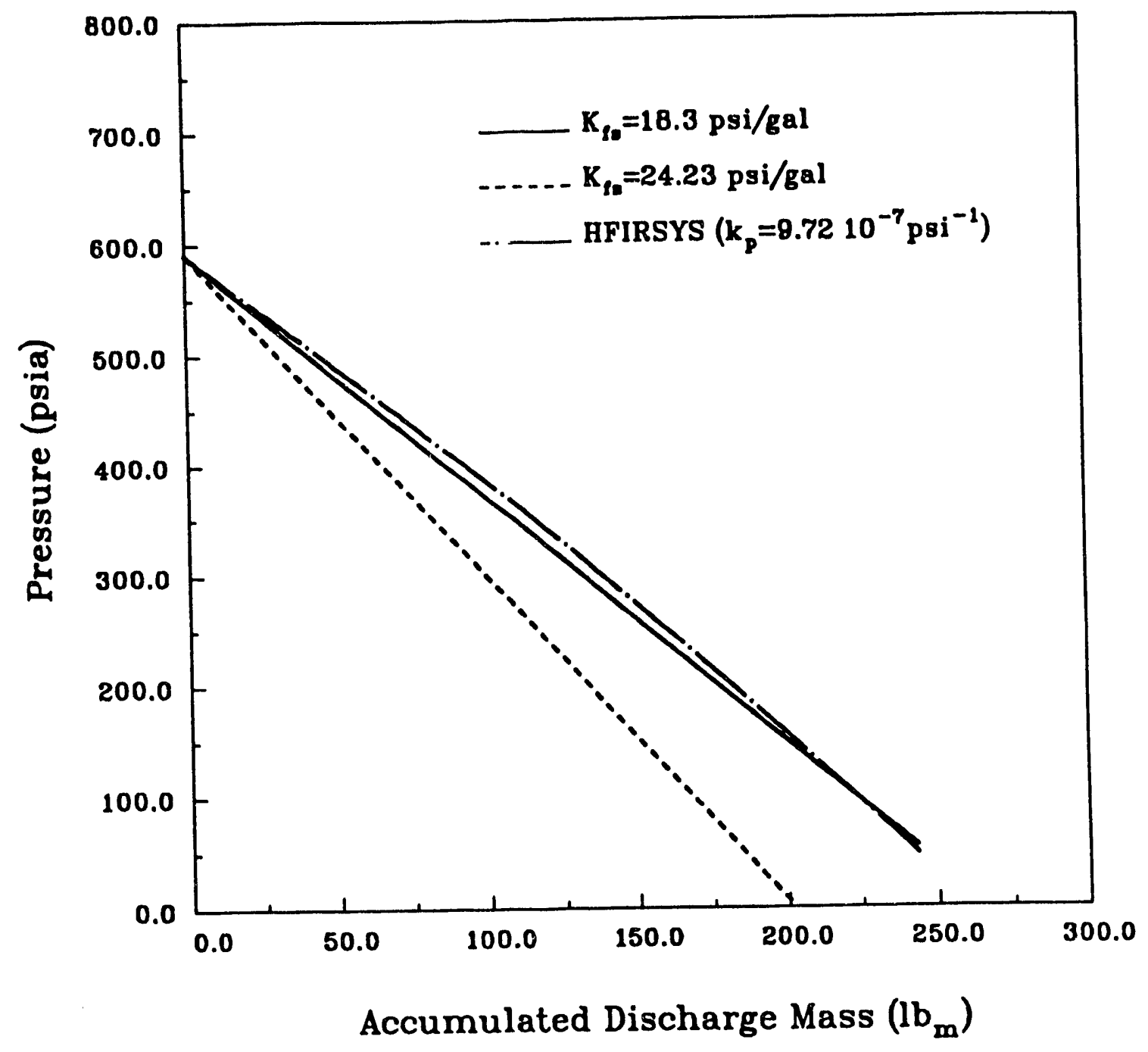

Fig. 18. Comparison of HFIRSYS reactor inlet pressure (structural elasticity included, $\left.\mathrm{k}_{\mathrm{pv}}=9.7210^{-7} \mathrm{psi1}\right)$ to system pressures calculated using $\mathrm{K}_{\mathrm{fs}}=24.23 \mathrm{psi} / \mathrm{gal}$ for $1844 \mathrm{ft}^{3}$ of primary coolant system volume. 


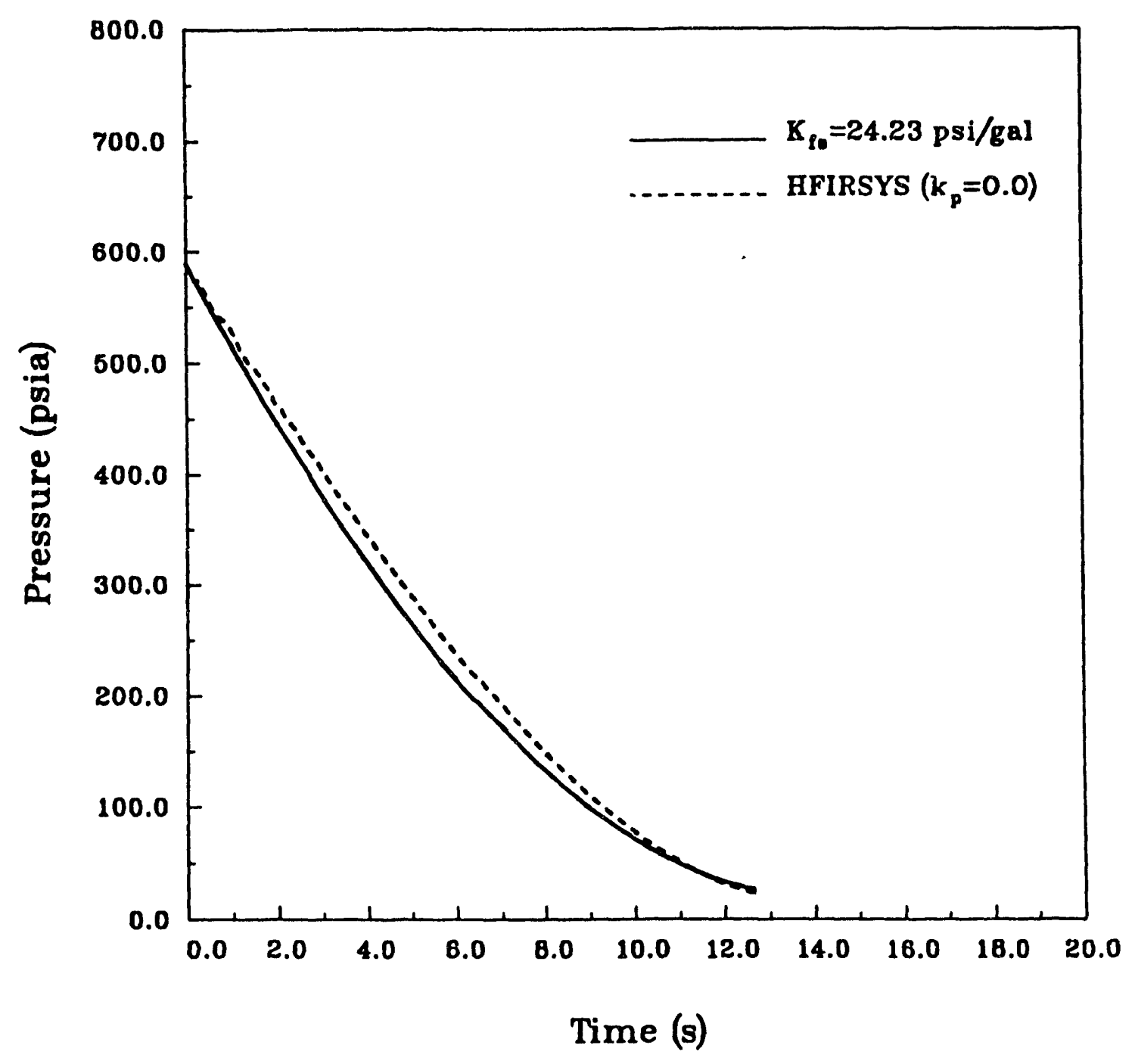

Fig. 19. Comparison of time dependent behavior of HFIRSYS reactor inlet pressure (no structural elasticity) to system pressure calculated using $\mathrm{K}_{\mathrm{fs}}=24.23 \mathrm{psi} / \mathrm{gal}$ for $1844 \mathrm{ft}^{3}$ of primary coolant system volume. 


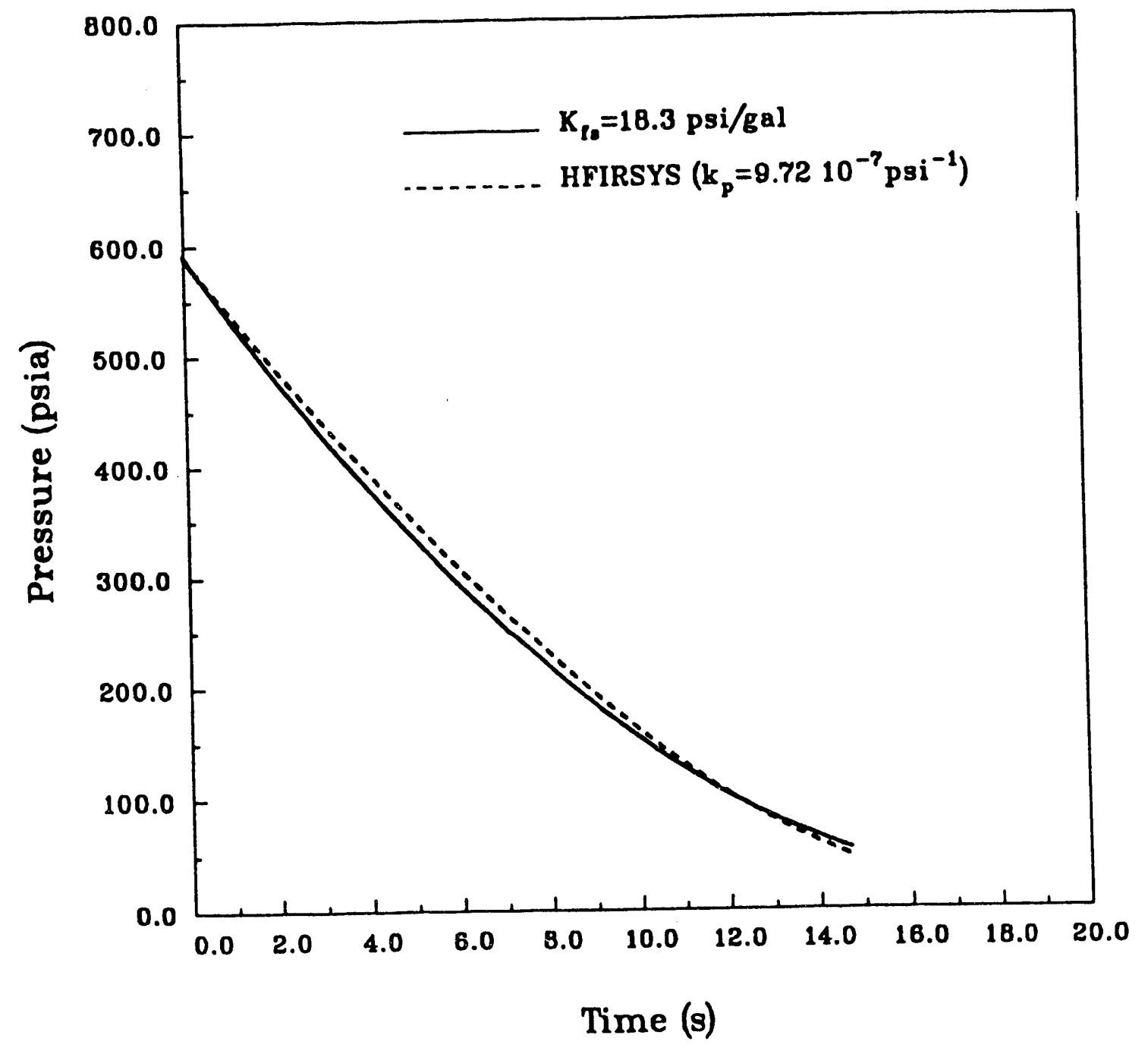

Fig. 20. Comparison of time dependent behavior of HFIRSYS reactor inlet pressure (structural elasticity included, $\mathrm{k}_{\mathrm{pv}}=9.7210^{-7} \mathrm{psi}^{-1}$ ) to system pressure calculated using $\mathrm{K}_{\mathrm{fs}}=18.3 \mathrm{psi} / \mathrm{gal}$ for $1844 \mathrm{ft}^{3}$ of primary coolant system volume. 


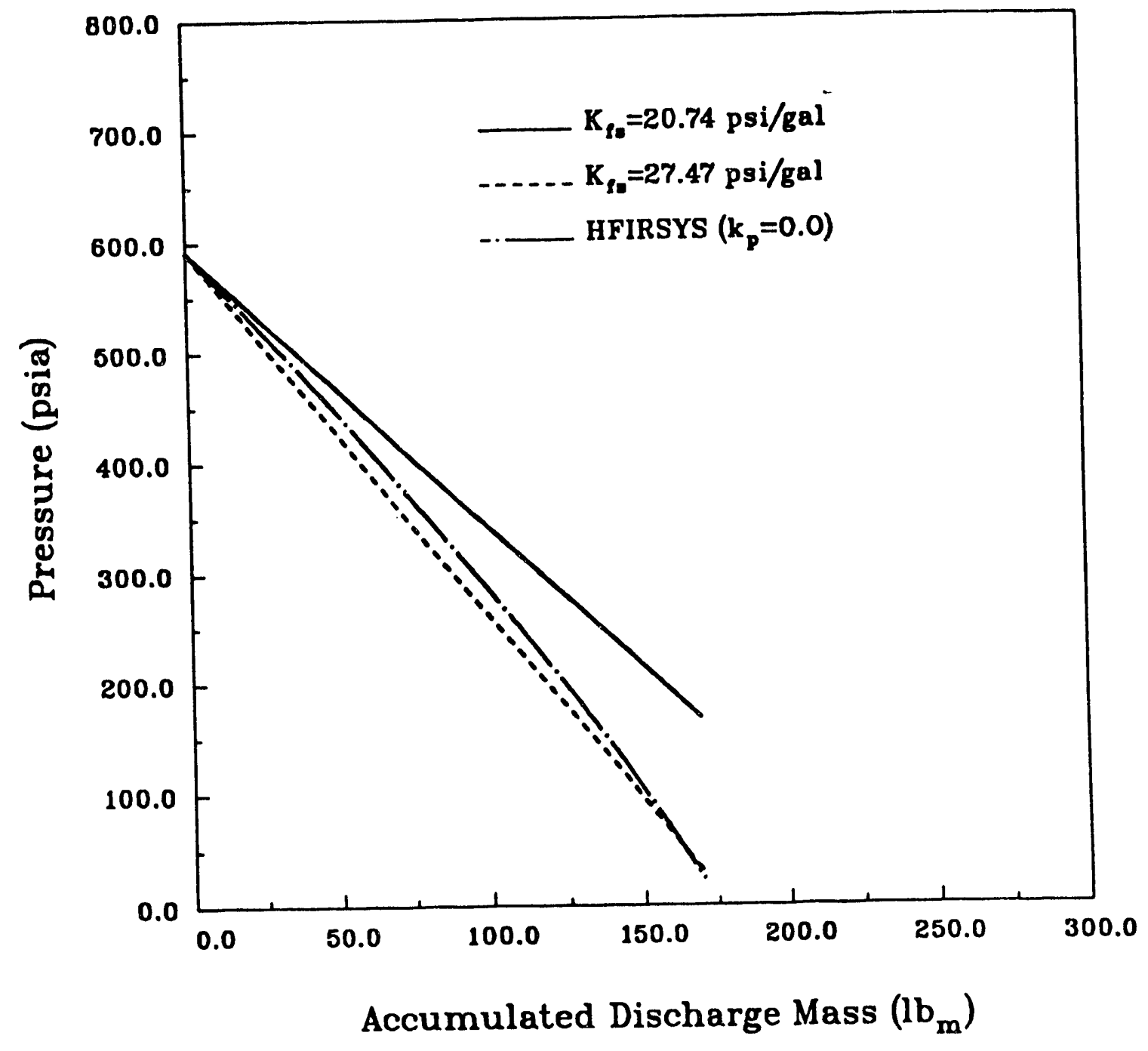

Fig. 21. Comparison of HFIRSYS reactor inlet pressure (no structural elasticity) to system pressure calculated using $\mathrm{K}_{\mathrm{fs}}=20.74 \mathrm{psi} / \mathrm{gal}$ and $\mathrm{K}_{\mathrm{fs}}=27.47 \mathrm{psi} / \mathrm{gal}$ for $1626 \mathrm{ft}^{3}$ of primary coolant system volume. 


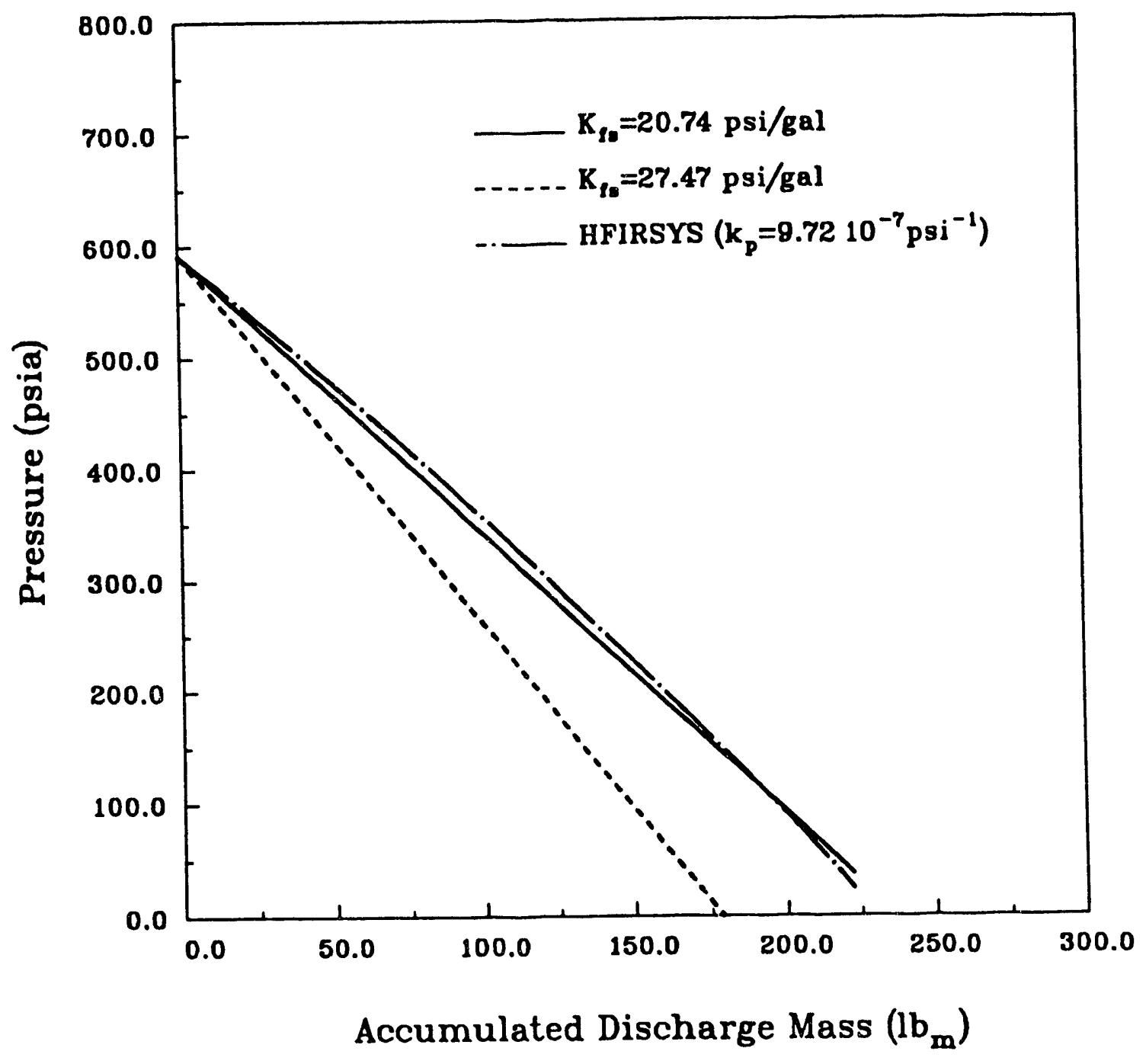

Fig. 22. Comparison of HFIRSYS reactor inlet pressure (structural elasticity included, $\mathrm{k}_{\mathrm{pv}}=9.7210^{-7} \mathrm{psi}^{-1}$ ) to system pressures calculated using $\mathrm{K}_{\mathrm{fs}}=20.74 \mathrm{psi} / \mathrm{gal}$ and $\mathrm{K}_{\mathrm{fs}}=27.47 \mathrm{psi} / \mathrm{gal}$ for $1626 \mathrm{ft}^{3}$ of primary coolant system volume. 


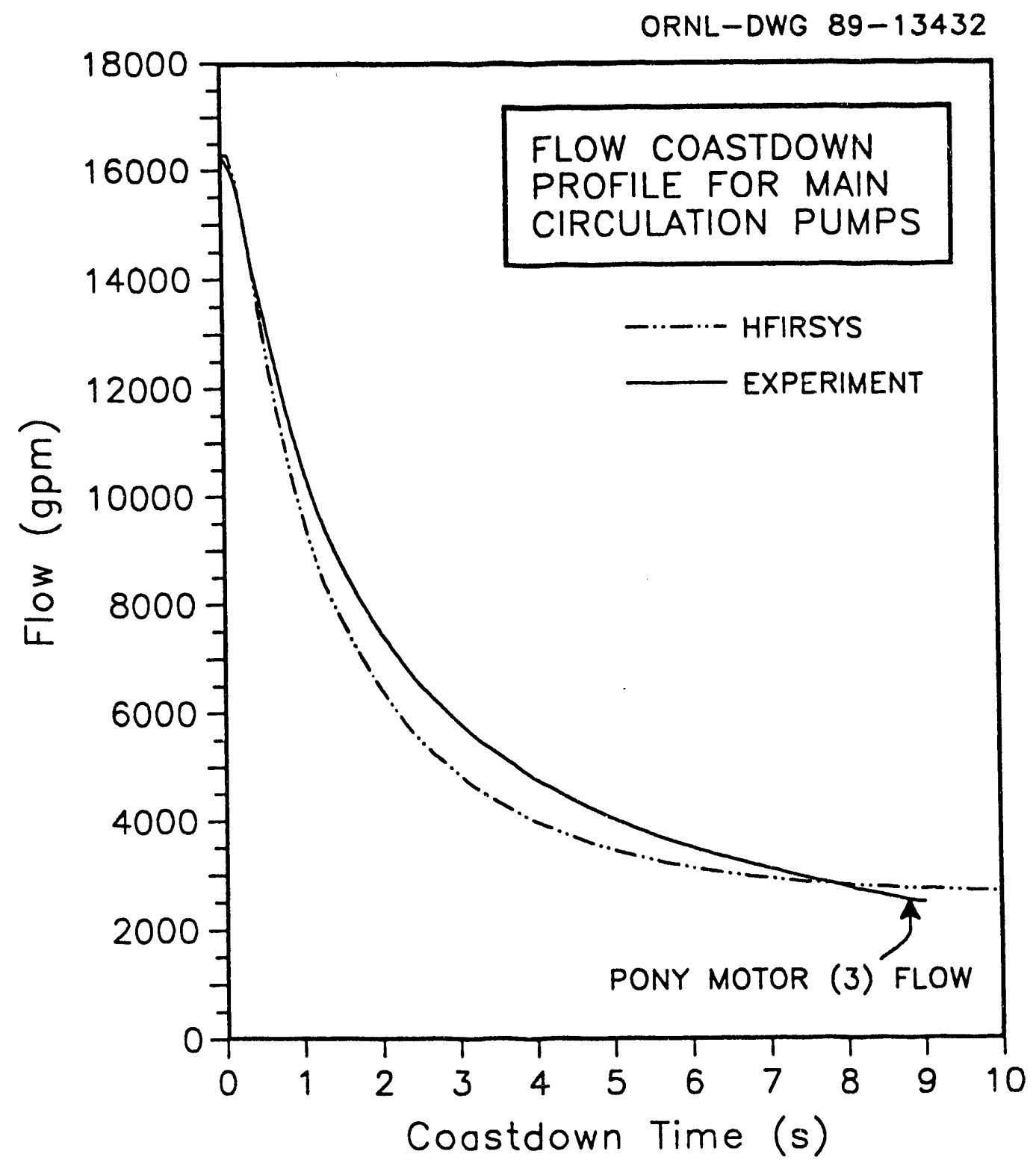

Fig. 23. Comparison of HFIRSYS flow coastdown profile (dotted line) to the experimentally measured profile (solid line). 


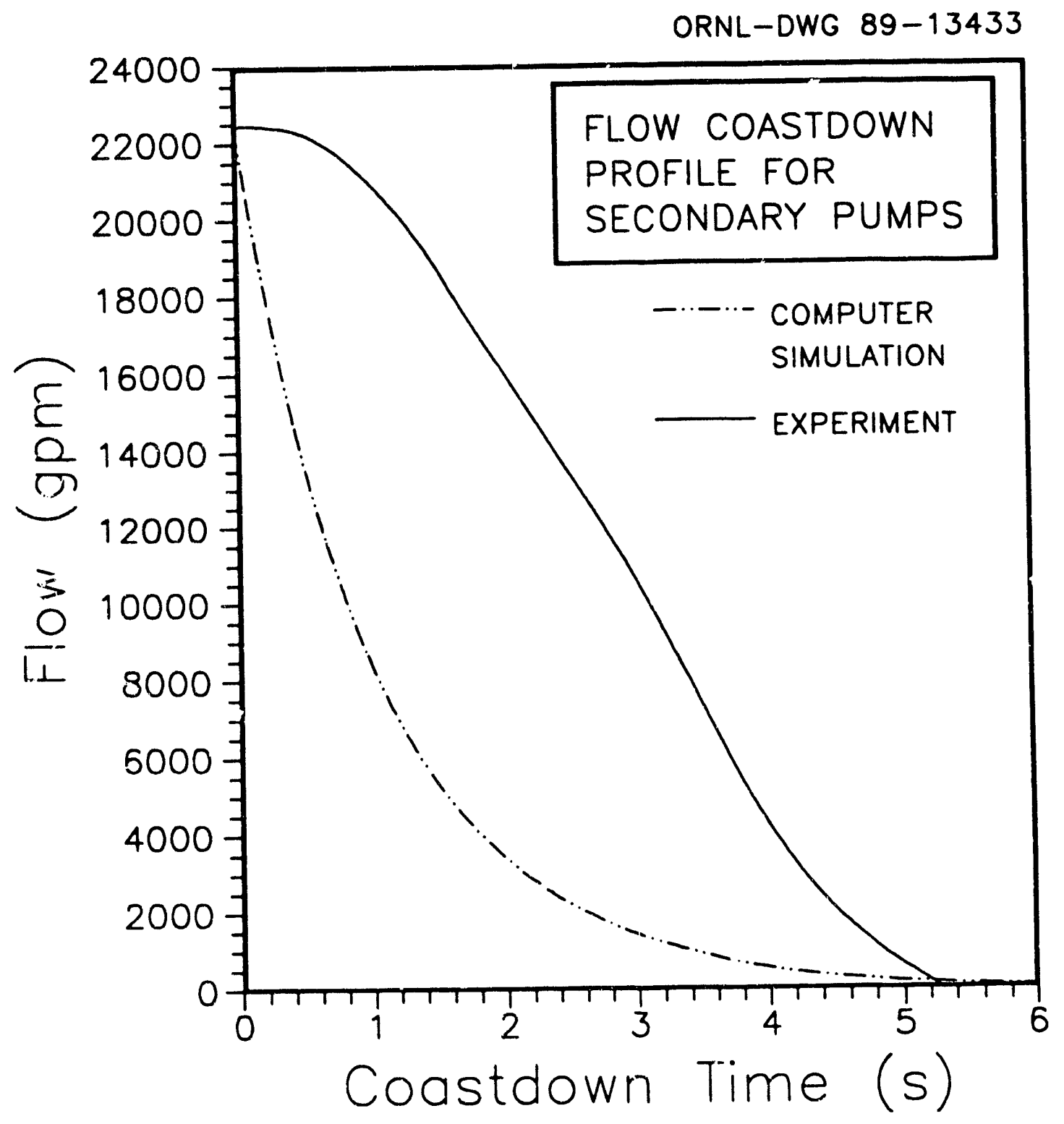

Fig. 24. Comparison of HFIRSYS secondary flow coastdown profile (dotted line) to the experimentally measured profile (solid line). 
ORNL-DWG 89-12402

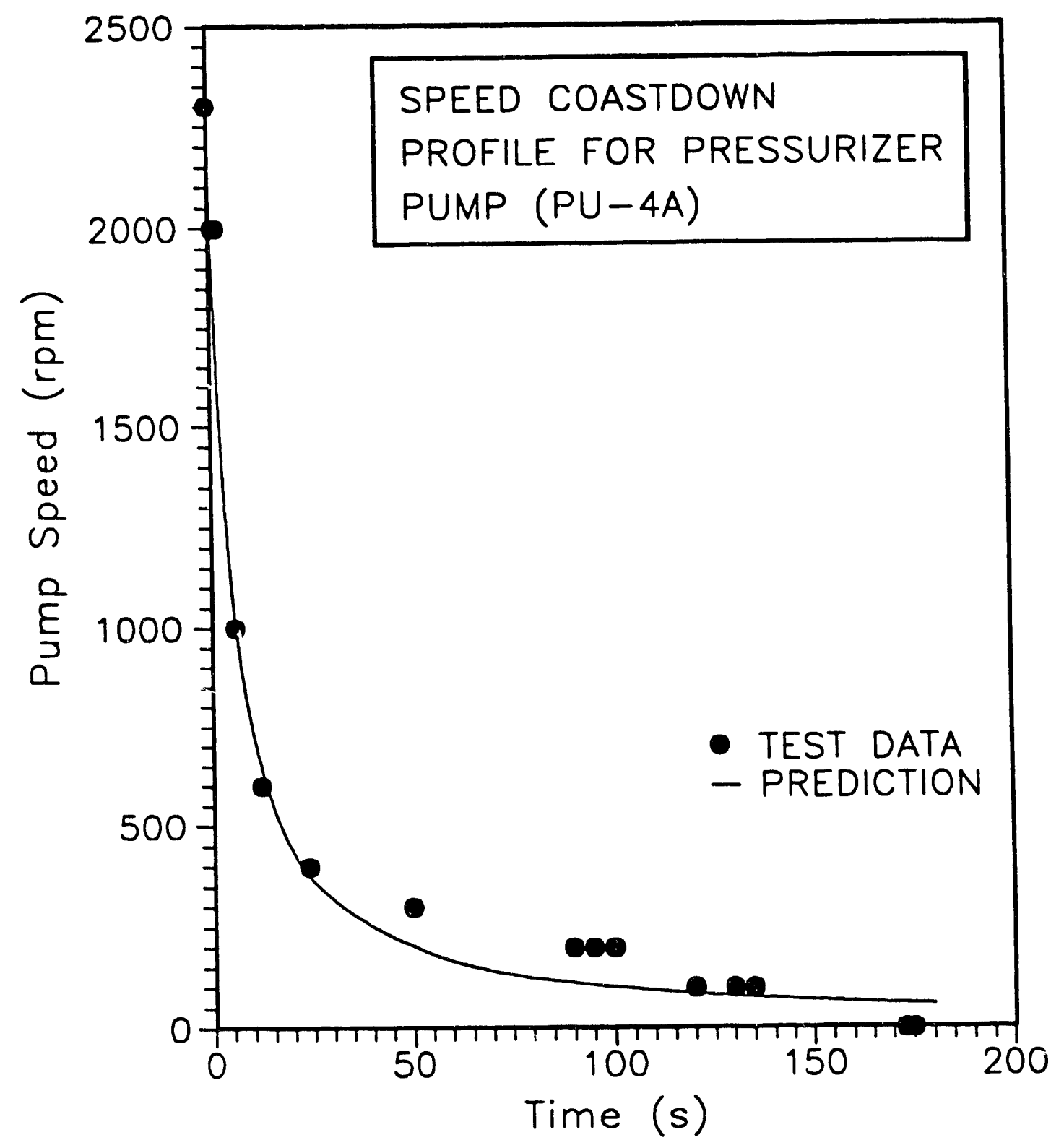

Fig. 25. Comparison of HFIRSYS speed coastdown profile for the main pressurizer pumps to the experimentally measured data. 


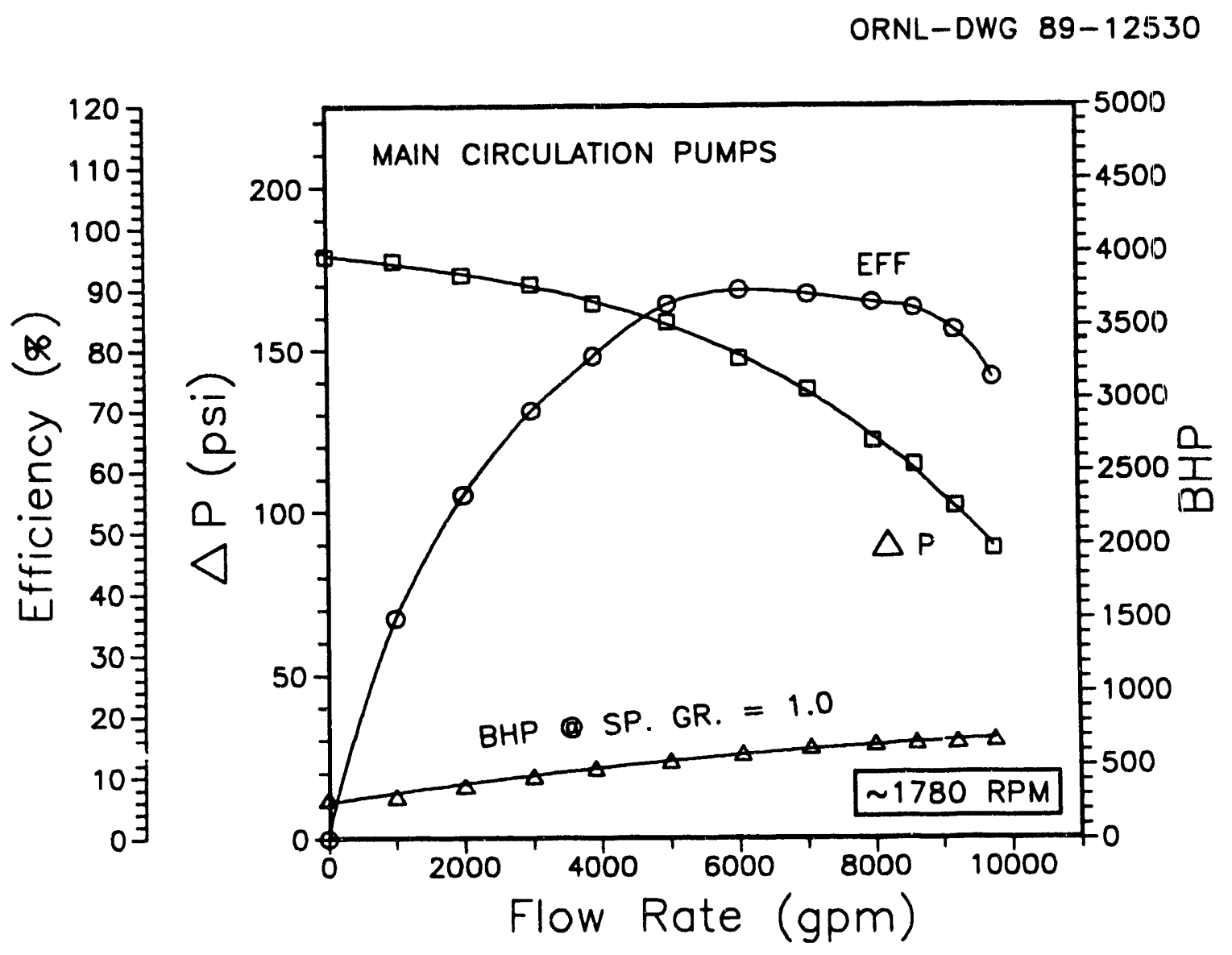

Fig. A.1. Main circulation pump performance curves at $1780 \mathrm{rpm}$. 


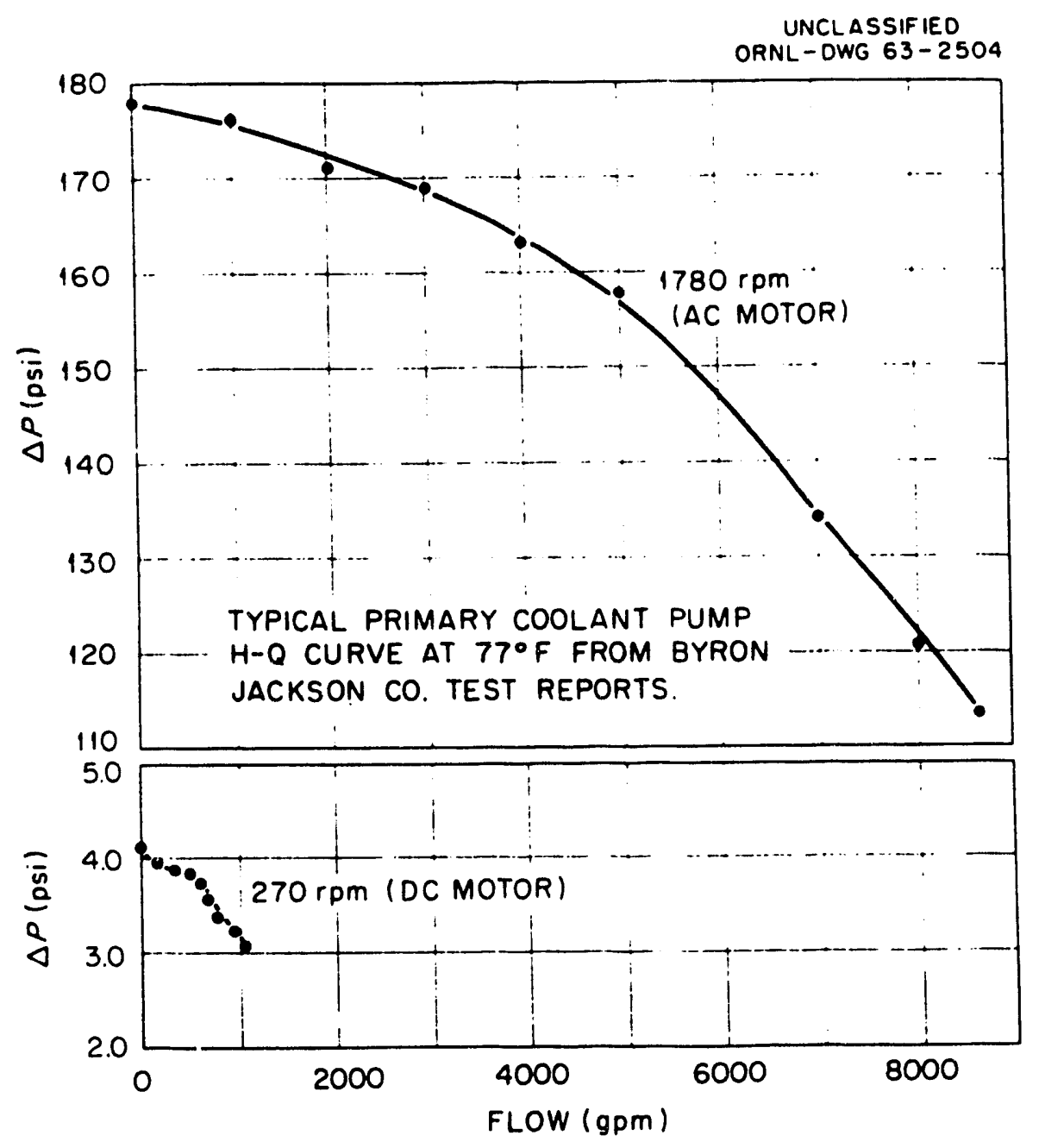

Fig. A.2. Pump head as a function of flow rate for ac and dc pony motor operation of the main circulation pumps. 


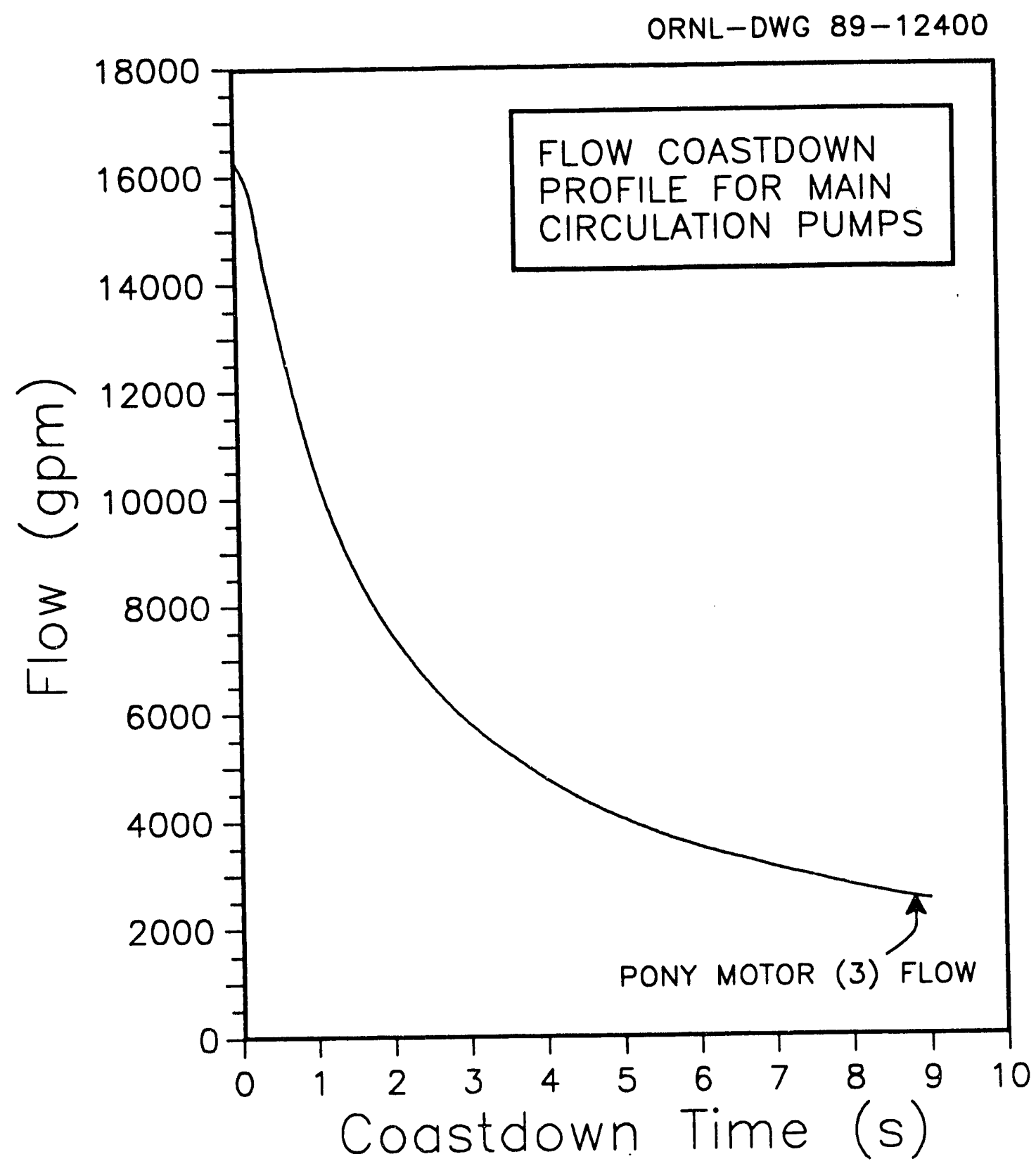

Fig. A.3. Flow coastdown profile for the main circulation pumps. 


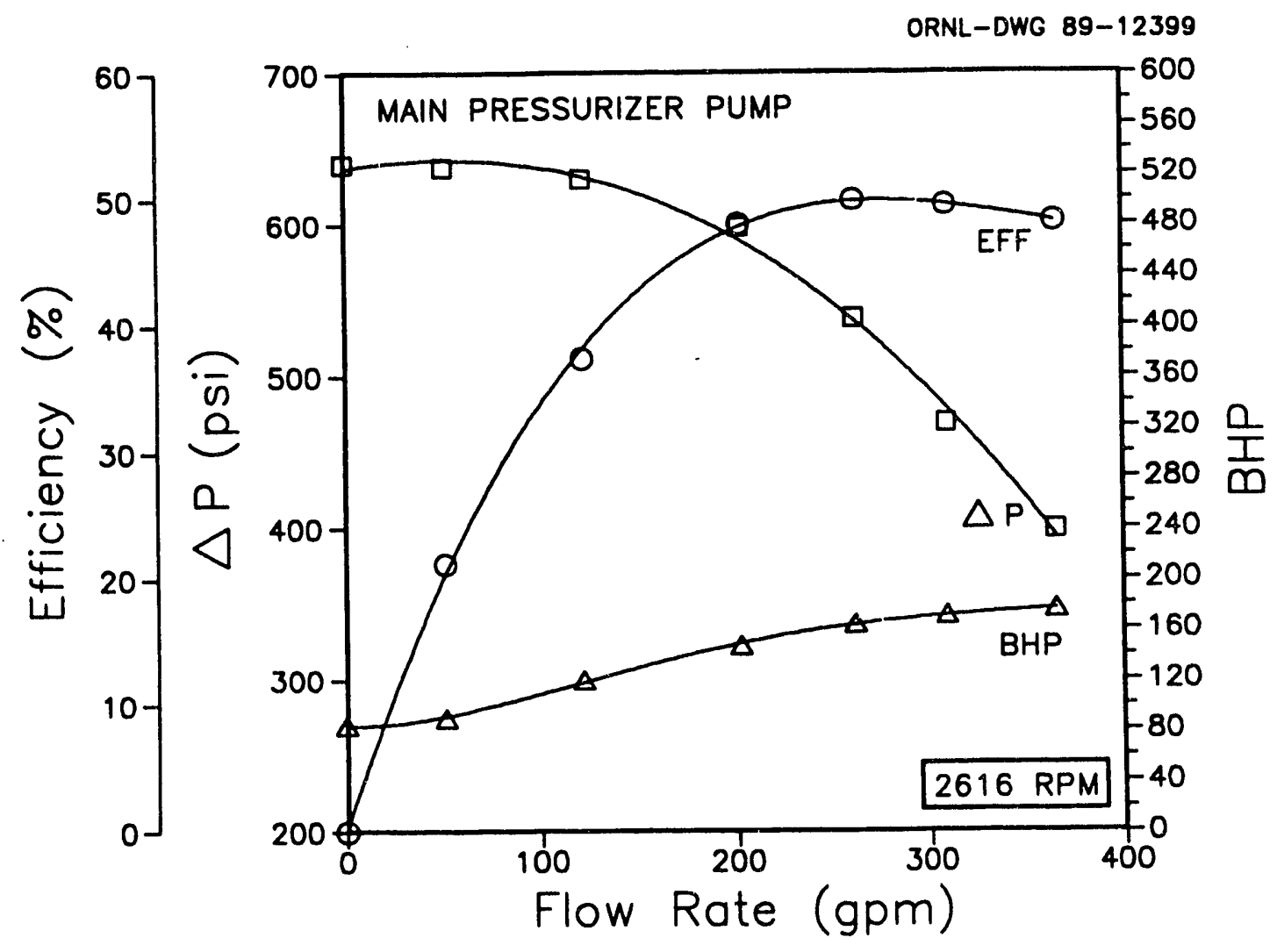

Fig. A.4. Main pressurizer pump performance curves at $2616 \mathrm{rpm}$. 


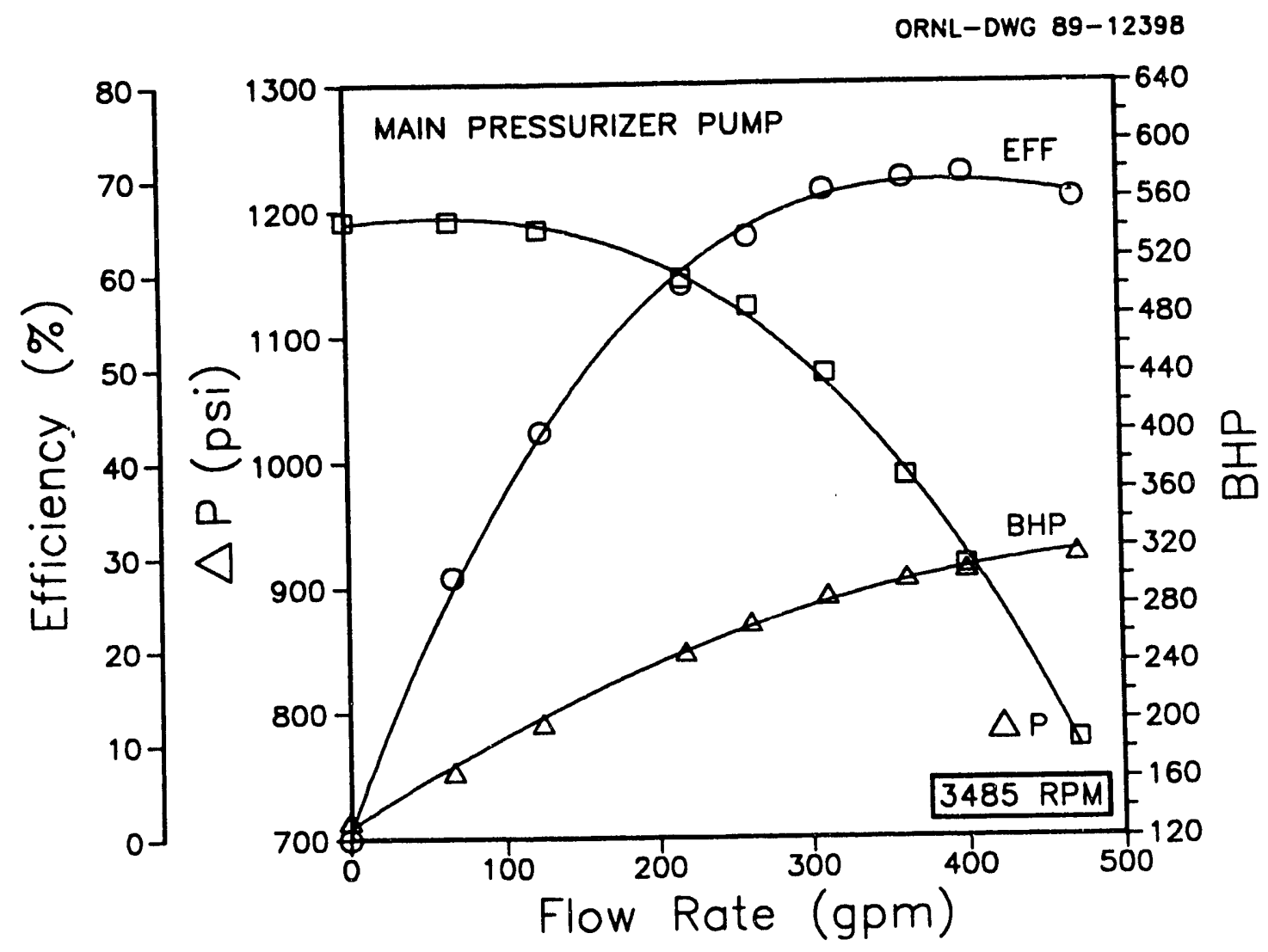

Fig. A.5. Main pressurizer pump performance curves at $3485 \mathrm{rpm}$. 


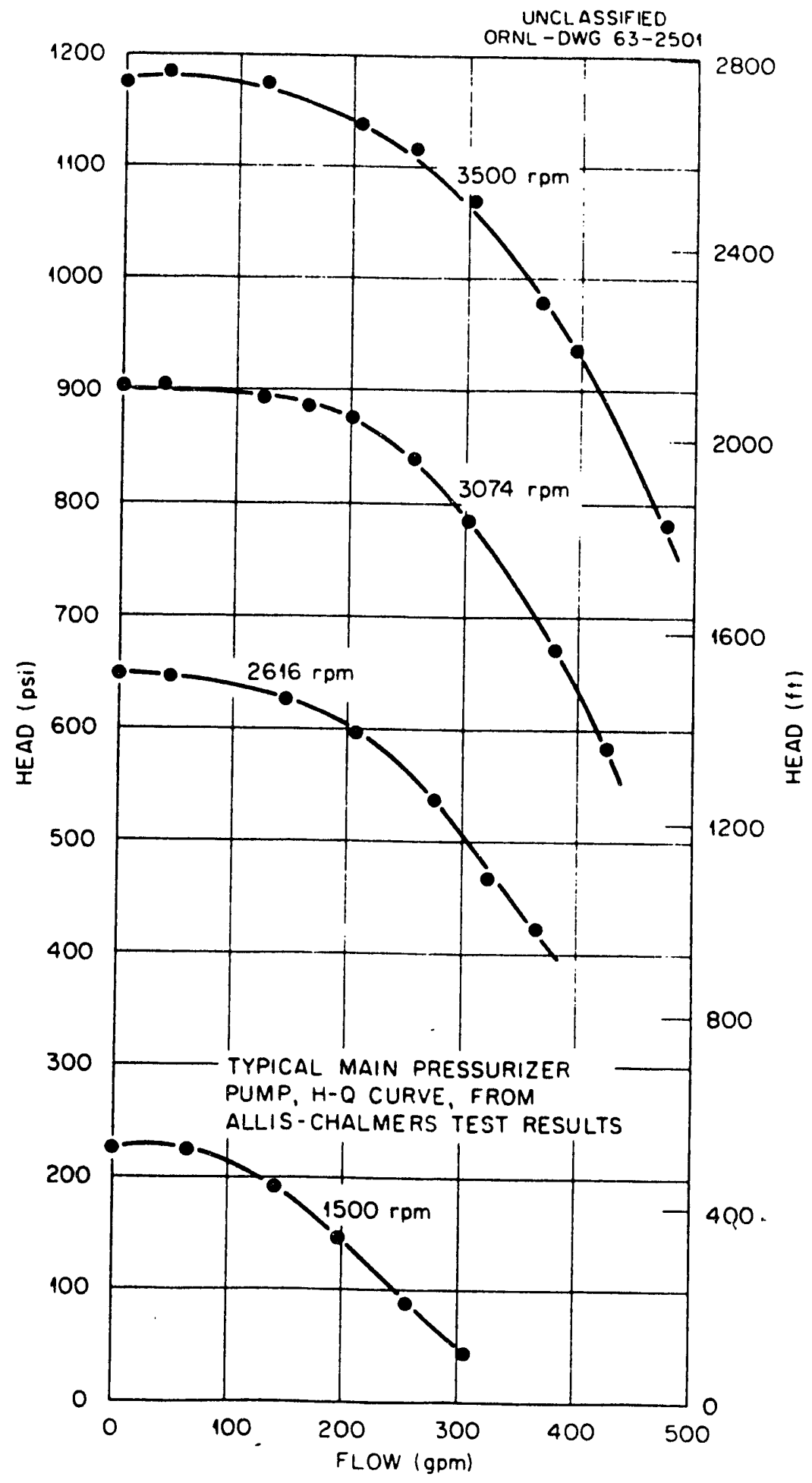

Fig. A.6. Pump head as a function of flow rate for the main pressurizer pumps. 
ORNL-DWG 89-12402

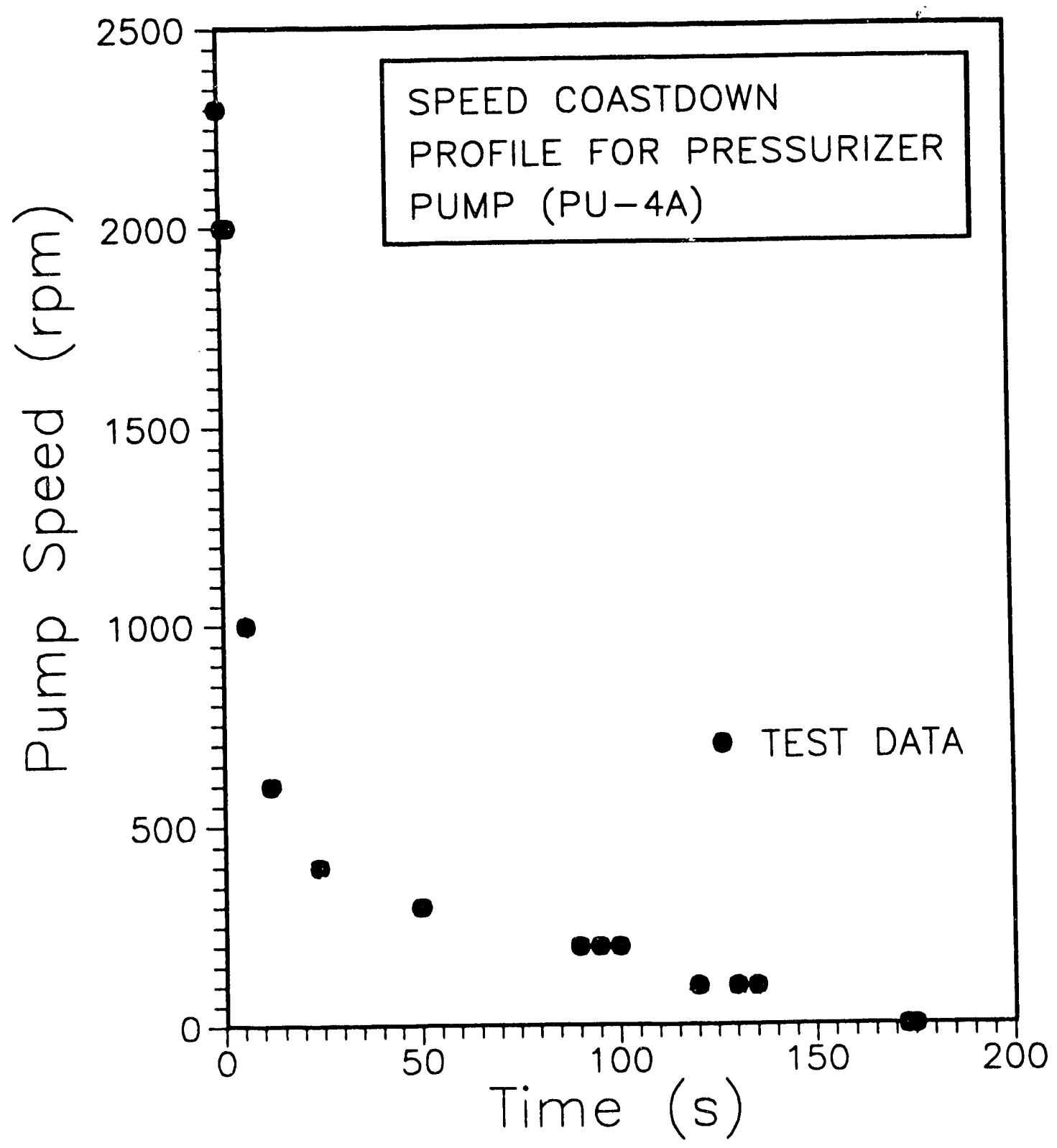

Fig. A.7. Speed coastdown profile for the main pressurizer pumps. 


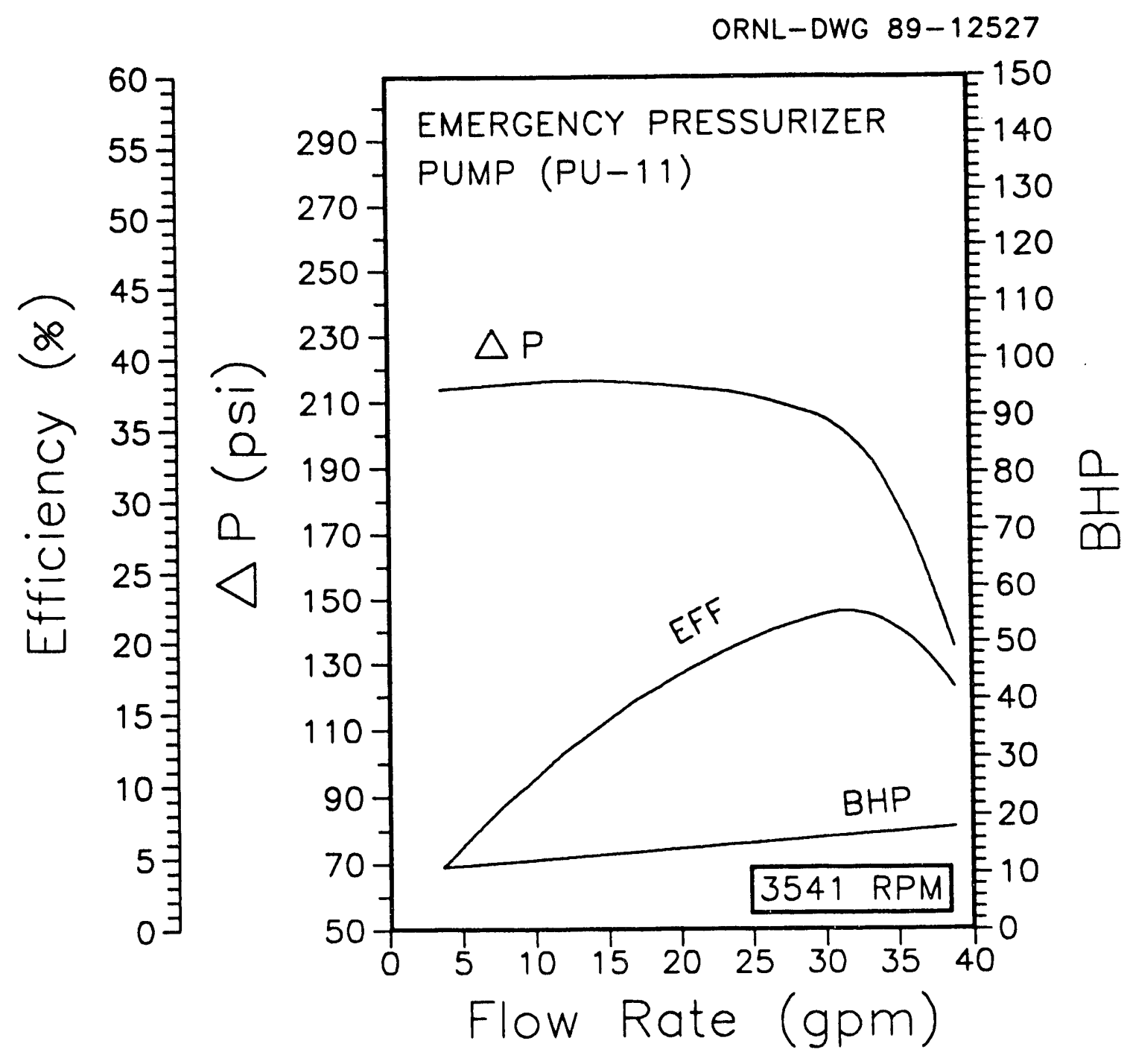

Fig. A.8. Auxiliary pressurizer pump performance curves at $3541 \mathrm{rpm}$. 


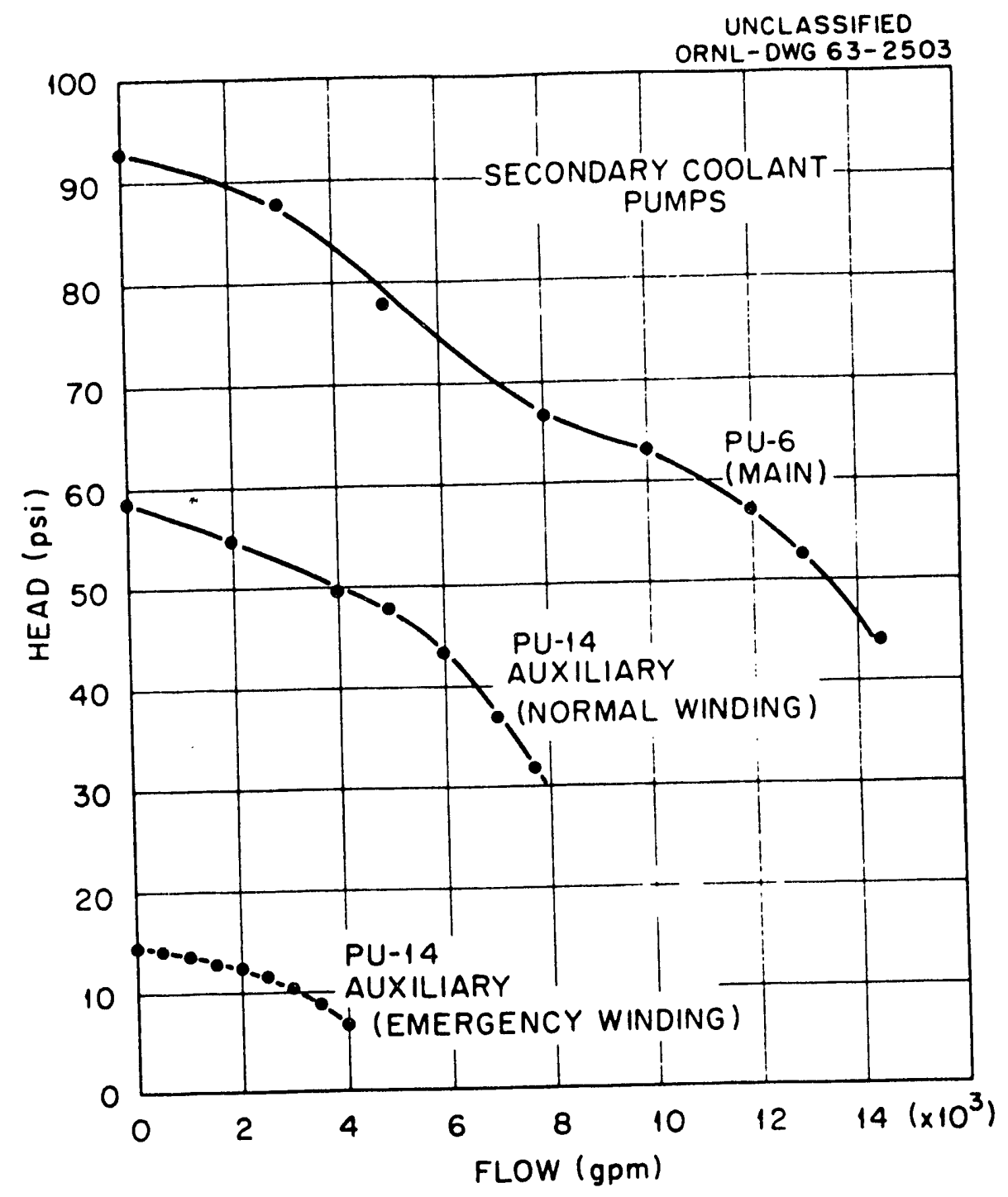

Fig. A.9. Pump head as a function of flow rate for the secondary coolant pumps. 


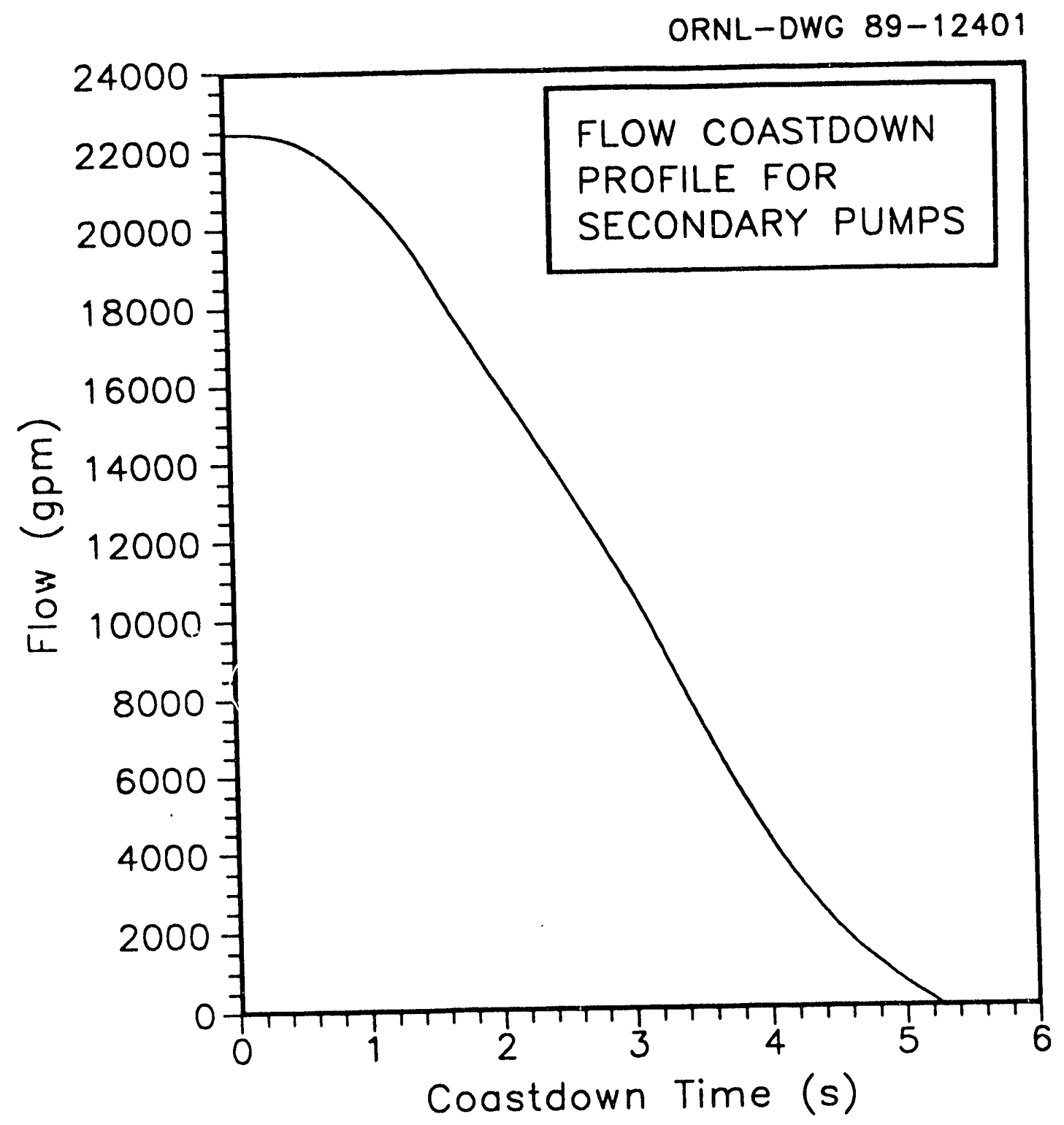

Fig. A.10. Flow coastdown profile for the secondary coolant pumps. 


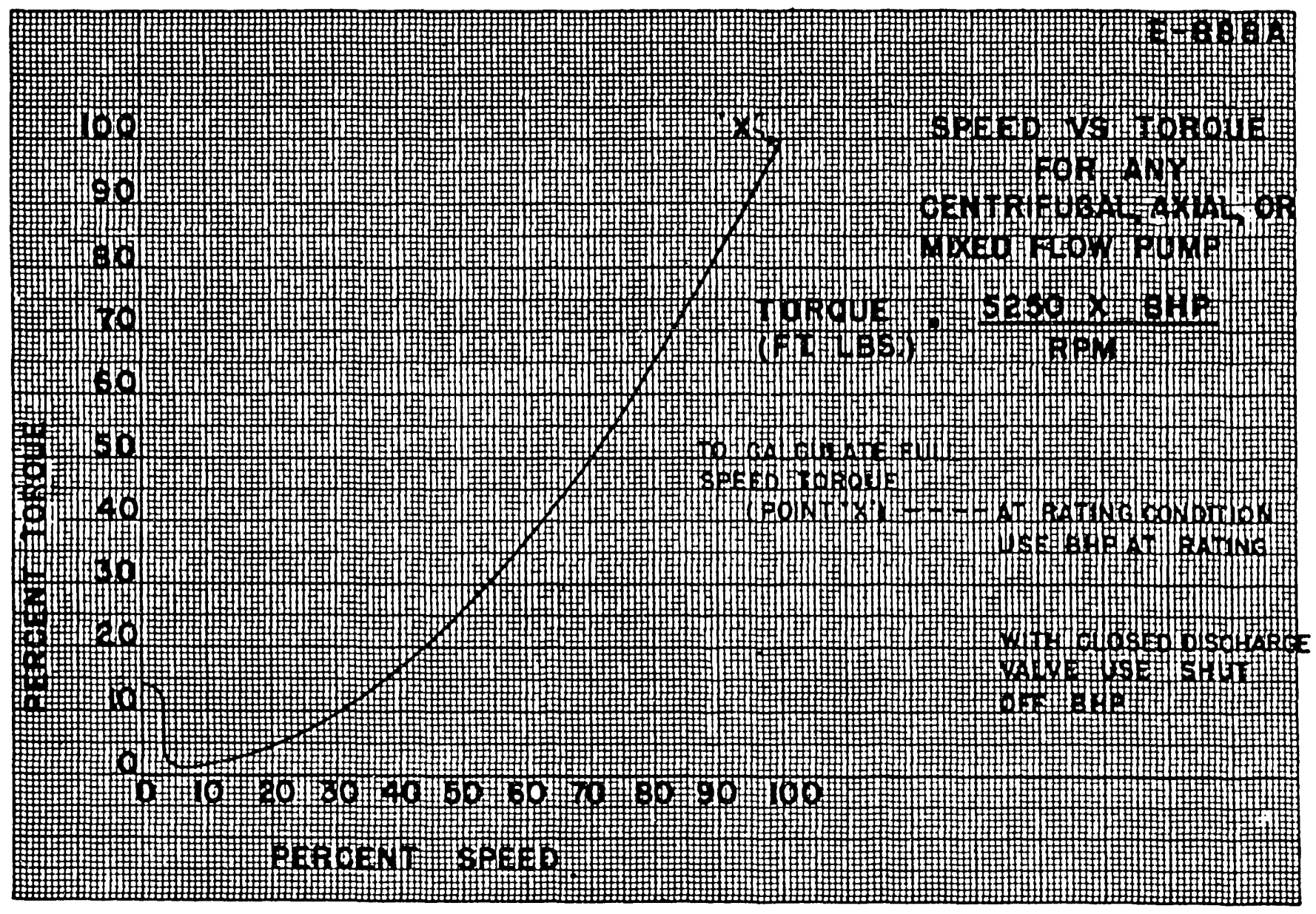

Fig. A.11 A general percent torque vs percent speed curve applicable to any centrifugal, axial or mixed flow pump. 


\section{INTERNAL DISTRIBUTION}

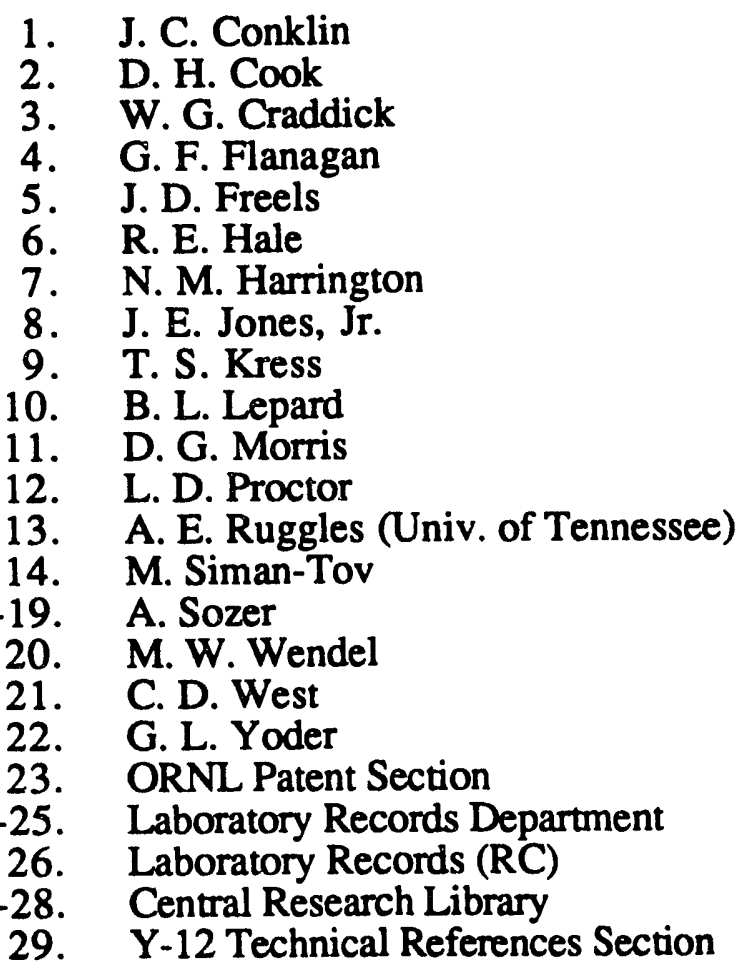

\section{EXTERNAL DISTRIBUTION}

30. Office of Assistant Manager for Energy Research and Development, DOE-Oak Ridge Field Office, P.O. Box 2001, Department of Energy, Oak Ridge, TN 37831-8600

31-40. Office of Scientific and Technical Information, P. O. Box 62, Oak Ridge, TN 37831 

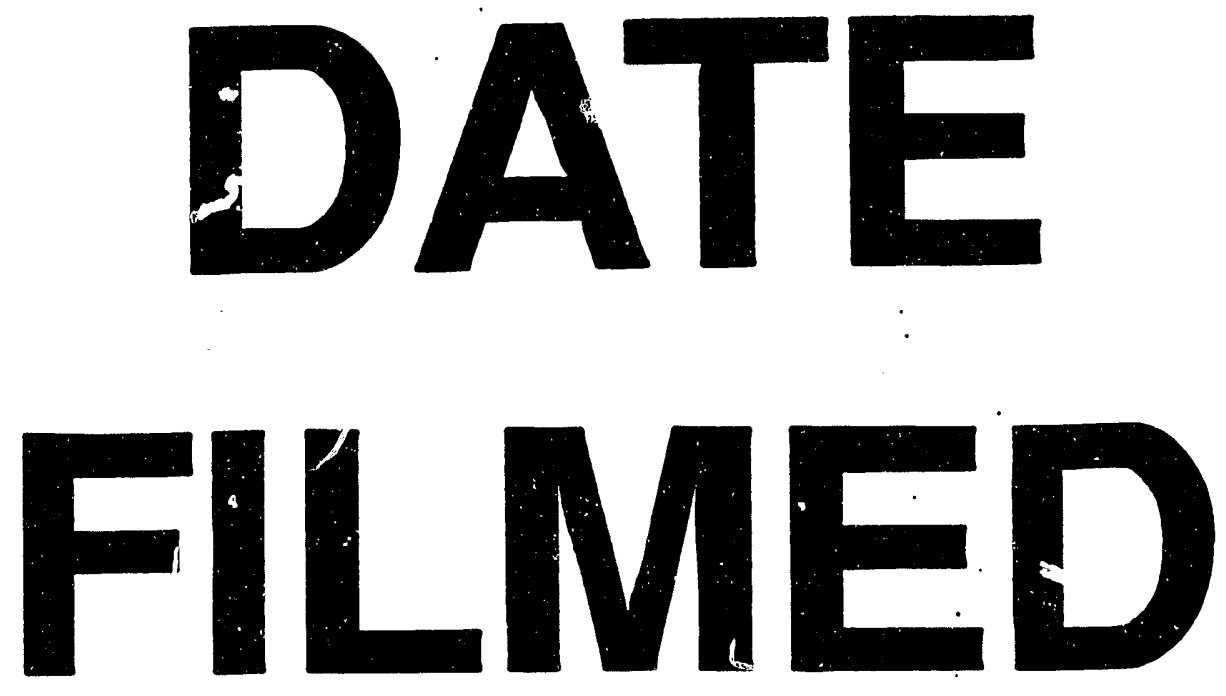

$10 / 15 / 93$
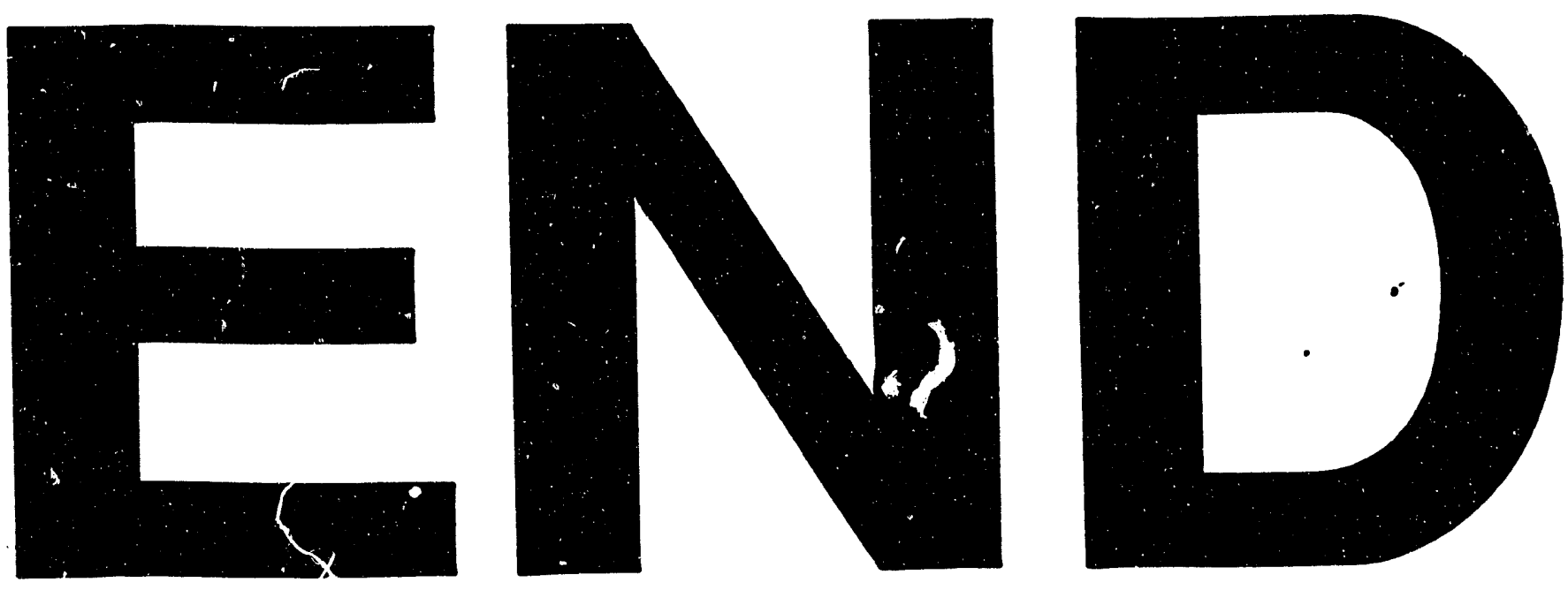
